UNIVERSIDADE DE SÃO PAULO

ESCOLA DE ENGENHARIA DE SÃO CARLOS

PROGRAMA DE PÓS-GRADUAÇÃO EM ENGENHARIA MECÂNICA

\title{
PROJETO E FABRICAÇÃO DE MOLDES PARA PRENSAGEM ISOSTÁTICA UTILIZANDO TECNOLOGIAS CAD/CAE E PROTOTIPAGEM RÁPIDA
}

\section{Rodrigo Bresciani Canto}

Dissertação apresentada à Escola de Engenharia de São Carlos, da Universidade de São Paulo, como parte dos requisitos para a obtenção do título de Mestre em Engenharia Mecânica

ORIENTADOR: Prof. Dr. Jonas de Carvalho

São Carlos

2002 
Em memória de Arthur Oliani Andrade. 


\section{Agradecimentos}

Ao Prof. Dr. Jonas de Carvalho, orientador, pela amizade e orientação no desenvolvimento do trabalho.

Ao Prof. Dr. Benedito de Moraes Purquerio, pelas contribuições que enriqueceram o trabalho.

À Juliana, pelo amor, carinho e confiança.

Aos meus pais e irmãos pelo carinho e apoio.

Aos doutorandos Neilor e Volnei pelo auxílio, sugestões e discussões ocorridas no decorrer deste trabalho.

Aos amigos e companheiros de trabalho, Amauri, Claudião, Coelho, Geraldo, Giba, Hubinger, Márcio, Neilor, Rogério, Romeu e Volnei pela amizade, apoio, incentivo e pelas discussões ocorridas no decorrer do trabalho.

Ao Dr. Carlos Alberto Fortulan e ao Dr. Paulo Alberto Silveira Wrege pelas colaborações indispensáveis à realização deste trabalho.

Ao Departamento de Engenharia de Materiais - DEMA da Universidade Federal de São Carlos, por disponibilizar o equipamento para a realização dos ensaios mecânicos.

À Fundação Parque de Alta Tecnologia de São Carlos - ParqTec e ao engenheiro Rodrigo Machado de Godoy pela construção do Protótipo Físico.

Ao Departamento de Engenharia de Estruturas da Escola de Engenharia de São Carlos, por disponibilizar o programa ABAQUS no início deste trabalho.

Aos Srs. Adão Santo Bolzan, José Carlos Botelho e José Carlos Risardi do Laboratório de Máquinas Ferramentas - LAMAFE, pelo apoio técnico nos trabalhos realizados no LAMAFE.

A todos os professores, funcionários e alunos do Departamento de Engenharia Mecânica que sempre estiveram presentes e participativos.

Aos amigos da pós-graduação, pelo companheirismo.

À Fundação de Amparo à Pesquisa do Estado de São Paulo - FAPESP, pelo financiamento concedido.

A Deus, por tudo. 


\section{SUMÁRIO}

LISTA DE FIGURAS .........................................................................................

LISTA DE ABREVIATURAS E SIGLAS ..........................................................vii

LISTA DE SÍMBOLOS ..................................................................................... viii

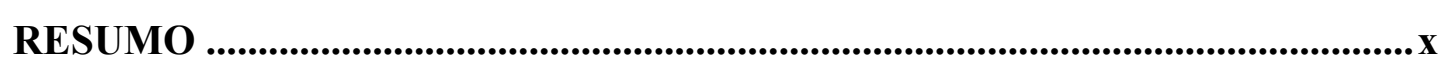

ABSTRACT ...............................................................................................

1 INTRODUÇÃO, OBJETIVOS E JUSTIFICATIVAS.........................................1

1.1 O PROCESSO DE PRENSAGEM ISOSTÁTICA..............................................

1.2 MOLDES PARA PRENSAGEM ISOSTÁTICA ………………………………....

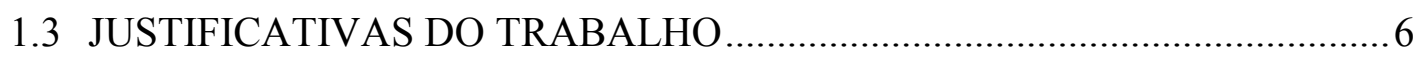

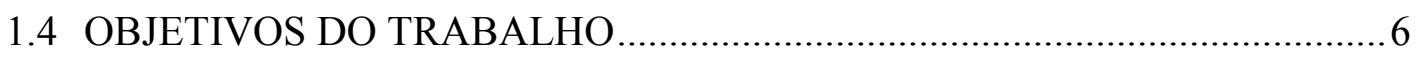

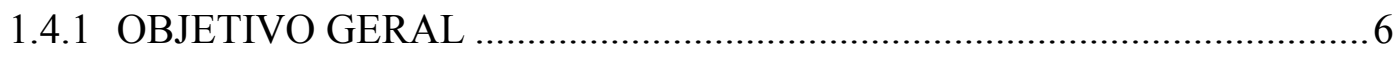

1.4.2 OBJETIVOS ESPECÍFICOS ................................................................

1.5 ESTUDO DE CASO: ESFERA PARA IMPLANTE DE QUADRIL..................

2 FUNDAMENTAÇÃO TEÓRICA .................................................................10

2.1 MODELAGEM DO PÓ CERÂMICO - MODELO DE DRUCKERPRAGER/CAP.

2.2 MODELAGEM DO MATERIAL ELASTOMÉRICO - MODELO HIPERELÁSTICO DE MOONEY-RIVLIN …………......................................

2.2.1 PEQUENAS DEFORMAÇÕES ELÁSTICAS...........................................17

2.2.2 GRANDES DEFORMAÇÕES ELÁSTICAS ............................................ 18

3 REVISÃO BIBLIOGRÁFICA .................................................................22

4 MATERIAIS E MÉTODOS .........................................................................27

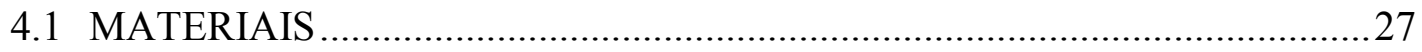

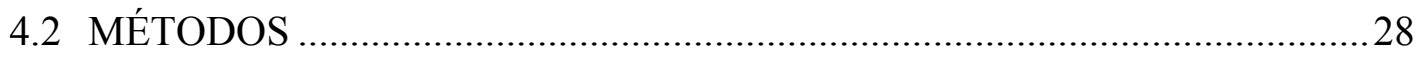

4.2.1 METODOLOGIA PARA PROJETO E FABRICAÇÃO DOS MOLDES ..28

4.2.2 ANÁLISE DO PROCESSO DE PRENSAGEM ISOSTÁTICA PELO MÉTODO DOS ELEMENTOS FINITOS .......................................................... 30

4.2.2.1 MODELAGEM DO CONTATO …………………............................

4.2.2.2 DETERMINAÇÃO DAS PROPRIEDADES E MODELAGEM DO MATERIAL CERÂMICO........................................................................................ 
4.2.2.3 DETERMINAÇÃO DAS PROPRIEDADES E MODELAGEM DO

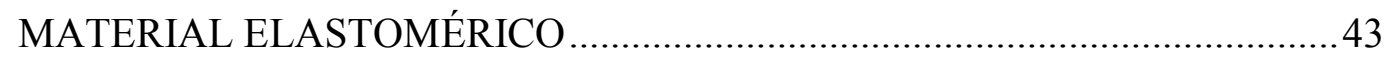

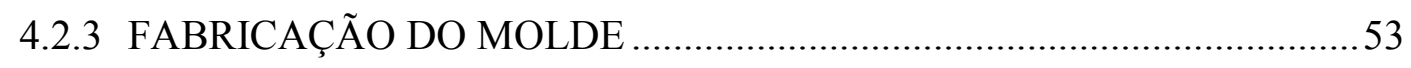

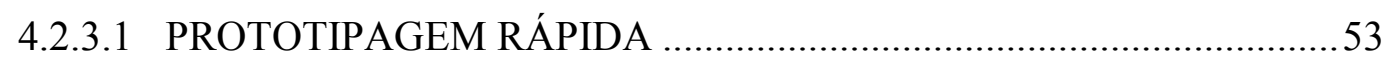

5 RESULTADOS E DISCUSSÕES....................................................................57

5.1 SIMULAÇÃO DO PROCESSO - MOLDE PRELIMINAR .............................57

5.2 SIMULAÇÃO DO PROCESSO - MOLDE ADEQUADO..............................59

5.3 CONSIDERAÇÕES GERAIS SOBRE AS SIMULAÇÕES ..........................60

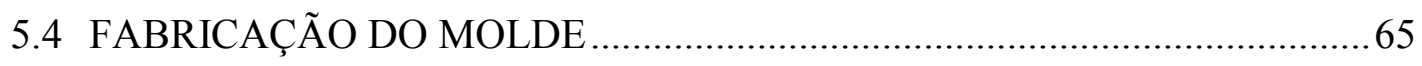

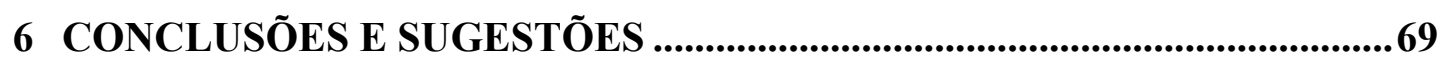

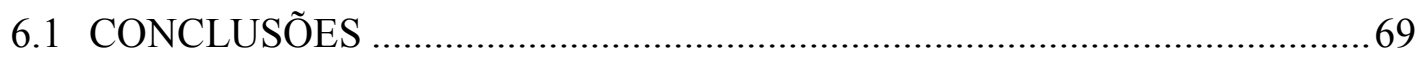

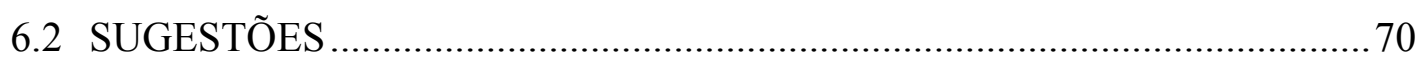

7 REFERÊNCIAS BIBLIOGRÁFICAS...........................................................71 


\section{LISTA DE FIGURAS}

Figura 1.1 - Esquema do processo de prensagem isostática dry bag ou fixed bag. Da esquerda para a direita, as etapas de alimentação do molde, prensagem e extração do compacto (adaptado de REED, 1995). 2

Figura 1.2 - Esquema do processo de prensagem isostática wet bag ou free bag. Da esquerda para a direita, as etapas de alimentação do molde, prensagem e peça compactada (adaptado de REED, 1995)......

Figura 1.3 - Moldes para prensagem isostática: (a) contração e (b) contração/expansão (adaptado de McEntire, 1984)

Figura 1.4 - Esfera cerâmica para implante de quadril: (a) dimensões após usinagem a verde; (b) dimensões após sinterização e acabamento [mm] (WREGE, 2000)......... 7 Figura 1.5 - Molde para prensagem isostática wet bag de esfera cerâmica para implante de quadril. [dimensões em mm] (WREGE, 2000). ...................................... 8

Figura 1.6 - Compacto obtido por Wrege (2000) utilizando o molde preliminar. .......8 Figura 1.7 - Esquema do compacto obtido por Wrege (2000) utilizando o molde preliminar e as dimensões do componente pretendido após usinagem a verde

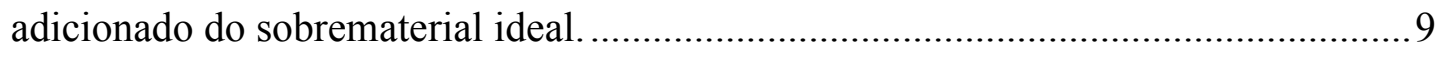

Figura 2.1 - Critério de von Mises (adaptado de CHEN et al, 1985)........................ 13

Figura 2.2 - Critério de Drucker-Prager (adaptado de CHEN et al, 1985).................13

Figura 2.3 - Modelo modificado de Drucker-Prager/cap no espaço das tensões principais.

Figura 2.4 - Modelo modificado de Drucker-Prager/cap: superfícies de plastificação no plano meridional (adaptado de HIBBIT et al., 2000). .15

Figura 2.5 - Curva típica de encruamento da superfície cap .................................... 16

Figura 2.6 - Aspecto da curva tensão-deformação de um material hiperelástico....... 17 Figura 3.1 - Matriz elastomérica usada por HENDERSON et al. (2000) para determinação da relação de tensão hidrostática - deformação volumétrica plástica do pó cerâmico. .25

Figura 4.1 - Fluxograma da metodologia de projeto, re-projeto e fabricação do molde. 28 
Figura 4.2 - Fluxograma da metodologia do Projeto Preliminar do Molde. 29

Figura 4.3 - Projeto do molde adequado obtido pela metodologia proposta. 30

Figura 4.4 - Análise do processo de prensagem isostática de pós cerâmicos - malha de elementos finitos e condições de contorno.

Figura 4.5 - Contato entre duas superfícies utilizando a interação finite sliding (adaptado de HIBBIT et al., 2000). 32

Figura 4.6 - Possível trajetória do nó 101 da superfície slave em contato com a superfície master utilizando a interação finite sliding (adaptado de HIBBIT et al., 2000)

Figura 4.7 - Contato entre duas superfícies utilizando a interação small sliding (adaptado de HIBBIT et al., 2000)..... 33

Figura 4.8 - Interação de contato entre material cerâmico e macho. 34

Figura 4.9 - Projeto do dispositivo cilindro-pistão (DCP). 36

Figura 4.10 - Esquema de funcionamento do dispositivo cilindro-pistão (DCP) e as fases do ensaio de compressão uniaxial.

Figura 4.11 - Dispositivo cilindro-pistão (DCP) utilizado e "corpos-de-prova" obtidos nos ensaios.

Figura 4.12 - Curva tensão-deformação no ensaio de compressão uniaxial do pó cerâmico.

Figura 4.13 - Caminho das tensões no plano meridional $\sqrt{J_{2}} \times p$ relacionado à curva tensão-deformação no ensaio de compressão uniaxial do pó cerâmico.

Figura 4.14 - Relação das tensões axiais e radiais no ensaio de compressão uniaxial do pó cerâmico.

Figura 4.15 - Esquema de obtenção da evolução do encruamento pela curva de compactação uniaxial do pó cerâmico.

Figura 4.16 - Ensaios mecânicos para a calibração de modelos hiperelásticos (adaptado de HIBBIT et al., 2000).... 44

Figura 4.17 - Ensaio de tração uniaxial (desenvolvido nesse trabalho) 45

Figura 4.18 - Ensaio de compressão uniaxial (Axel Products, 2000)

Figura 4.19 - Ensaio de tração planar (Axel Products, 2000)

Figura 4.20 - Ensaio de compressão volumétrica adaptado (Axel Products, 2000)... 45

Figura 4.21 - Ensaio de tração Equibiaxial .45 
Figura 4.22 - Máquina Universal de Ensaios - INSTRON - 5569 (DEMA,

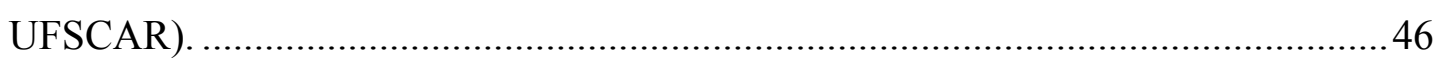

Figura 4.23 - Corpos-de-prova para compressão uniaxial........................................ 47

Figura 4.24 - Molde em nylon para vazamento do elastômero.................................. 47

Figura 4.25 - Dispositivo para corte dos corpos-de-prova para ensaio de compressão

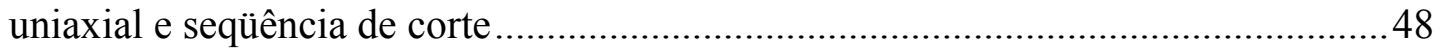

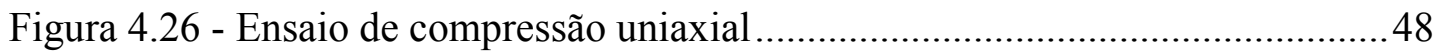

Figura 4.27 - Curvas tensão-deformação do ensaio de compressão uniaxial para três

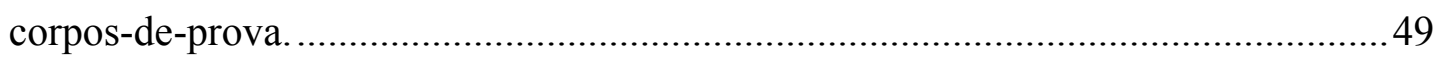

Figura 4.28 - Corpo-de-prova para tração uniaxial (unidades em $\mathrm{mm}$ ) .....................50

Figura 4.29 - Caixa de vidro para vazamento do polímero .......................................50

Figura 4.30 - Matriz para corte dos corpos-de-prova para ensaio de tração uniaxial e

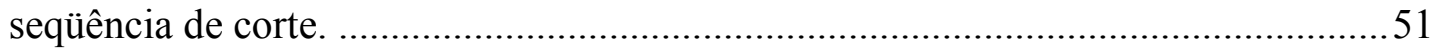

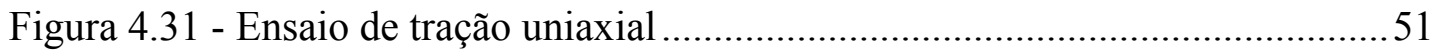

Figura 4.32 - Curvas tensão-deformação do ensaio de tração uniaxial para três

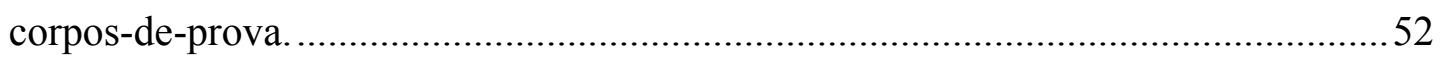

Figura 4.33 - Ensaio de compressão volumétrica confinado no DCP........................52

Figura 4.34 - Curva tensão-contração volumétrica do ensaio de compressão volumétrica confinado.

Figura 4.35 - (a) Protótipo virtual da matriz elastomérica obtido pela modelagem sólida no sistema $C A D$; (b) Protótipo físico da matriz elastomérica obtido pela tecnologia de Prototipagem Rápida..

Figura 4.36 - Base em nylon para a fixação do protótipo físico para realização das

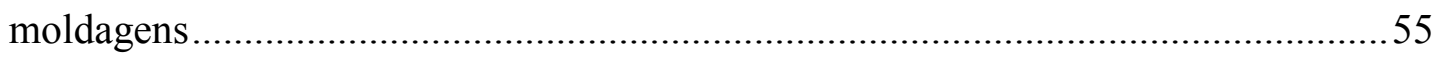

Figura 4.37 - Seqüência de moldagem para a obtenção da matriz elastomérica ........55

Figura 4.38 - Seqüência de moldagem para a obtenção da gaiola suporte..................56

Figura 5.1 - Simulação do processo de prensagem isostática para o molde preliminar: (a) geometria inicial; (b) geometria após a simulação do processo de prensagem isostática.

Figura 5.2 - Simulação do processo de prensagem isostática para o molde preliminar: Resultados teóricos obtidos pelo método dos elementos finitos (MEF), perfil pretendido e resultados experimentais. 58 
Figura 5.3 - Simulação do processo de prensagem isostática para o molde preliminar: (a) geometria inicial; (b) geometria após a simulação do processo de prensagem isostática.

Figura 5.4 - Simulação do processo de prensagem isostática para o molde adequado: Resultados teóricos obtidos pelo método dos elementos finitos (MEF), perfil pretendido e resultados experimentais. 60

Figura 5.5 - Magnitude de deslocamentos nas direções axial e radial. [unidades em $\mathrm{m}]$

Figura 5.6 - Estado de deformações plásticas no sentido circunferencial. 62

Figura 5.7 - Localização dos pontos escolhidos para analisar o caminho das tensões desenvolvidos na simulação do processo de prensagem isostática.

Figura 5.8 - Caminho das tensões para os pontos de 1 a 6 traçados no plano meridional $q \times p$. 63

Figura 5.9 - Simulação com a matriz elastomérica $(\mu=0,20)$. 65

Figura 5.10 - Simulação com a matriz elastomérica $(\mu=0,05)$. 65

Figura 5.11 - Simulação sem a matriz elastomérica $(\mu=0,20)$. 65

Figura 5.12 - Simulação sem a matriz elastomérica $(\mu=0,05)$. 65

Figura 5.13 - Matrizes auxiliares para a fabricação do molde para prensagem isostática .66

Figura 5.14 - Molde completo desenvolvido na metodologia apresentada e compacto obtido no molde após o processo de prensagem isostática wet bag do pó cerâmico. 67 Figura 5.15 - Comparação entre os processos de prensagem isostática desenvolvidos no molde preliminar e no molde adequado pela metodologia proposta.

Figura 5.16 - Compactos obtidos pelo processo de prensagem isostática: (a) compacto obtido do molde preliminar e (b) compacto obtido do molde adequado. (c) componente após a usinagem a verde. .68 


\title{
LISTA DE ABREVIATURAS E SIGLAS
}

\author{
ABS - Acrylonitrile Butadiene Styrene \\ ASTM - American Society for Testing and Materials \\ CAD - Computer Aided Design \\ CAE - Computer Aided Engineering \\ DCP - Dispositivo Cilindro-Pistão \\ FDM - Fused Deposition Modeling \\ MEF - Método dos Elementos Finitos \\ PU - Poliuretana \\ STL - STereoLithography
}




\section{LISTA DE SÍMBOLOS}

c - Parâmetro da Superfície de Drucker-Prager no plano $\left(\sqrt{J_{2}} \times p\right)$

d - Parâmetro da Superfície de Drucker-Prager no plano $(q \times p)$

$\mathrm{e}_{\mathrm{xx}}$ - Componente de deformação finita na direção $x$

e - Componente de deformação finita na direção $y$

$\mathrm{e}_{\mathrm{zz}}$ - Componente de deformação finita na direção $z$

E - Módulo de Young

$\mathrm{F}_{\mathrm{c}} \quad$ - Superfície cap

$\mathrm{F}_{\mathrm{s}} \quad$ - Superfície de cisalhamento de Drucker-Prager

$F_{t} \quad$ - Superfície de Transição

G - Módulo de Cisalhamento

$I_{1} \quad$ - Primeiro invariante de tensões

$I_{1}^{\prime} \quad$ - Primeiro invariante de deformações (para grandes deformações)

$I_{2}^{\prime}$ - Segundo invariante de deformações (para grandes deformações)

$I_{3}^{\prime} \quad$ - Terceiro invariante de deformações (para grandes deformações)

$J_{2} \quad$ - Segundo invariante de tensões desviadoras

K - Módulo Volumétrico

k - Parâmetro da Superfície de von Mises

$\mathrm{k}_{0} \quad$ - Coeficiente de Empuxo no Repouso

L - Comprimento atual

$\mathrm{L}_{0} \quad$ - Comprimento inicial

M - constrained modulus

$\mathrm{m}$ - Inclinação da curva de descarregamento no plano $\left(\sqrt{J_{2}} \times \mathrm{p}\right)$

P - Pressão de compressão hidrostática

p - tensão média

$\mathrm{p}_{\mathrm{a}} \quad$ - Parâmetro de evolução do encruamento da superfície cap

$\mathrm{p}_{\mathrm{b}}$ - Tensão Hidrostática de plastificação na compressão

q - Tensão Equivalente de von Mises 
R - Parâmetro de forma da superfície cap

$\mathrm{V}_{0} \quad$ - Volume original

W - Função de Densidade de Energia de Deformação

Z - altura atual

$\mathrm{Z}_{0} \quad$ - altura original

$\alpha \quad$ - Parâmetro de forma da superfície de transição

$\beta$ - Parâmetro da Superfície de Drucker-Prager no plano ( $q \times p)$

$\Delta V$ - Variação Volumétrica

$\varepsilon \quad$ - Deformação

$\varepsilon_{Z} \quad$ - Deformação axial verdadeira

$\varepsilon_{z}^{p l}$ - Deformação axial plástica

$\varepsilon_{v o l}^{p l}$ - Deformação plástica volumétrica

$\varepsilon_{1} \quad$ - Deformação longitudinal

$\varepsilon_{2} \quad$ - Deformação Transversal

$\gamma \quad$ - Parâmetro da Superfície de Drucker-Prager no plano $\left(\sqrt{J_{2}} \times p\right)$

$\lambda$ - Estiramento

$\lambda_{1}$ - Estiramento na primeira direção principal

$\lambda_{2}$ - Estiramento na segunda direção principal

$\lambda_{3}$ - Estiramento na terceira direção principal

$\mu \quad$ - Coeficiente de atrito

$v \quad$ - Coeficiente de Poisson

$\sigma$ - Tensão

$\sigma_{Z}$ - Tensão Axial

$\sigma_{r} \quad$ - Tensão Radial

$\sigma_{1}$ - Tensão na primeira direção principal

$\sigma_{2}$ - Tensão na segunda direção principal

$\sigma_{3}$ - Tensão na terceira direção principal

$\tau \quad$ - Tensão de Cisalhamento

$\xi \quad$ - Distorção 


\section{RESUMO}

CANTO, R. B. Projeto e fabricação de moldes para prensagem isostática utilizando tecnologias CAD/CAE e prototipagem rápida. São Carlos, 2002. 74p. Dissertação (Mestrado) - Escola de Engenharia de São Carlos, Universidade de São Paulo.

Apresenta uma metodologia para o projeto e fabricação de moldes para prensagem isostática de pó cerâmico (alumina) utilizando ferramentas computacionais $C A D / C A E$ associadas à tecnologia de Prototipagem Rápida. $\mathrm{O}$ processo de prensagem isostática é simulado utilizando o método dos elementos finitos. Para a representação da compactação do pó cerâmico é utilizado o modelo de Drucker-Prager/cap e para a representação do comportamento do material elastomérico é utilizado o modelo hiperelástico de Mooney-Rivlin, ambos disponíveis no programa ABAQUS ${ }^{\circledR}$. Tal simulação visa obter o projeto do molde de forma mais rápida e precisa, ajustando-o até que se alcance um molde adequado para produzir um compacto com uma quantidade de sobrematerial ideal para o processo de usinagem a verde. Para isso utilizou-se como estudo de caso uma esfera cerâmica para implante de quadril. Um protótipo virtual do molde adequado obtido das simulações é então modelado e reproduzido em plástico ABS (Acrylonitrile Butadiene Styrene) pela tecnologia de Prototipagem Rápida FDM (Fused Deposition Modeling). Esse protótipo físico é a base para o desenvolvimento de matrizes rígidas e em silicone, que são utilizadas para a confecção da parte flexível do molde (matriz elastomérica) e de partes rígidas como a gaiola suporte obtidas por vazamento dos polímeros. Constatou-se a viabilidade da utilização da metodologia de projeto e fabricação do molde para prensagem isostática, considerando que as simulações mostraram-se bastante coerentes com os resultados experimentais obtidos de componentes prensados.

Palavras-chave: moldes, prensagem isostática, método dos elementos finitos, prototipagem rápida, pó cerâmico. 


\begin{abstract}
CANTO, R. B. Design and manufacturing of moulds in isostatic pressing using CAD/CAE technology and rapid prototyping. São Carlos, 2002. 74p. Dissertação (Mestrado) - Escola de Engenharia de São Carlos, Universidade de São Paulo.

This work presents a methodology for the design and fabrication of ceramic powder isostatic pressing moulds using CAD and CAE tools and Rapid Prototyping. The isostatic pressing process was simulated using the finite element method. The compaction behavior of ceramic powder is described by the Drucker-Prager/cap constitutive model and the behavior of elastomeric material is described by the Mooney-Rivlin constitutive model within the commercial finite element software ABAQUS $^{\circledR}$. These simulations are required to adjust the mould design in order to suit the geometry of the compact and green machining allowance. For this study, it is used a case study consisting of pressing a ceramic sphere for hip implant stem. A virtual prototype was designed from the geometry obtained from the simulations and reproduced in Acrylonitrile Butadiene Styrene (ABS) polymer, using the Rapid Prototyping technology - Fused Deposition Modeling (FDM). Silicone moulds were obtained from the polymer prototype and used to aid in the making of the elastomeric bag and mould support cage. The methodology used in this investigation was validate considering that the simulations yield to a good agreement with measured manufactured components.
\end{abstract}

Keywords: moulds, isostatic pressing, finite element method, rapid prototyping, ceramic powder. 


\section{INTRODUÇÃO, OBJETIVOS E JUSTIFICATIVAS}

\subsection{O PROCESSO DE PRENSAGEM ISOSTÁTICA}

O processo de prensagem isostática de pós cerâmicos, tradicionalmente utilizado na produção de velas de ignição de motores automotivos, é caracterizado pela grande uniformidade e alta qualidade dos produtos gerados. Atualmente, este é o método mais utilizado pela indústria de componentes cerâmicos de precisão, tais como: componentes de bombas, bicos de solda, ferramentas de usinagem, partes de motores automotivos e de máquinas ferramentas e aplicações biomédicas.

O processo utiliza-se de um molde que pode ser constituído de diversas partes, sendo a principal parte, a membrana elastomérica flexível ou a matriz elastomérica. Neste processo a cavidade da matriz elastomérica é preenchida por pó cerâmico e é posteriormente selada. A superfície externa da matriz elastomérica é comprimida por um fluido pressurizado gradativamente pela ação de uma prensa isostática, gerando o compactado a verde (compacto) que posteriormente poderá ser usinado e sinterizado dependendo das características exigidas pelo produto. Pressões na ordem de 70 a $500 \mathrm{MPa}$ podem ser utilizadas nesse processo. Comercialmente são aplicadas pressões de 7 a $200 \mathrm{MPa}$ (WREGE, 2000).

A prensagem isostática é particularmente aplicada a produtos que apresentam formas cilíndricas ou esféricas. Cavidades internas podem ser obtidas com a adição de machos dentro da matriz elastomérica.

Várias concepções de prensas isostáticas foram desenvolvidas, sendo que as principais são agrupadas em prensas isostáticas a frio e prensas isostáticas a quente. A prensagem isostática a frio é o método mais empregado pela indústria cerâmica, devido à utilização de líquidos pressurizados à temperatura ambiente no interior do vaso. Por outro lado, a prensagem isostática a quente é um processo no qual a 
pressão e a temperatura variam independentemente e simultaneamente (FORTULAN, 1997).

Dependendo das dimensões do componente pretendido, do nível de sofisticação ou de requisitos de produção, dois tipos de processos a frio vêm sendo utilizados: o processo dry bag (fixed bag) e o processo wet bag (free bag). $\mathrm{Na}$ prensagem isostática $d r y$ bag, esquematizada na Figura 1.1, o operador do equipamento não entra em contato com o fluido, pois o molde é integrado ao vaso de pressão e neste caso a tampa do molde é a própria tampa do vaso. Nesse processo altas taxas de produção podem ser alcançadas pela possibilidade em se automatizar os estágios de alimentação do molde e extração do compacto (BORTZMEYER, 1992).
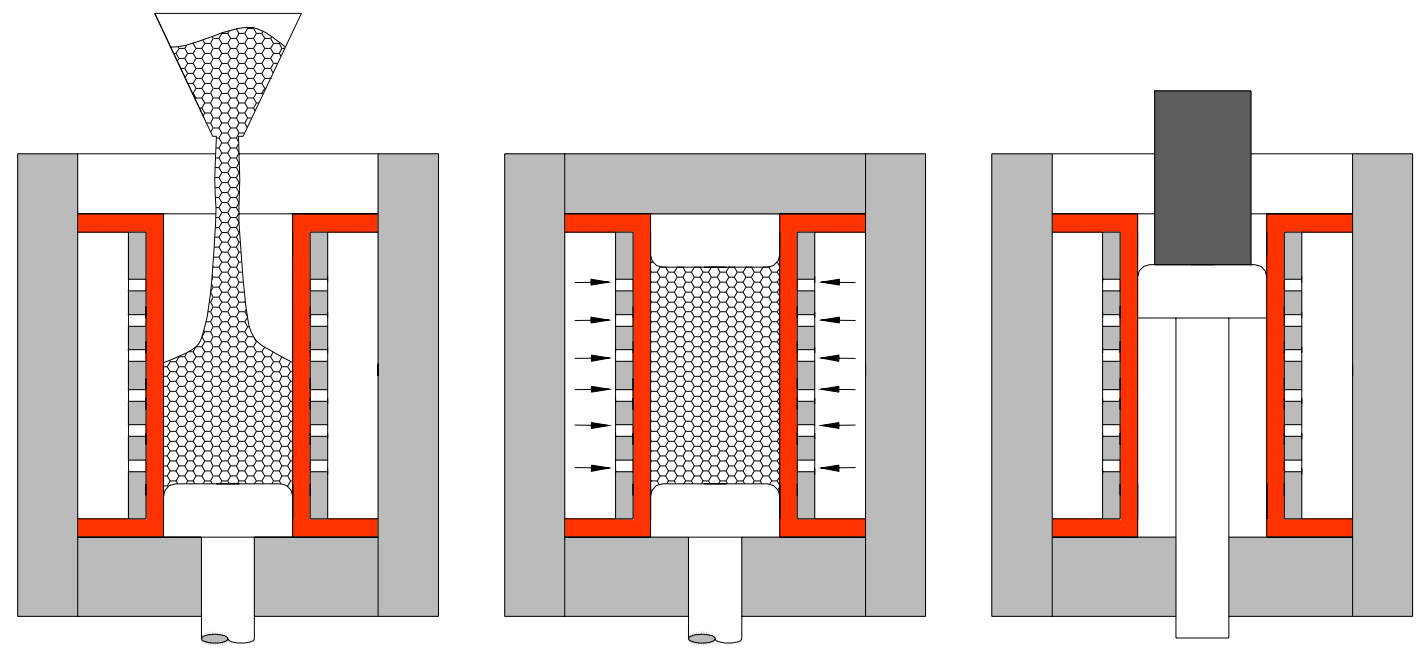

Figura 1.1 - Esquema do processo de prensagem isostática dry bag ou fixed bag. Da esquerda para a direita, as etapas de alimentação do molde, prensagem e extração do compacto (adaptado de REED, 1995).

$\mathrm{Na}$ prensagem isostática wet bag, esquematizada na Figura 1.2, o molde contendo o pó cerâmico é introduzido no interior do vaso de pressão da prensa, e o operador tem contato com o fluido em cada alimentação e descarga dos moldes (McENTIRE, 1984). Esse processo é apropriado para peças grandes, mas não permite altas taxas de produção. 

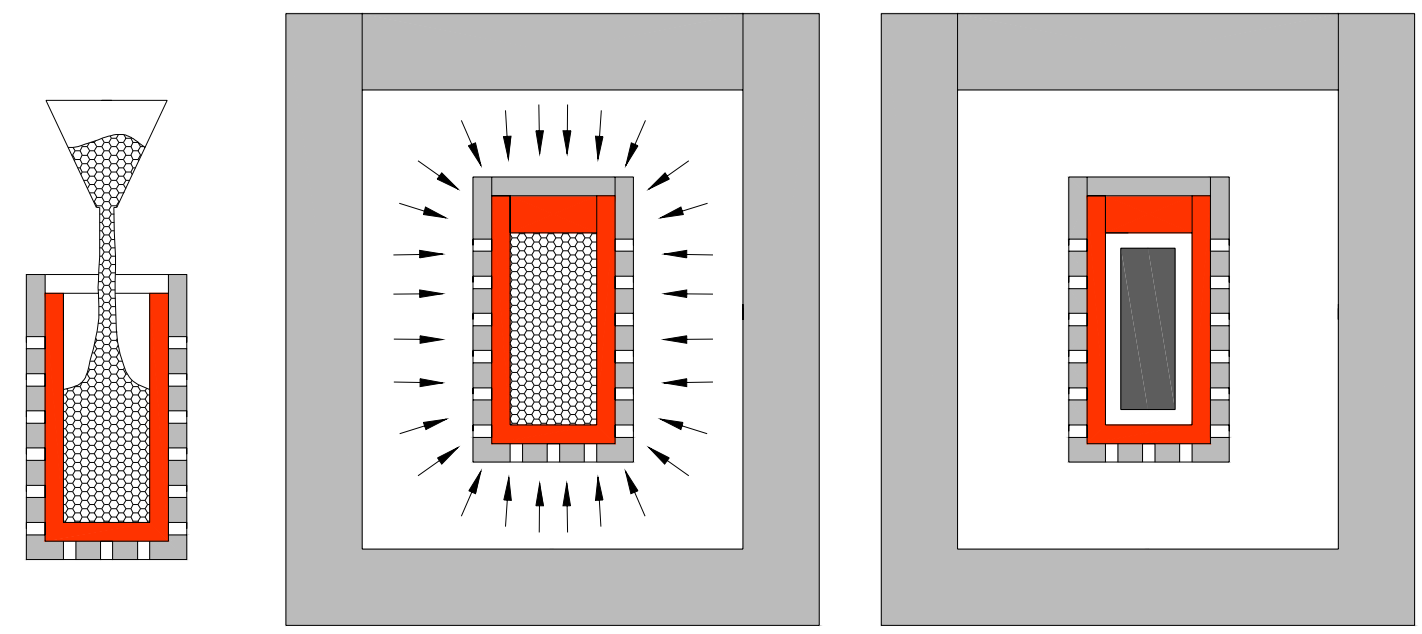

Figura 1.2 - Esquema do processo de prensagem isostática wet bag ou free bag. Da esquerda para a direita, as etapas de alimentação do molde, prensagem e peça compactada (adaptado de REED, 1995).

\subsection{MOLDES PARA PRENSAGEM ISOSTÁTICA}

Os materiais empregados na construção dos moldes devem possuir características mecânicas que possibilitem a construção de estruturas rígidas, como suportes e machos, e estruturas flexíveis, como membranas (matriz elastomérica). Entre os materiais utilizados destacam-se alguns polímeros rígidos e os aços para a confecção de estruturas rígidas, e borrachas naturais ou poliuretanas para a fabricação de estruturas flexíveis (WREGE, 2000). Ultimamente, a poliuretana vem se destacando em função das características de autolubrificação, excelente resistência à abrasão, compatibilidade química com muitos materiais e grande disponibilidade de durezas (McENTIRE, 1984).

Os machos são normalmente fabricados em aço de alta resistência ou metal duro com acabamento polido. Materiais de baixa resistência não são recomendados. O material do macho deve ser quimicamente compatível com o pó compactado, pois a abrasão do macho pelo pó ocasiona a introdução de impurezas no compacto. A gaiola suporte deve apoiar a matriz elastomérica sem deformá-la e ser de material suficientemente durável para suportar a manipulação. Dependendo da complexidade do componente a ser prensado os moldes poderão conter molas, machos expansíveis e várias partes flexíveis (McENTIRE, 1984).

A dureza e a espessura da parede da matriz elastomérica têm importância crucial no projeto do molde. Elastômeros de baixa dureza geram peças de baixa 
qualidade devido à compactação irregular gerando variações na geometria da peça a verde. Materiais considerados de alta dureza ( $>70$ Shore A) geram superfícies de textura uniforme, mas podem ocasionar danos no compacto, uma vez que na descompressão, os movimentos axiais e radiais não estão em equilíbrio. Sendo assim, a tensão induzida na peça no descarregamento pode resultar em fissuras (McENTIRE, 1984).

Durante a compactação, o ar comprimido que permanece dentro do material pode causar problemas, gerando vazios que diminuem sua resistência mecânica ou até fissurar o compacto no descarregamento (KINGERY et al., 1976).

A introdução de aditivos orgânicos no pó cerâmico diminui a tendência da ocorrência de fissuras no compacto (McENTIRE, 1984). Entretanto esses aditivos podem bloquear a saída do ar para o exterior da peça. Por isso, antes da prensagem isostática pode-se recorrer à utilização de vácuo (GONÇALVES, 2000).

As formas do molde não afetam apenas as dimensões do compacto. Mudanças abruptas de seção não permitem a movimentação do pó durante o processo de compactação, resultando em estreitamentos, saliências e fissuras nestas áreas. Dependendo do material utilizado na fabricação da tampa do molde, poderá haver movimento de pó nesta região com a ocorrência de rebarbas. Essas poderão ser evitadas com a utilização de tampas de material flexível, proporcionando assim movimentação axial independente para a tampa.

Dois conceitos de projeto podem ser utilizados na concepção dos moldes para a prensagem isostática: os baseados na contração e aqueles baseados na expansão da cavidade da matriz elastomérica. Pode-se ainda utilizar-se de uma combinação destes dois tipos. Na Figura 1.3 é mostrado o conceito do molde de contração e uma combinação dos dois conceitos: contração e expansão. 


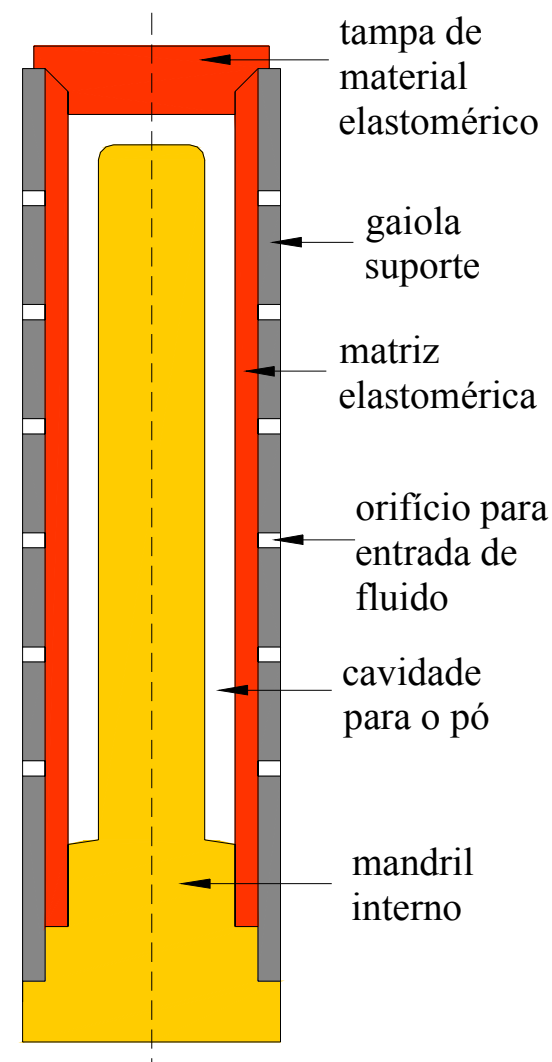

(a)

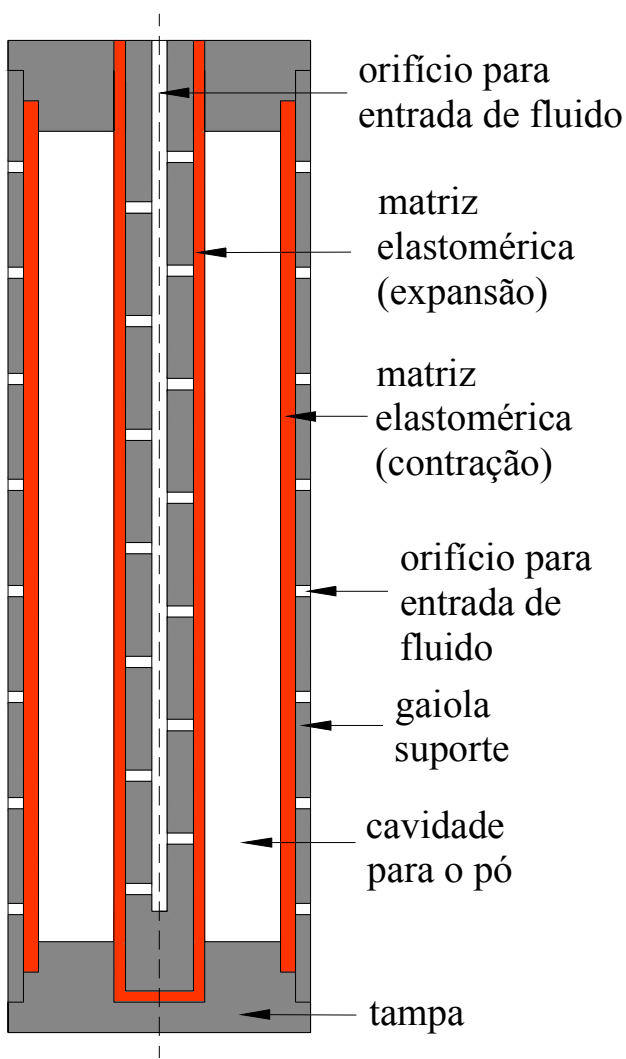

(b)

Figura 1.3 - Moldes para prensagem isostática: (a) contração e (b) contração/expansão (adaptado de McEntire, 1984).

Os moldes de contração são utilizados na produção de sólidos esféricos, cilíndricos ou com formas complexas. A introdução de um macho permite a produção de peças com perfis específicos ou furação interna. Melhores tolerâncias dimensionais são obtidas na superfície interna da peça, ou seja, nas superfícies em contato com as partes rígidas do molde.

Os moldes de expansão trabalham de forma oposta aos de contração. A peça é obtida através do movimento radial da matriz elastomérica sob pressão contra um elemento rígido. Melhores tolerâncias dimensionais são obtidas na superfície externa da peça, apresentando como característica a dificuldade de extração do compacto. 


\subsection{JUSTIFICATIVAS DO TRABALHO}

$\mathrm{Na}$ prensagem isostática de pós cerâmicos produz-se peças com uma determinada quantidade de sobrematerial, necessária para posterior usinagem e obtenção do componente na forma e tolerância dimensional final desejadas. Este sobrematerial, quando em excesso, representa para o produto final uma parcela significativa de custos, não só pelo desperdício de material, como também pelo gasto adicional em usinagem, acabamento, mão-de-obra e componentes perdidos.

Atualmente, o projeto de moldes de componentes cerâmicos obtidos pelo processo de prensagem isostática tem sido realizado empiricamente, por tentativaerro e baseado em cálculos simples de contração volumétrica obtidos de experiências anteriores do projetista (HENDERSON et al., 2000).

Com o auxílio de ferramentas Computer Aided Design (CAD) e Computer Aided Engineering ( $C A E$ ) busca-se calcular as dimensões do molde com maior precisão simulando o processo de prensagem isostática. Com isso, torna-se possível obter o projeto do molde de forma mais rápida e precisa, estabelecendo uma quantidade de sobrematerial ideal para o processo de usinagem a verde.

A geometria da matriz elastomérica adequada (que pode adquirir formas bastante complexas em função da adequação realizada) será produzida por moldagem a partir de padrão produzido em plástico Acrylonitrile Butadiene Styrene $(A B S)$, utilizando a tecnologia de prototipagem rápida Fused Deposition Modeling $(F D M)$, que possibilita a obtenção de modelos físicos de geometrias complexas diretamente a partir do modelo $C A D$ tridimensional.

\subsection{OBJETIVOS DO TRABALHO}

\subsubsection{OBJETIVO GERAL}

Desenvolver uma metodologia para o projeto e fabricação de moldes para prensagem isostática de pós cerâmicos utilizando ferramentas computacionais $C A D / C A E$ associadas à tecnologia de Prototipagem Rápida. 


\subsubsection{OBJETIVOS ESPECÍFICOS}

- Utilizar o método dos elementos finitos para a simulação do processo de prensagem isostática, a fim de adequar o projeto do molde de acordo com características pré-definidas do componente pretendido.

- Utilizar um modelo físico em $A B S$ gerado na máquina de Prototipagem Rápida para auxiliar na fabricação do molde.

- Fabricar o componente cerâmico utilizando o molde projetado segundo uma metodologia proposta.

\subsection{ESTUDO DE CASO: ESFERA PARA IMPLANTE DE QUADRIL}

O estudo de caso deste trabalho é uma esfera cerâmica para implante de quadril. A fabricação desse componente envolve as etapas:

1. Prensagem isostática wet bag;

2. Usinagem a verde do compacto;

3. Sinterização;

4. Retificação e acabamento.

O diâmetro externo da peça após a usinagem a verde é a dimensão de maior interesse neste estudo, e é mostrada na Figura 1.4a. Na Figura 1.4b são mostradas as dimensões da peça após sinterização (onde há retração volumétrica) e operações finais de acabamento.

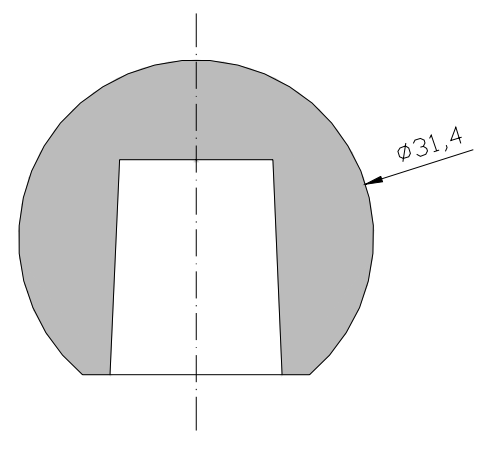

(a)

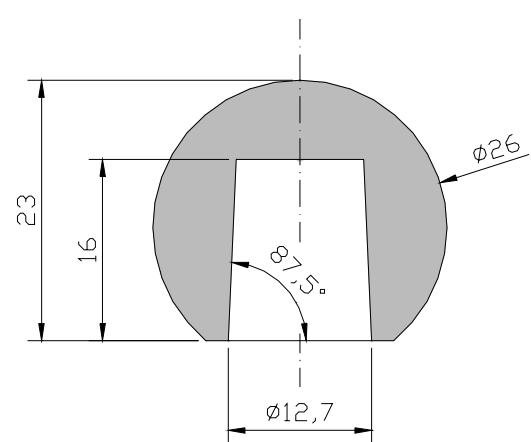

(b)

Figura 1.4 - Esfera cerâmica para implante de quadril: (a) dimensões após usinagem a verde; (b) dimensões após sinterização e acabamento [mm] (WREGE, 2000). 
O estudo do processo desenvolvido na etapa 1 (prensagem isostática) é o foco principal deste trabalho. O projeto preliminar do molde de contração utilizado para a prensagem do compacto é apresentado na Figura 1.5, e foi desenvolvido por Wrege (2000). O molde é formado basicamente por quatro partes: gaiola (estrutura rígida de suporte), matriz elastomérica, macho metálico e tampa. Após o preenchimento da cavidade da matriz elastomérica, as diferentes partes são montadas e travadas na parte inferior pela tampa com rosca, onde se encontra fixado o macho através de um parafuso. Em seguida o molde é colocado no vaso de pressão da prensa wet bag onde lhe é aplicado a carga externa isostática de $100 \mathrm{MPa}$. O compacto obtido por Wrege (2000) é mostrado na Figura 1.6.
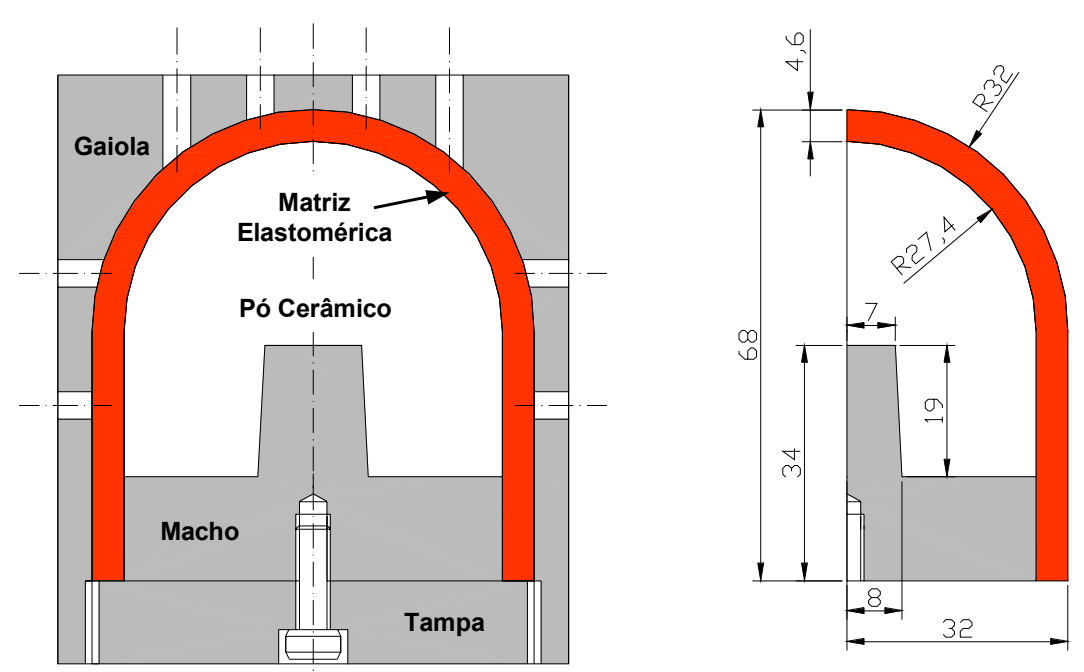

Figura 1.5 - Molde para prensagem isostática wet bag de esfera cerâmica para implante de quadril. [dimensões em mm] (WREGE, 2000).

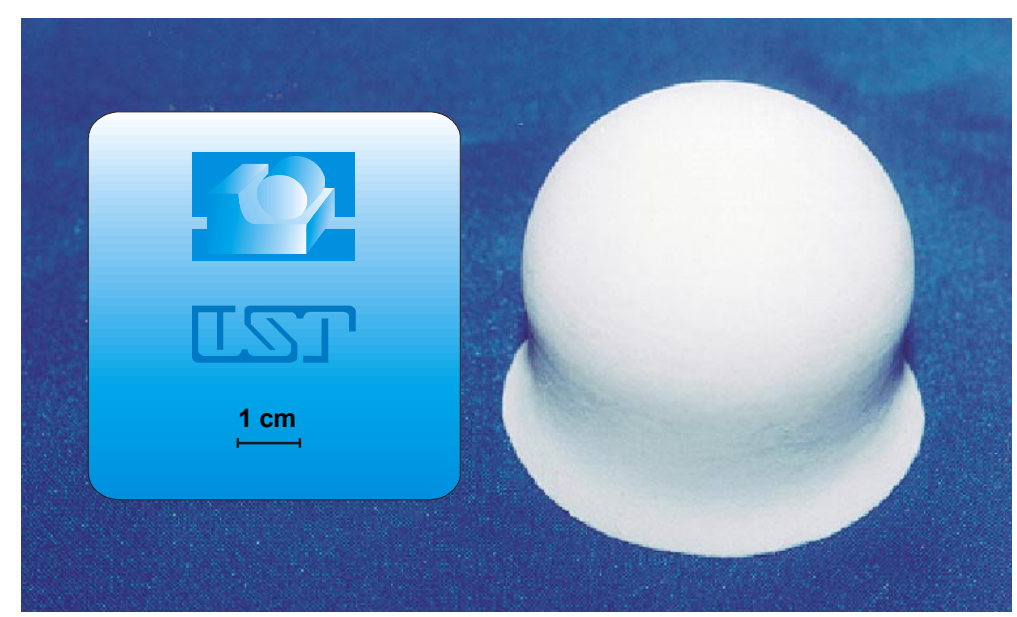

Figura 1.6 - Compacto obtido por Wrege (2000) utilizando o molde preliminar. 
Na Figura 1.7 é mostrado um esquema indicando as proporções reais que representa o compacto obtido por Wrege (2000) e o componente pretendido após usinagem a verde. A linha tracejada representa o sobrematerial para a usinagem a verde de $2 \mathrm{~mm}$, considerado como ideal neste estudo de caso, que será objetivado no re-projeto do molde.

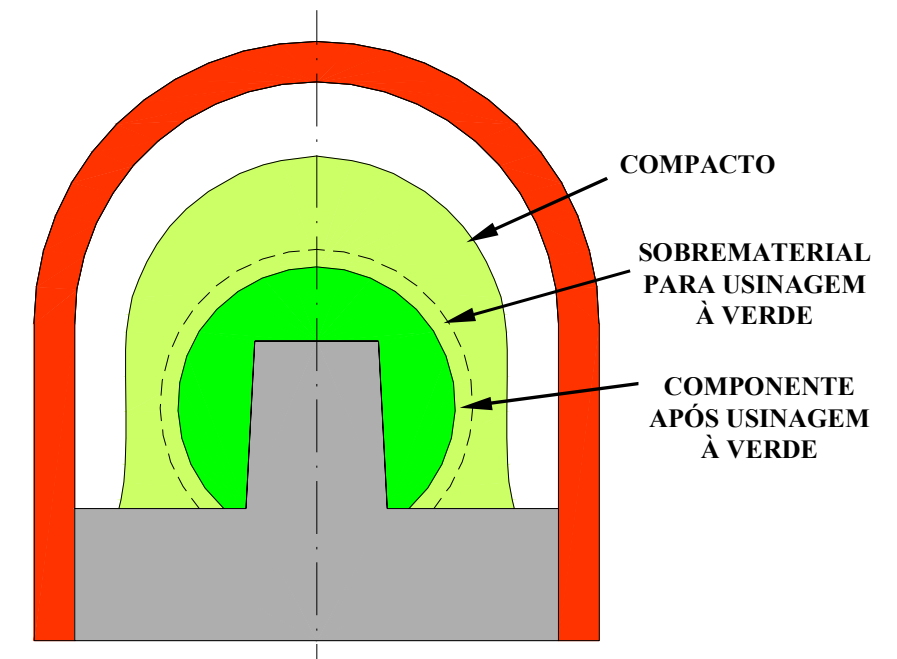

Figura 1.7 - Esquema do compacto obtido por Wrege (2000) utilizando o molde preliminar e as dimensões do componente pretendido após usinagem a verde adicionado do sobrematerial ideal.

Vale ressaltar, que Wrege (2000) desenvolveu uma metodologia para a obtenção da esfera para implante de quadril, desenvolvendo todas as etapas da fabricação: preparação dos materiais, projetos de moldes e equipamentos, prensagem, usinagem e acabamento. No entanto, o projeto do molde para a prensagem isostática, que não era o foco principal do seu trabalho, foi realizado com o auxílio de cálculos simples de percentual de retração volumétrica. 


\section{Capítulo 2}

\section{FUNDAMENTAÇÃO TEÓRICA}

\subsection{MODELAGEM DO PÓ CERÂMICO - MODELO DE DRUCKER- PRAGER/CAP}

$\mathrm{Na}$ solução de problemas da mecânica do pó, duas abordagens podem ser destacadas: a abordagem micromecânica e a abordagem macromecânica. A abordagem micromecânica consiste em considerar cada partícula do pó com um certo volume, sendo o meio material constituído por um agrupamento dessas partículas e pelos vazios formados nos interstícios. Nessa abordagem, consideram-se as propriedades das partículas, a disposição e o contato entre as mesmas, possibilitando analisar o comportamento do meio, onde as partículas podem ser deformadas e rearranjadas. A abordagem macromecânica consiste em modelar o pó como um meio contínuo e homogêneo, onde as propriedades serão compostas por uma combinação das propriedades das partículas e dos vazios formados nos interstícios.

Ransing et al. (2000) estudaram a modelagem micromecânica para um pó metálico constatando as dificuldades na obtenção de um modelo constitutivo para o material e o alto custo computacional quando comparada à modelagem macromecânica. Em outro estudo, utilizaram uma abordagem macromecânica que consiste em considerar o material em pó como um fluido compressível. Contudo, este tipo de tratamento pode gerar dificuldades à medida que um alto grau de compressibilidade é exigido.

Para o estudo do comportamento do material cerâmico envolvido no processo de prensagem isostática, devido sua natureza granulada ou em pó, recorreu-se à abordagem macromecânica desenvolvida em estudos da Mecânica dos Sólidos, particularmente da Mecânica dos Solos. Segundo Chen et al. (1985), apesar de os materiais granulados (solos) constituírem um meio descontínuo, costuma-se adotar a 
hipótese da continuidade a fim de se empregar as teorias matemáticas de elasticidade, plasticidade e viscosidade quando se fizerem necessárias.

Segundo Chiaverini (2001) pode-se dividir o comportamento dos pós, quando submetidos à compressão, em três estágios:

- no primeiro estágio ocorre o rearranjo das partículas, de modo a eliminar parcialmente os vazios. Segundo Henderson et al. (2000) esse mecanismo ocorre geralmente quando as tensões hidrostáticas são baixas quando comparadas às de cisalhamento (por exemplo, durante a vibração do molde) ou no início da aplicação de uma pressão isostática;

- o segundo estágio envolve a deformação plástica das partículas, que depende principalmente da ductilidade dessas partículas.

- no terceiro estágio, as partículas de pó que tornaram-se frágeis devido ao encruamento ocorrido durante os estágios anteriores, quebram e formam fragmentos menores.

Os três estágios geralmente se sobrepõem.

Dessa forma, os mecanismos desenvolvidos ao longo do processo de compactação de pós, analisados de forma macromecânica, acarretam um comportamento não linear, onde o comportamento do material se altera à medida que é compactado.

O modelo modificado de Drucker-Prager/cap foi desenvolvido para representar o comportamento de solos, sendo possível utilizá-lo para representar o comportamento de materiais em pó. Esse modelo utiliza a superfície de DruckerPrager (DRUCKER \& PRAGER, 1952) limitada por uma superfície cap no eixo das tensões hidrostáticas.

Na eq. (2.1) é mostrado o critério de von Mises,

$$
f\left(J_{2}\right)=\sqrt{J_{2}}-k=0
$$

onde $k$ é um valor de referência associado à tensão de escoamento no ensaio uniaxial de tração simples e $J_{2}$ é o segundo invariante de tensões desviadoras definido em função das tensões principais na eq. (2.2). 


$$
J_{2}=\frac{1}{6}\left[\left(\sigma_{1}-\sigma_{2}\right)^{2}+\left(\sigma_{2}-\sigma_{3}\right)^{2}+\left(\sigma_{3}-\sigma_{1}\right)^{2}\right]
$$

$\mathrm{Na}$ eq. (2.3) é mostrado o critério de Drucker-Prager,

$$
F_{s}=f\left(J_{2}, I_{1}\right)=\sqrt{J_{2}}-\operatorname{tg}(\gamma) \frac{I_{1}}{3}-c=0
$$

onde, $\gamma$ e $c$ são parâmetros do material associados ao ângulo de atrito interno e a coesão do material, respectivamente. Este critério também é conhecido como critério de von Mises estendido (CHEN et al.,1985), a medida que introduz no critério de von Mises uma dependência do primeiro invariante das tensões $I_{l}$, que pode ser definido em função das tensões principais pela eq. (2.4).

$$
I_{1}=\sigma_{1}+\sigma_{2}+\sigma_{3}
$$

Num espaço definido pelas três tensões principais, a superfície de von Mises é um cilindro que envolve o eixo das tensões hidrostáticas $p$ onde $\sigma_{1}=\sigma_{2}=\sigma_{3}$, conforme esquematizado na Figura 2.1 e a superfície de Drucker-Prager é um cone que envolve o eixo das tensões hidrostáticas, conforme esquematizado na Figura 2.2.

Para representar o comportamento do processo de prensagem de um pó, que envolve altas variações volumétricas, faz-se necessário o uso de um modelo de material que represente essas variações volumétricas. Quando o material plastifica e segue a regra da normalidade (o estado de tensões progride segundo uma direção normal à superfície de plastificação) seu volume se mantém constante no critério de plastificação de von Mises enquanto no critério de Drucker-Prager é variável. Além disso, ao limitar a superfície de Drucker-Prager no eixo das tensões hidrostáticas, o critério de Drucker-Prager/cap se torna adequado para representar variações volumétricas quando o material plastifica por ação das tensões desviadoras (superfície de Drucker-Prager) e por ação das tensões hidrostáticas (superfície cap). 


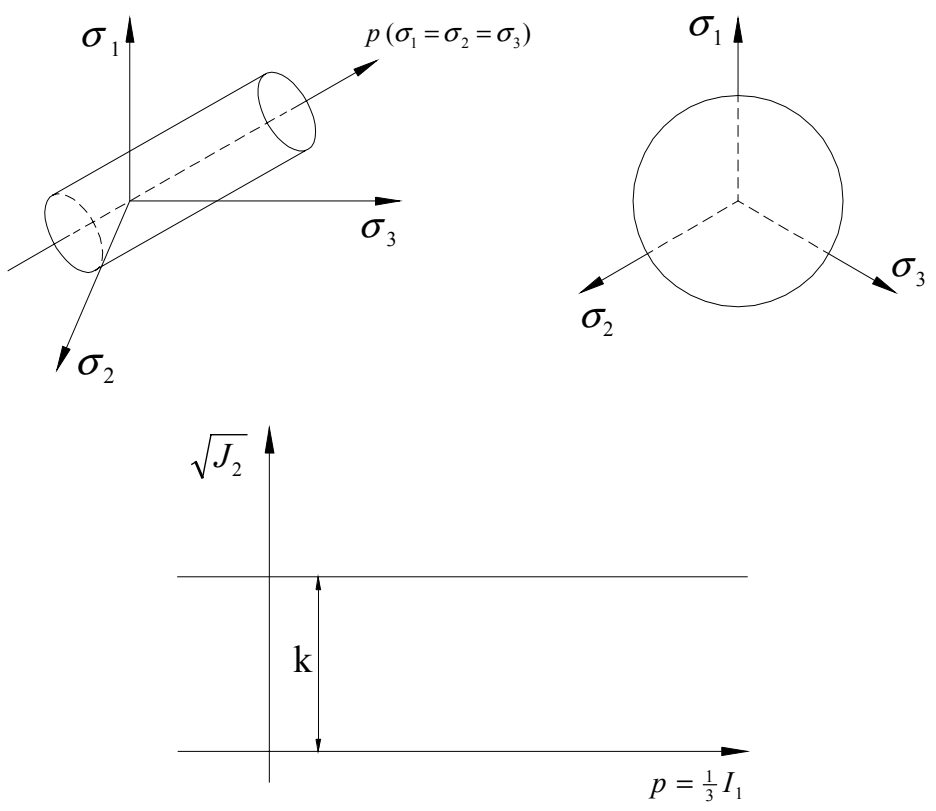

Figura 2.1 - Critério de von Mises (adaptado de CHEN et al, 1985).
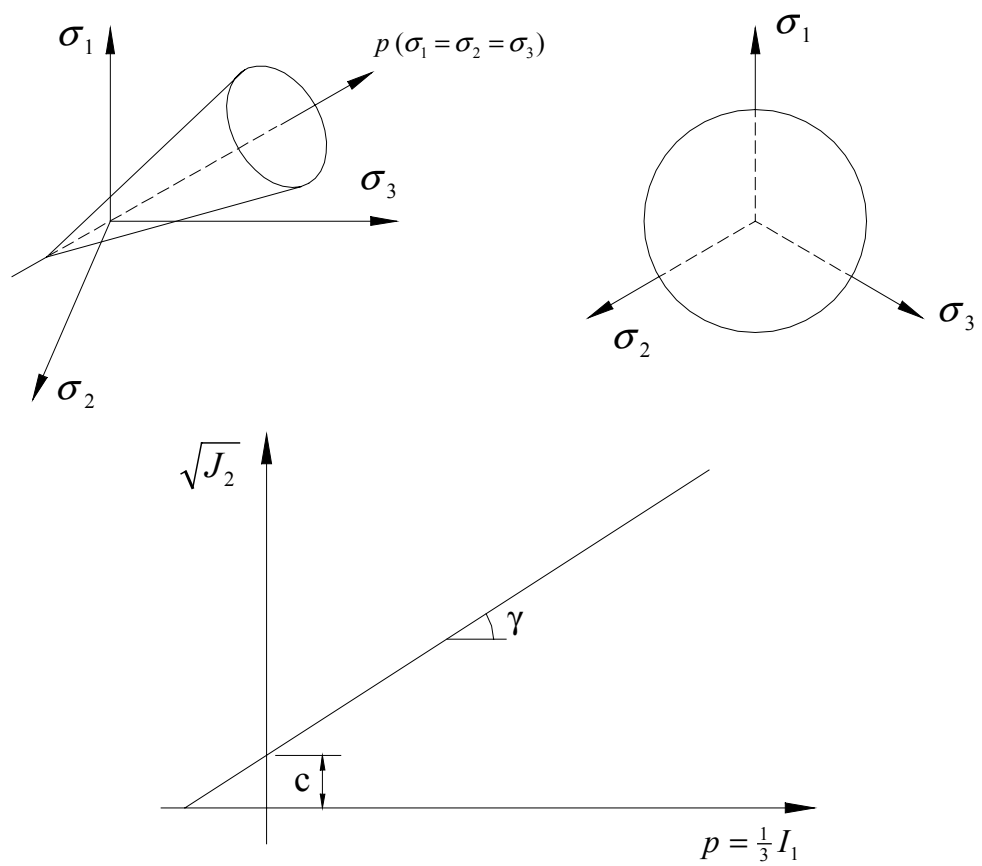

Figura 2.2 - Critério de Drucker-Prager (adaptado de CHEN et al, 1985).

O critério de Drucker-Prager/cap, disponível no programa ABAQUS ${ }^{\circledR}$, é mostrado no espaço das tensões principais da Figura 2.3 e no plano meridional ( $q \mathrm{x}$ 
p) da Figura 2.4, onde $q$ é a tensão equivalente de Mises dada pela eq. (2.5) e $p$ é a tensão média dada pela eq.(2.6).

$$
\begin{aligned}
& q=\sqrt{\frac{1}{2}\left[\left(\sigma_{1}-\sigma_{2}\right)^{2}+\left(\sigma_{2}-\sigma_{3}\right)^{2}+\left(\sigma_{3}-\sigma_{1}\right)^{2}\right]}=\sqrt{3 J_{2}} \\
& p=\frac{\left(\sigma_{1}+\sigma_{2}+\sigma_{3}\right)}{3}=\frac{I_{1}}{3}
\end{aligned}
$$

Segundo HIBBIT et al. (2000), nesse modelo a superfície de plastificação é formada por dois segmentos principais: uma superfície de plastificação por cisalhamento $\left(F_{s}\right)$ introduzida por Drucker-Prager (DRUCKER \& PRAGER, 1952) e outra superfície cap $\left(F_{c}\right)$ que intercepta o eixo das tensões hidrostáticas, e limita a superfície de plastificação no eixo das tensões hidrostáticas. A superfície cap possibilita um mecanismo de encruamento que representa a compactação do material e auxilia no controle da variação volumétrica quando o material plastifica por cisalhamento, proporcionando um certo amolecimento. Este amolecimento é representado pelo modelo quando há aumento plástico de volume devido a plastificação do material na superfície de Drucker-Prager.

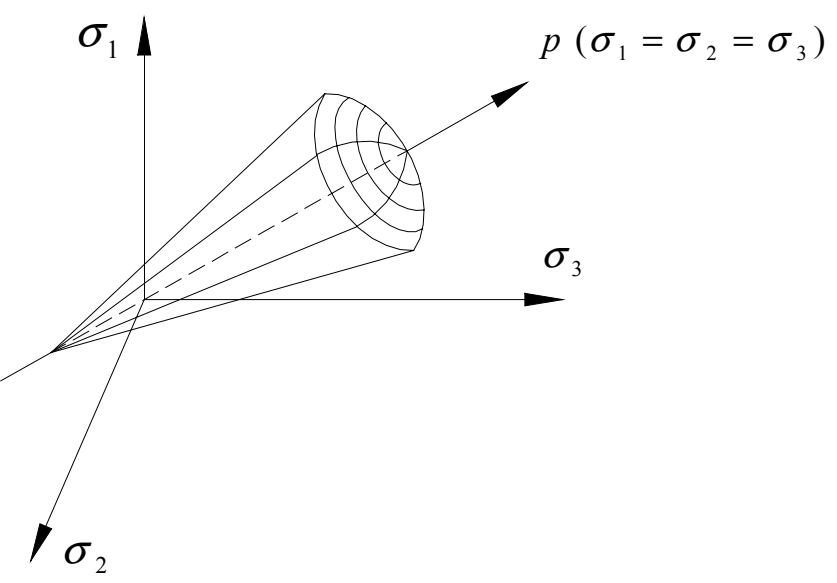

Figura 2.3 - Modelo modificado de Drucker-Prager/cap no espaço das tensões principais. 


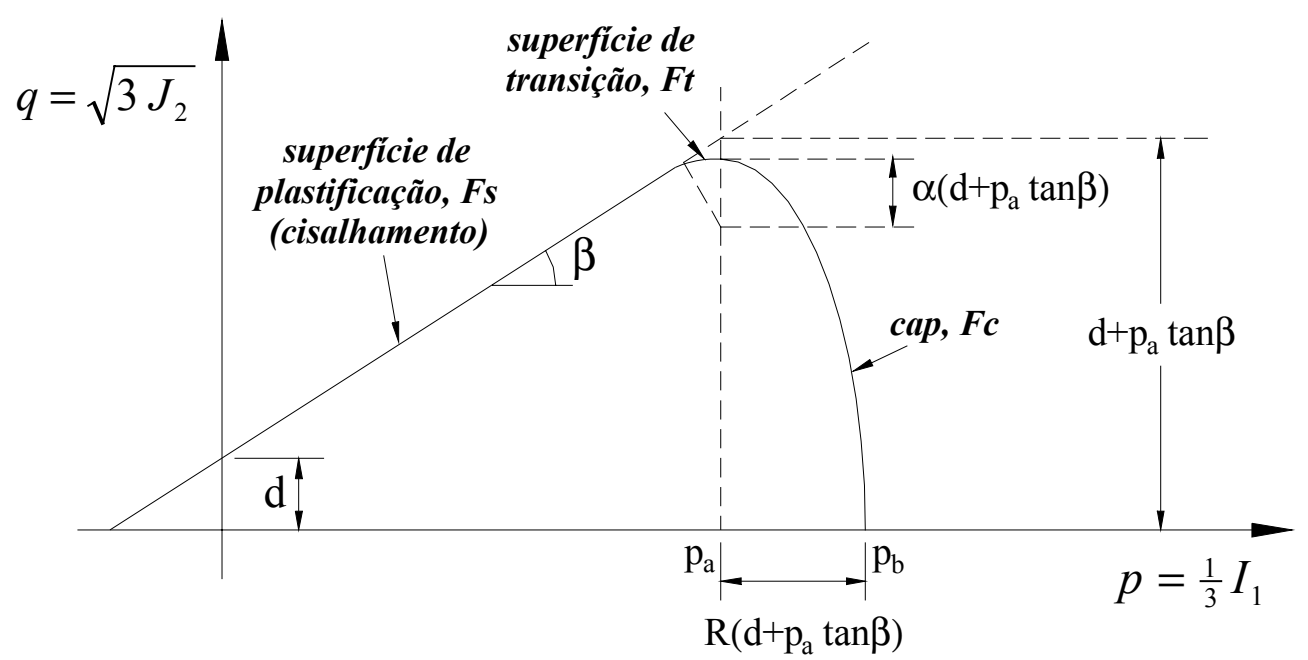

Figura 2.4 - Modelo modificado de Drucker-Prager/cap: superfícies de plastificação no plano meridional (adaptado de HIBBIT et al., 2000).

Neste plano meridional ( $q \times p$ ), a superfície de Drucker-Prager $F_{s}$, é dada pela eq. (2.7) e depende agora dos parâmetros $\beta$ e $d$.

$$
F_{s}=q-p \operatorname{tg}(\beta)-d=0
$$

A superfície cap é escrita na eq.(2.8), onde $R$ é um parâmetro do material que controla a forma da superfície cap, $p_{a}$ (dado pela eq.2.9) é um parâmetro de evolução que representa a deformação plástica volumétrica induzindo um encruamento/amolecimento e o parâmetro $\alpha$ é um número pequeno (tipicamente entre 0,01 e 0,05$)$ usado para definir a superfície de transição $\left(F_{t}\right)$ dada pela eq.(2.10) (HIBBIT et al., 2000). A lei de encruamento/amolecimento é definida por uma função que relaciona a tensão hidrostática de plastificação na compressão $p_{b}$, com a deformação plástica volumétrica, mostrada na Figura 2.5.

$$
\begin{aligned}
& F_{c}=\sqrt{\left(p-p_{a}\right)^{2}+\left[\frac{R q}{(1+\alpha-\alpha / \cos (\beta))}\right]^{2}}-R\left(d+p_{a} \operatorname{tg}(\beta)\right)=0 \\
& p_{a}=\frac{p_{b}-R d}{(1+R \operatorname{tg} \beta))}
\end{aligned}
$$




$$
F_{t}=\sqrt{\left(p-p_{a}\right)^{2}+\left[q-\left(1-\frac{\alpha}{\cos (\beta)}\right)\left(d+p_{a} \operatorname{tg}(\beta)\right)\right]^{2}}-\alpha\left(d+p_{a} \operatorname{tg}(\beta)\right)=0
$$

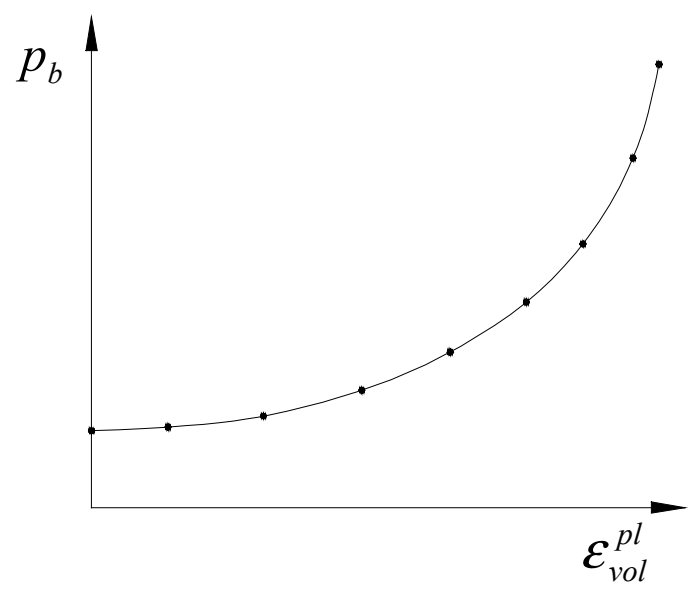

Figura 2.5 - Curva típica de encruamento da superfície cap.

\subsection{MODELAGEM DO MATERIAL ELASTOMÉRICO - MODELO HIPERELÁSTICO DE MOONEY-RIVLIN}

Um elastômero é um material polimérico hiperelástico, de estrutura amorfa e isotrópica, caracterizado por uma curva tensão-deformação não-linear, esquematizada na Figura 2.6, com comportamento independente do carregamento, quase-incompressível e com completo retorno elástico (SALA, 1996). Segundo AlQureshi (1984), o termo elastômero ou borracha pode ser designado de uma maneira mais geral, como um material que depois de deformado por ação de um carregamento externo, tem a capacidade de retornar às suas dimensões originais, quando descarregado. A AMERICAN SOCIETY FOR TESTING AND MATERIALS (ASTM) define borracha como um material natural ou sintético que já se encontra, ou pode ser submetido a um estado vulcanizado no qual apresenta elevada capacidade de deformação e alta capacidade de retornar rapidamente ao seu estado original. 


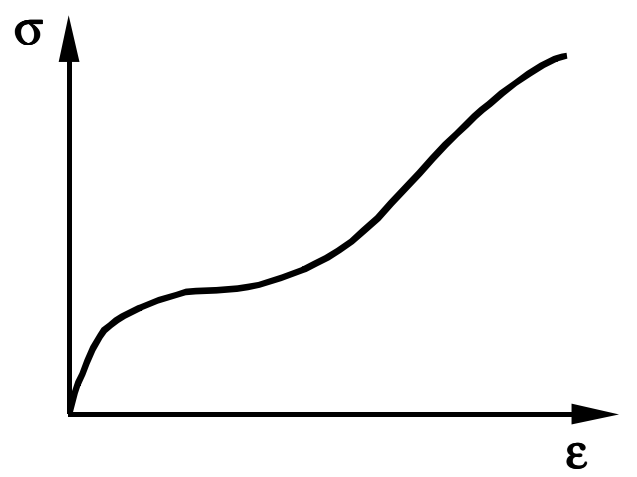

Figura 2.6 - Aspecto da curva tensão-deformação de um material hiperelástico.

Componentes constituídos de borrachas ou elastômeros têm um papel importante em processos de fabricação e produtos, devido às suas excelentes propriedades elásticas e viscoelásticas que permitem inúmeras aplicações, tais como: vedadores, tampas, amortecedores ou absorvedores de energia, moldes, entre outras.

\subsubsection{PEQUENAS DEFORMAÇÕES ELÁSTICAS}

Um material elástico isotrópico pode ser representado por duas constantes elásticas fundamentais. A primeira, denominada de Módulo Volumétrico $(K)$, expressa a resistência à contração do material quando submetido a uma pressão de compressão hidrostática. O Módulo Volumétrico $(K)$ é apresentado na eq.(2.11) onde a pressão aplicada é proporcional à razão entre a variação volumétrica $\Delta V$ pelo volume original $V_{0}(\mathrm{GENT}, 1992)$.

$$
P=K\left(\frac{\Delta V}{V_{0}}\right)
$$

A segunda constante descreve a resistência do material ao cisalhamento simples, denominada de Módulo de Cisalhamento $(G)$, sendo definida pela relação entre a tensão de cisalhamento $(\tau)$ aplicada e a distorção $(\xi)$ sofrida pelo material, indicada na eq.(2.12) (GENT, 1992). 


$$
G=\frac{\tau}{\xi}
$$

Outras constantes mais comumente utilizadas são derivadas dessas duas. $\mathrm{O}$ Módulo de Young $(E)$ pode ser definido pela razão entre a tensão $(\sigma)$ e sua correspondente deformação $(\mathcal{E})$ no caso unidimensional, ou calculado com o auxílio de $K$ e $G$, como é mostrado na eq.(2.13). O Coeficiente de Poisson ( $v$ ) é definido pela razão entre a deformação transversal $\left(\varepsilon_{2}\right)$ e a deformação longitudinal $\left(\varepsilon_{l}\right)$ para uma amostra padronizada submetida a um estado uniaxial de tensão, ou calculado também com o auxílio de $K$ e $G$, como é mostrado na eq.(2.14).

$$
\begin{aligned}
& E=\frac{\sigma}{\varepsilon}=\frac{9 K G}{3 K+G} \\
& v=\frac{\varepsilon_{2}}{\varepsilon_{1}}=\frac{3 K-2 G}{2(3 K+G)}
\end{aligned}
$$

As borrachas têm altos valores para o Módulo Volumétrico $(K=1,5 \sim 2 \mathrm{GPa})$ quando comparados aos valores do módulo de cisalhamento $(G=0,5 \sim 10 \mathrm{MPa})$. O Módulo de Young $E$ é aproximadamente três vezes o valor do Módulo de Cisalhamento $G$. O coeficiente de Poisson $v$ está próximo do valor máximo de 0,5 para materiais incompressíveis (aproximadamente 0,4995) (GENT, 1992).

\subsubsection{GRANDES DEFORMAÇÕES ELÁSTICAS}

Como descrito anteriormente os elastômeros são caracterizados por apresentarem grandes deformações elasticamente recuperáveis. Estes materiais podem ser representados por modelos de comportamento hiperelástico, que se caracterizam por permitirem grandes deformações e deslocamentos, porém baixíssimas variações volumétricas, visto que podem ser considerados incompressíveis ou quase incompressíveis. 
Para teoria de deformações elásticas com grandes deformações não se utilizam as relações lineares tradicionalmente conhecidas. A deformação é definida, neste caso, em termos do estiramento $\lambda$ definido na eq.(2.15).

$$
\lambda=\frac{L}{L_{0}}
$$

onde $L_{0}$ é o comprimento inicial e $L$ é o comprimento atual num estado deformado para um caso unidimensional. Utilizando-se do tensor de deformações de Green, vale a eq.(2.16) (DIETER, 1981):

$$
\begin{aligned}
& \lambda_{1}^{2}=1+2 \bar{e}_{x x} \\
& \lambda_{2}^{2}=1+2 \bar{e}_{y y} \\
& \lambda_{3}^{2}=1+2 \bar{e}_{z z}
\end{aligned}
$$

onde $\bar{e}_{x x}, \bar{e}_{y y}, \bar{e}_{z z}$ são as componentes da deformação finita definidas pelas eq.(2.17)

(a) (b)

$$
\begin{aligned}
& \bar{e}_{x x}=\overbrace{\frac{\partial u}{\partial x}+\frac{1}{2}\left\{\left(\frac{\partial u}{\partial x}\right)^{2}+\left(\frac{\partial v}{\partial x}\right)^{2}+\left(\frac{\partial w}{\partial x}\right)^{2}\right\}} \\
& \bar{e}_{y y}=\frac{\partial u}{\partial y}+\frac{1}{2}\left\{\left(\frac{\partial u}{\partial y}\right)^{2}+\left(\frac{\partial v}{\partial y}\right)^{2}+\left(\frac{\partial w}{\partial y}\right)^{2}\right\} \\
& \bar{e}_{z z}=\frac{\partial u}{\partial z}+\frac{1}{2}\left\{\left(\frac{\partial u}{\partial z}\right)^{2}+\left(\frac{\partial v}{\partial z}\right)^{2}+\left(\frac{\partial w}{\partial z}\right)^{2}\right\}
\end{aligned}
$$

e $u, v$ e $w$ são as componentes do deslocamento relativo aos eixos $x, y$ e $z$, respectivamente. 
Os termos (a) das eq.(2.17) são as parcelas lineares da deformação (utilizados para o cálculo de pequenas deformações), enquanto que os termos (b) são as parcelas não-lineares que são acrescidas para o cálculo de grandes deformações.

Os invariantes de deformação (pela medida quadrática) são definidos como:

$$
\begin{aligned}
& I_{1}^{\prime}=\lambda_{1}{ }^{2}+\lambda_{2}{ }^{2}+\lambda_{3}{ }^{2} \\
& I_{2}^{\prime}=\lambda_{1}{ }^{2} \lambda_{2}{ }^{2}+\lambda_{2}{ }^{2} \lambda_{3}{ }^{2}+\lambda_{3}{ }^{2} \lambda_{1}{ }^{2} \\
& I_{3}^{\prime}=\lambda_{1}{ }^{2} \lambda_{2}{ }^{2} \lambda_{3}{ }^{2}
\end{aligned}
$$

Gent (1982), baseando-se na teoria de Rivlin, descreveu que um material incompressível, elástico e isotrópico pode ser representado por uma Função Potencial Elástica ou Função de Densidade de Energia de Deformação (quantidade de energia elástica armazenada por unidade de volume) sendo esta função dependente dos 3 invariantes de deformação $\left(I_{1}^{\prime}, I_{2}^{\prime}, I_{3}^{\prime}\right)$.

Segundo Peng et al. (1997) para materiais perfeitamente incompressíveis, há a condição de incompressibilidade dada por:

$$
\sqrt{I_{3}^{\prime}}=\lambda_{1} \lambda_{2} \lambda_{3}=1
$$

e a Função de Densidade de Energia de Deformação $(W)$ torna-se independente do terceiro invariante e será dada por:

$$
W=W\left(I_{1}^{\prime}, I_{2}^{\prime}\right)=\sum_{i=0}^{\infty} C_{i j}\left(I_{1}^{\prime}-3\right)^{i}\left(I_{2}^{\prime}-3\right)^{j}
$$

sendo comumente conhecida como Função de Rivlin.

Os valores de $C_{i j}$ são constantes relacionadas ao material. Num caso particular, onde $C_{10}=C_{1}$ e $C_{01}=C_{2}$ e os outros termos $C i j=0$, tem-se a Função de Mooney, ou mais comumente conhecida como Função de Mooney-Rivlin (PENG et al.,1997) representada na eq.(2.21).

$$
W=C_{1}\left(I_{1}^{\prime}-3\right)+C_{2}\left(I_{2}^{\prime}-3\right)
$$


Várias outras formas de Energia Potencial de Deformação são usadas para representar materiais hiperelásticos, e estão baseadas nos invariantes de deformação ou nas deformações principais, onde o comportamento do material pode ser assumido como perfeitamente incompressível ou quase incompressível. Dentre os modelos hiperelásticos mais utilizados podem ser citados: Modelo de Neo-Hookean, Modelo de Mooney-Rivlin, Modelo Polinomial, Modelo de Ogden e o Modelo de Arruda-Boyce (HIBBIT et al., 2000).

É interessante acrescentar que a modelagem de um material quase incompressível (a maioria dos elastômeros) em estado confinado apresenta problemas de travamento da solução (locking) e os modelos devem ter uma parcela adicional que represente esta incompressibilidade. Este travamento geralmente ocorre por problemas de divisões por zero, como exemplo no cálculo do módulo volumétrico $K$ pela eq.(2.11), a medida que as variações volumétricas tendem a zero e conseqüentemente o valor do Módulo Volumétrico tende a infinito. Peng et al (1997) apresentaram brevemente o uso de Multiplicadores de Lagrange e o Método da Penalidade como alternativas de contornar este problema.

Com a adição da parcela para modelagem da quase incompressibilidade do material, a Função de Mooney-Rivlin passa a ser dada pela eq.(2.22).

$$
W=C_{1}\left(I_{1}^{\prime}-3\right)+C_{2}\left(I_{2}^{\prime}-3\right)+D
$$




\section{REVISÃO BIBLIOGRÁFICA}

Nos últimos anos vários trabalhos têm sido realizados objetivando a simulação de processos de prensagem de materiais cerâmicos e metálicos, porém a maioria desses trabalhos se concentra em estudos de processos de prensagem em matrizes rígidas.

Dimilia \& Reed (1983) e Song \& Chandler (1990) investigaram a transmissão de tensões no material, o atrito e a relação de tensões axial/radial na compactação de pó cerâmico (alumina) em um dispositivo cilindro-pistão (DCP) instrumentado com extensômetros. Henke et al. (1986), utilizando um procedimento análogo, analisaram a influência de aditivos no material em pó e constataram que enquanto a influência de aglutinantes foi desprezível na relação de tensões axial/radial, a adição de lubrificantes foi considerável, aumentando a tensão radial de reação nas paredes do cilindro para um mesmo material.

Shima \& Mimura (1986), através de um dispositivo para ensaios triaxiais, realizaram uma série de ensaios com pó cerâmico, variando as relações das tensões aplicadas nas três direções, e constataram maior influência de tensões hidrostáticas nos modelos de compactação de pós cerâmicos quando comparados com os pós metálicos.

Bortzmeyer (1992) descreve as principais diferenças no comportamento dos pós quando carregados: os pós metálicos, pós cerâmicos e os solos. Assim, mostra as diferenças na modelagem desses diferentes tipos de materiais, ressaltando a maior complexidade da modelagem do pó cerâmico.

Aydin et al. (1996), baseados em Nelson (1977) e Dimaggio et al. (1971), obtém os principais parâmetros para a modelagem da prensagem de alumina 
realizando um ensaio uniaxial em um DCP, e utilizam esses parâmetros para calibrar o modelo de material de Drucker-Prager/cap. Analisam pelo método dos elementos finitos essa prensagem uniaxial, onde estudam e comparam os perfis de densidades com medidas experimentais.

Tszeng \& Wu (1996) utilizaram parâmetros de ensaios triaxiais na calibração de um novo modelo de escoamento rígido-plástico para pós metálicos (aço e cobre). Akisanya et al. (1997) comparam alguns modelos de material utilizando parâmetros de ensaios triaxiais e uniaxiais em pós de cobre.

Briscoe \& Özkan (1997) descrevem a importância da utilização de aglomerantes orgânicos para aumentar a fluidez em pós com partículas de dimensões submicrométricas. Utilizando um DCP analisaram a influência de alguns fatores na compactação de pós de alumina, tais como: aspect ratio (a relação entre a altura e o diâmetro das amostras a serem compactadas), a lubrificação das paredes da matriz e a taxa de compactação. Apesar de constatarem uma influência da taxa de compactação nas densidades do material compactado, essa diminuiu à medida que se utilizou um material mais seco, tornando-se desprezível.

Briscoe \& Rough (1998) analisaram a distribuição de densidades na peça compactada utilizando métodos experimentais e análises numéricas para a matriz lubrificada e sem lubrificação. A previsão dos perfis de densidades foi obtida relacionando as tensões geradas na amostra compactada a valores de densidades, onde essa relação foi regida por uma equação empírica.

Quando os materiais em pó são submetidos a uma vibração, seus grãos se arranjam de modo a se acomodarem numa disposição mais estável. Neste estado, o material (considerado como meio contínuo) se expande quando cisalhado. Nixon \& Chandler (1999) apresentam um modelo capaz de prever tal comportamento quando os materiais em pó são submetidos a pequenos carregamentos cisalhantes.

Baccino \& Moret (2000) vêm desenvolvendo um programa para otimização de projetos de moldes para processos de prensagem isostática à quente. O programa utiliza-se de ferramentas $C A D$ e do método dos elementos finitos.

Zeuch et al. (2001) descreve o uso de ensaios triaxiais e hidrostáticos para a determinação de parâmetros elásticos e plásticos para pós de alumina e como estes parâmetros se comportam para diferentes pressões de compactação. 
Park \& Kim (2001) analisaram a distribuição de densidades na peça compactada utilizando métodos experimentais e análises numéricas. Associaram valores de dureza para a obtenção das densidades experimentais das peças compactadas. Constataram que as tensões cisalhantes influenciam na densificação do material para baixas pressões de confinamento. Seu novo modelo cap previu melhor o adensamento do material que outros modelos (Drucker-Prager e Cam-Clay).

Para desenvolver um novo modelo constitutivo para a compactação de pós metálicos Gu et al. (2001) utilizaram-se de ensaios triaxiais. Esse modelo é formado por uma superfície de plastificação por cisalhamento baseada no critério de MohrCoulomb e uma superfície cap de forma elíptica.

Segundo Chtourou et al. (2002), são necessários procedimentos padronizados para a calibração de modelos cap. Assim propuseram e aplicaram uma metodologia de ensaios uniaxiais, hidrostáticos e triaxiais em pós metálicos para a calibração de modelos de material.

Recentemente alguns trabalhos desenvolveram estudos do comportamento de pós no processo de prensagem isostática a frio e são apresentados a seguir.

Kim \& Lee (1998) estudaram os efeitos do atrito entre um pó metálico e o macho interno do molde no processo de prensagem isostática a frio de um tubo de paredes finas. Os coeficientes de atrito foram determinados através de uma relação entre a tensão de compactação e a tensão de extração do compacto. Para representar o comportamento do pó metálico, utilizaram um modelo elasto-plástico desenvolvido por Shima \& Oyane (1976) e calibrado em ensaio uniaxial num DCP. A fim de simplificar a análise a matriz elastomérica não foi modelada e a tensão isostática foi aplicada diretamente no pó metálico. Esta simplificação é apropriada quando o compacto possui geometrias simplificadas.

Henderson et al. (2000) modelaram o processo de prensagem isostática de um tubo de material refratário (grafite, alumina e aglomerante). Para representar o comportamento do material cerâmico, desenvolveram um modelo elasto-plástico com uma superfície de plastificação elíptica. Para a calibração desse modelo utilizaram dois tipos de ensaios com o material cerâmico. Um ensaio uniaxial em um DCP instrumentado desenvolvido por Song \& Chandler (1990), e um ensaio em uma matriz elastomérica cilíndrica selada por uma tampa metálica, conforme 
esquematizado na Figura 3.1, a fim de determinar parâmetros de encruamento do material. Este procedimento não representa uma compactação isostática perfeita devido à tampa metálica não flexível.

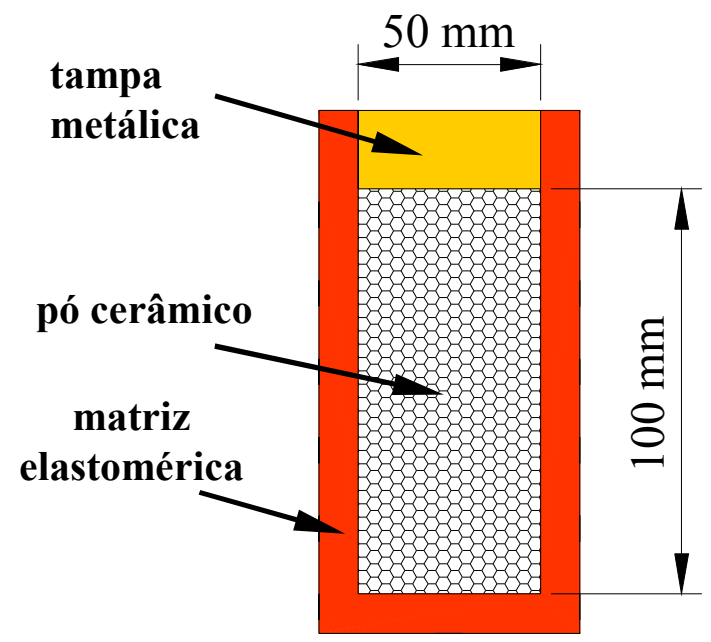

Figura 3.1 - Matriz elastomérica usada por HENDERSON et al. (2000) para determinação da relação de tensão hidrostática - deformação volumétrica plástica do pó cerâmico.

Na modelagem da matriz elastomérica envolvida no processo de fabricação do tubo refratário, Henderson et al. (2000), utilizaram o modelo de Mooney-Rivlin. Este modelo foi calibrado através de ensaios mecânicos de compressão hidrostática e tração uniaxial. Dessa forma os autores analisaram a influência da matriz elastomérica nas simulações constatando sua importância. Para isso realizaram análises da prensagem do mesmo componente com e sem a modelagem da matriz elastomérica. Quando a matriz elastomérica não foi modelada constataram a presença de distorções na forma prevista do compacto pelo método dos elementos finitos.

Por outro lado, Kim et al. (2001) também estudaram a influência da matriz elastomérica em simulações do processo de prensagem isostática a frio de pós metálicos não constatando influências consideráveis. Para representar o comportamento do pó metálico, utilizaram um modelo elasto-plástico desenvolvido por Shima \& Oyane (1976). Na modelagem da matriz elastomérica utilizaram o modelo hiperelástico de Ogden, calibrado através de ensaios mecânicos de compressão hidrostática, compressão uniaxial e tração uniaxial. 
O presente trabalho utilizou o modelo de Drucker-Prager/cap para representar o comportamento do material cerâmico. Para a calibração desse modelo utilizou-se um ensaio de compressão uniaxial em um DCP. O modelo hiperelástico de MooneyRivlin foi utilizado para representar o comportamento da matriz elastomérica e calibrado através de ensaios uniaxiais de compressão e tração e compressão volumétrica. 


\section{MATERIAIS E MÉTODOS}

\subsection{MATERIAIS}

O pó cerâmico foi o mesmo utilizado por Wrege (2000) e foi obtido a partir de:

- 99,90\% em peso de Alumina S5G - 99,5\%

Granulometria: \# 325 mesh.

Procedência: Alcan Alumínio do Brasil S.A.

Densidade Compactada: $1,20 \mathrm{~g} / \mathrm{cm}^{3}$.

Área superficial: 0,95 m2/g.

Diâmetro esférico equivalente: $4,08 \mathrm{~mm}$.

- Álcool polivinílico (PVAL).

Procedência: Vetec Química Fina Ltda.

Peso molecular: 72.000 .

- $\mathrm{MgO}$ de alta pureza $0,25 \%$ em peso.

Procedência: Labsynth Produtos para Laboratórios Ltda.

Peso Molecular: 40,30.

O material elastomérico utilizado para a confecção da matriz elastomérica foi uma poliuretana (PU) - UREOL ${ }^{\circledR}$ (composta de 18 partes em massa do componente 6414-B em 100 partes em massa do componente XB 5073-1) de fabricação CIBAGEIGY QUÍMICA S.A. 
As matrizes flexíveis, que auxiliam na fabricação do molde, foram geradas a partir de borracha de silicone (composta de 10 partes em massa do componente RP4644-E em 100 partes em massa do componente RP4644-R).

Para a obtenção da matriz rígida, que auxilia na fabricação do molde, e da Gaiola Suporte do molde de prensagem foi utilizado uma poliuretana (PU) a base de óleo de mamona.

\subsection{MÉTODOS}

\subsubsection{METODOLOGIA PARA PROJETO E FABRICAÇÃO DOS MOLDES}

O fluxograma proposto neste trabalho que esquematiza a metodologia de projeto, re-projeto e fabricação do molde, é mostrado na Figura 4.1, e foi dividido em 3 fases principais para um melhor estudo.

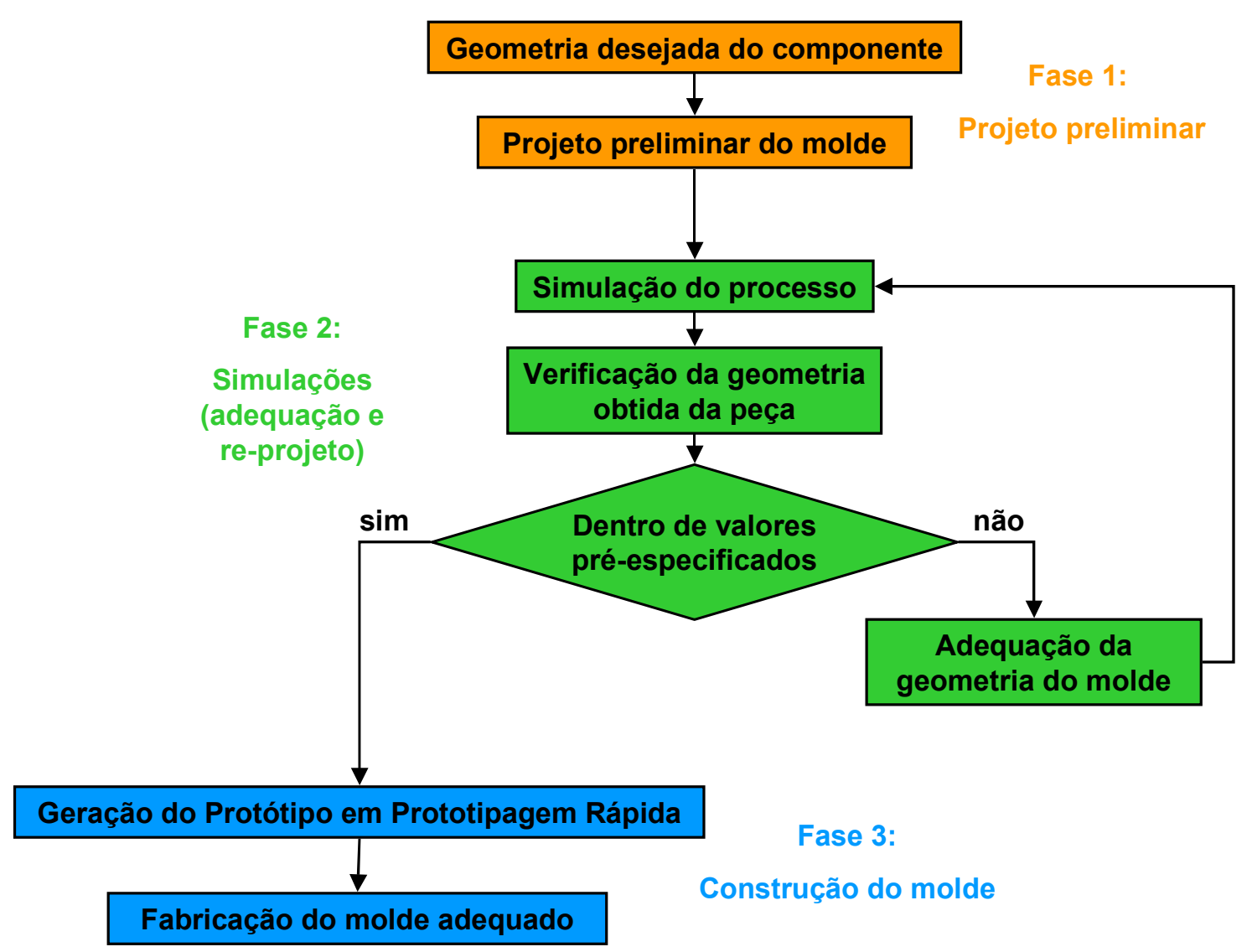

Figura 4.1 - Fluxograma da metodologia de projeto, re-projeto e fabricação do molde. 
Atualmente, o procedimento utilizado na indústria para projetar o molde de prensagem isostática de componentes é baseado em "tentativa-erro", auxiliado por cálculos simples de compactação ou por informações resultantes de experiências anteriores. Esse trabalho propõe uma metodologia para o projeto e adequação do molde, através de protótipos virtuais, que são testados e analisados com base em simulações computacionais até que se alcance um projeto adequado às condições geométricas previamente estabelecidas a partir do componente final pretendido.

Entretanto, para se iniciar o processo de projeto e adequação do molde é necessário estabelecer um projeto preliminar. Dessa forma, o fluxograma da Figura 4.2 propõe uma metodologia para se projetar o molde preliminar (Fase 1 do fluxograma da Figura 4.1) onde são considerados alguns parâmetros de processo (que não são objetos de estudo diretos desse trabalho).

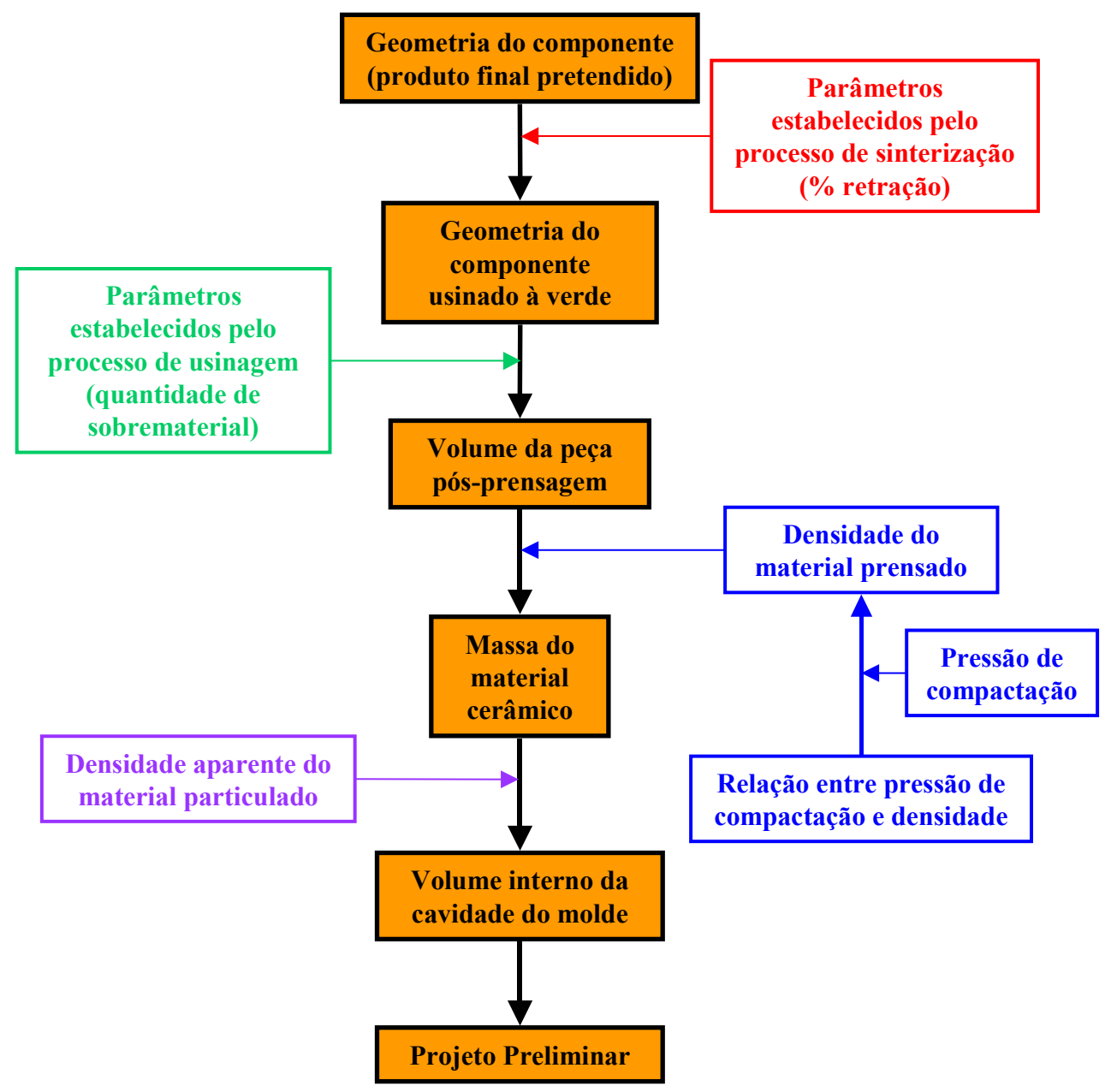

Figura 4.2 - Fluxograma da metodologia do Projeto Preliminar do Molde. 
Neste trabalho, o projeto do molde preliminar não foi realizado seguindo a metodologia proposta na Figura 4.2, pois esse projeto preliminar foi aproveitado de um trabalho anterior, conforme descrito no item 1.5

A Fase 2 do fluxograma da Figura 4.1, que envolve as simulações para adequação e re-projeto do molde, será exposta nos itens a seguir, onde apresenta-se a metodologia para a obtenção das propriedades do pó cerâmico e do elastômero e as simulações do processo de prensagem utilizando o molde preliminar e o molde adequado pela utilização da metodologia.

\subsubsection{ANÁlise do PRocesso de PRensagem isostática Pelo MÉTODO DOS ELEMENTOS FINITOS}

Utilizando a metodologia proposta, modificou-se a dimensão do molde até alcançar uma geometria que satisfizesse os valores pré-estabelecidos segundo os resultados obtidos da simulação. Assim obteve-se o projeto do molde adequado, mostrado na Figura 4.3.

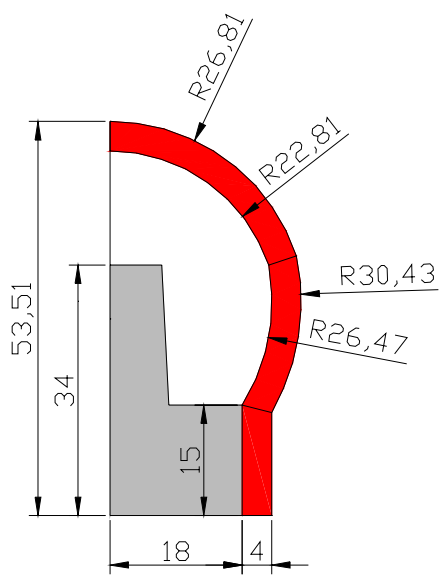

Figura 4.3 - Projeto do molde adequado obtido pela metodologia proposta.

Para a construção da malha para a simulação, modelou-se o pó cerâmico com elementos axi-simétricos tipo CAX8 (Continuum AXisymmetric de 8 nós) com o modelo de Drucker Prager/cap. Modelou-se a matriz elastomérica com elementos axi-simétricos tipo CAX8H (Continuum AXisymmetric de 8 nós, com formulação Híbrida, que permitem a modelagem da quase-incompressibilidade do material) com 
o modelo hiperelástico de Mooney-Rivlin. O macho e a parte inferior da gaiola foram modelados através de superfícies analíticas rígidas. Essa opção permite uma maior simplicidade na análise, visto que essas superfícies substituem os elementos necessários para se modelar essas partes de maneira convencional. $\mathrm{O}$ uso dessa opção é viável, pois as possíveis deformações (relativamente pequenas) das partes metálicas do molde (macho e gaiola) podem ser desprezadas. Assim, tal simplificação não influenciará no objetivo principal da análise que visa estudar a forma e dimensões externas do compacto.

Na Figura 4.4 são mostradas a malha de elementos finitos, as condições de contorno e as superfícies analíticas rígidas. Na superfície externa dos elementos da matriz elastomérica foi aplicada uma pressão de compressão uniforme de $100 \mathrm{MPa}$, dividida em passos de carga.

Foram definidas superfícies de contato, onde se pôde modelar a interação entre essas superfícies como, por exemplo, deslizamentos tangenciais e coeficientes de atrito.

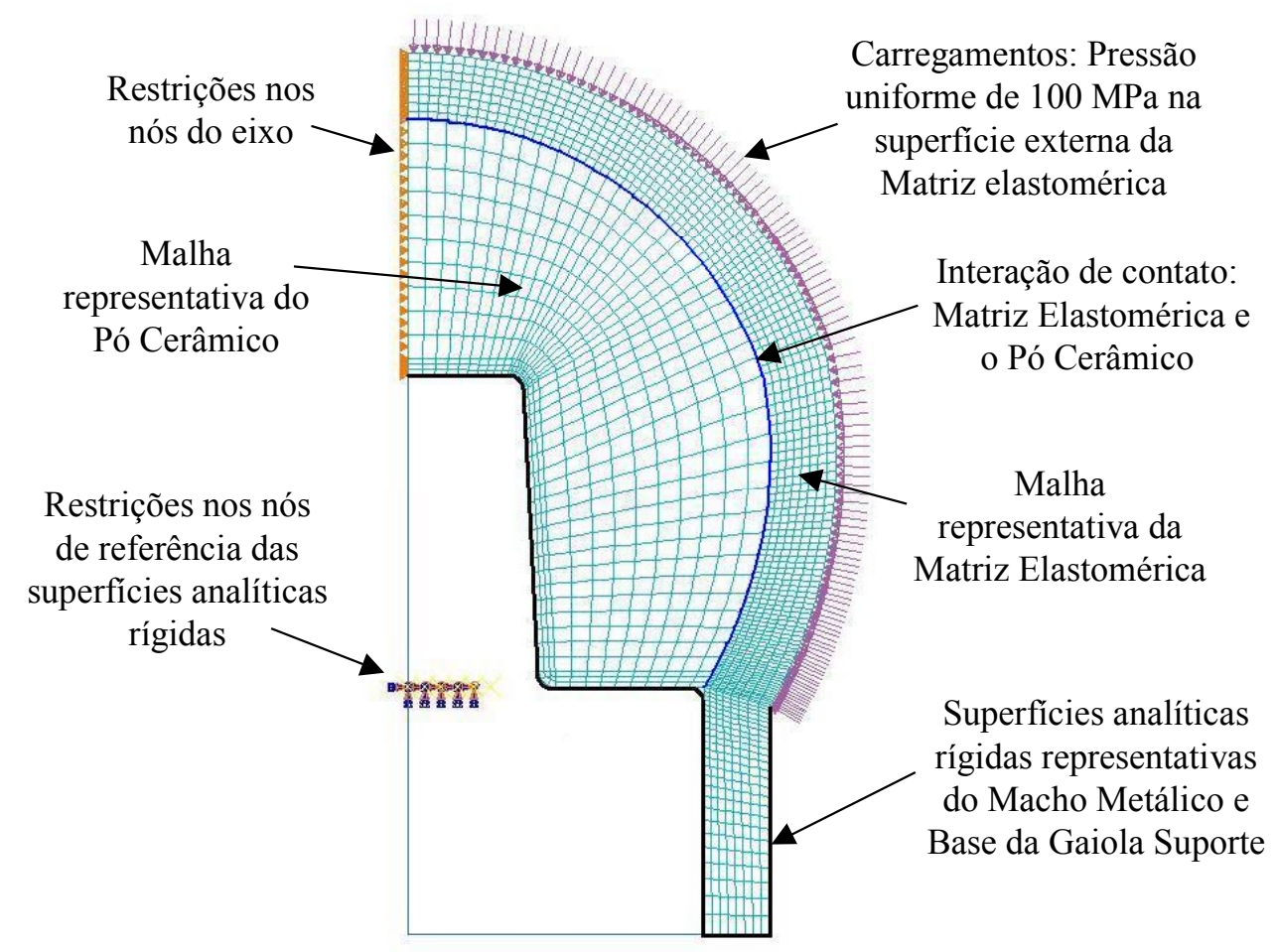

Figura 4.4 - Análise do processo de prensagem isostática de pós cerâmicos - malha de elementos finitos e condições de contorno. 


\subsubsection{MODELAGEM DO CONTATO}

$\mathrm{Na}$ modelagem de problemas de contato utilizando o ABAQUS 6.2-1 é necessária a definição de dois tipos de superfícies, slave e master para estabelecer a interação de contato. As superfícies são definidas através das faces dos elementos ou utilizando elementos específicos para contato. Geralmente define-se como superfície slave as superfícies deformáveis e mais refinadas, e como superfície master as superfícies rígidas (ou relativamente mais rígidas) e menos refinadas. O programa apresenta dois principais tipos de modelos de interação de contato entre duas superfícies (HIBBIT et al., 2000):

1 - Finite sliding é o modelo mais geral e possibilita qualquer tipo de movimento como a separação, deslizamento de grandes amplitudes e rotações arbitrárias entre as superfícies em contato. Apresenta maior custo computacional, pois o algoritmo analisará o contato de cada nó da superfície slave com toda a superfície master. Conforme esquematizado na Figura 4.5, o nó 101 da superfície slave, por exemplo, pode entrar em contato em qualquer ponto ao longo da superfície master, e quando em contato, estará restrito a movimentar-se ao longo dessa superfície.

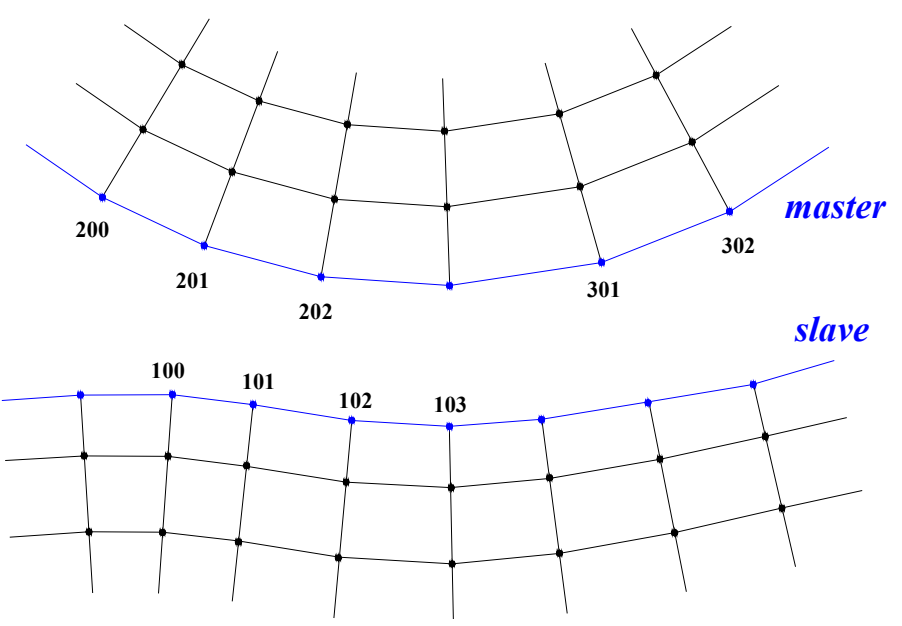

Figura 4.5 - Contato entre duas superfícies utilizando a interação finite sliding (adaptado de HIBBIT et al., 2000)

Na Figura 4.6 é mostrada uma possível evolução do contato entre o nó 101 e a superfície master. No instante $\mathrm{t}=\mathrm{t}_{1} \mathrm{o}$ nó 101 está em contato com a face do elemento definida pelos nós 201 e 202 e a transferência das forças de contato se dá 
somente entre o nó 101 e os nós 201 e 202. Mais tarde, no instante $t=t_{2}$, o nó 101 poderá estar em contato com a face do elemento definida pelos nós 301 e 302 e a transferência das forças de contato se dá somente entre o nó 101 e os nós 301 e 302.

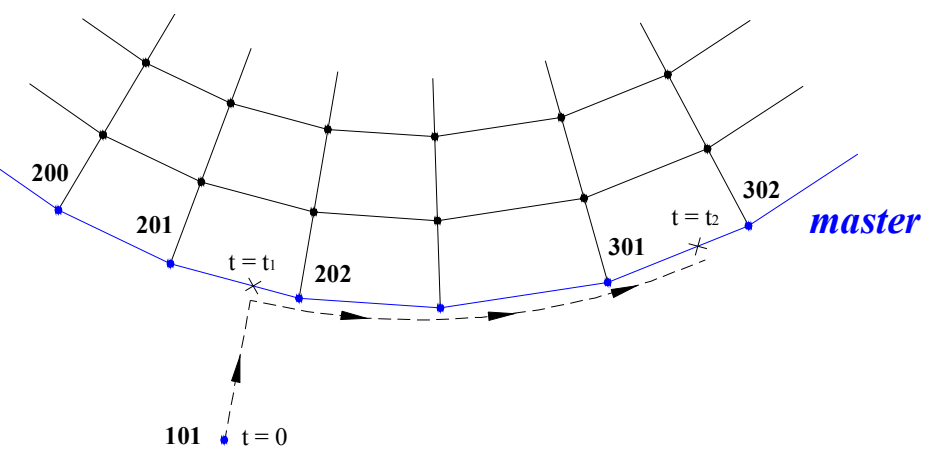

Figura 4.6 - Possível trajetória do nó 101 da superfície slave em contato com a superfície master utilizando a interação finite sliding (adaptado de HIBBIT et al., 2000).

2 - Small sliding é um modelo mais simplificado e de menor custo computacional quando comparado com o modelo finite sliding, pois o algoritmo analisará o contato do nó da superfície slave com uma superfície tangente local a um ponto de projeção do nó da superfície slave na superfície master, conforme esquematizado na Figura 4.7. Cada plano tangente local é definido por um ponto âncora (anchor point) $X_{0}$ na superfície master associado a um vetor de orientação $N\left(X_{0}\right)$.

Figura 4.7 - Contato entre duas superfícies utilizando a interação small sliding (adaptado de HIBBIT et al., 2000) 
As direções dos vetores nodais unitários de orientação $N_{n}$ são definidas pela média entre as normais das faces dos elementos adjacentes que pertencem à superfície master. O vetor de orientação $N\left(X_{0}\right)$ é definido pela função de forma do elemento com a face que contém os nós 1 e 2 calculada com base nos vetores $N_{l}$ e $N_{2}$. Assim o ponto âncora é definido quando a projeção de $N\left(X_{0}\right)$ intercepta o nó 102 da superfície slave.

$\mathrm{Na}$ Figura 4.8a é esquematizada a interação de contato utilizada entre o material cerâmico e o macho metálico. A superfície de contato do pó cerâmico foi considerada como slave e a superfície analítica rígida como master. Nesse caso foi utilizada a interação de contato finite sliding. Essa opção foi utilizada devido aos grandes deslizamentos relativos entre as duas superfícies. Nessa interação o coeficiente de atrito adotado foi de 0,05, valor baseado em Kim \& Lee (1998) e representa o baixo atrito nessa região devido à lubrificação com grafite em pó.

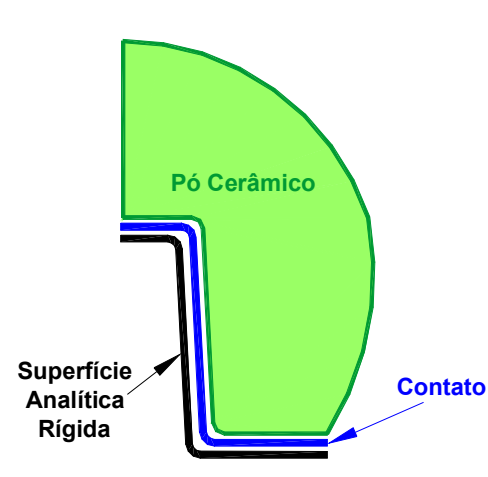

(a)

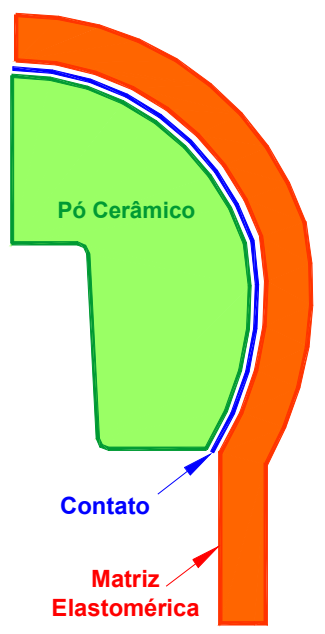

(b)

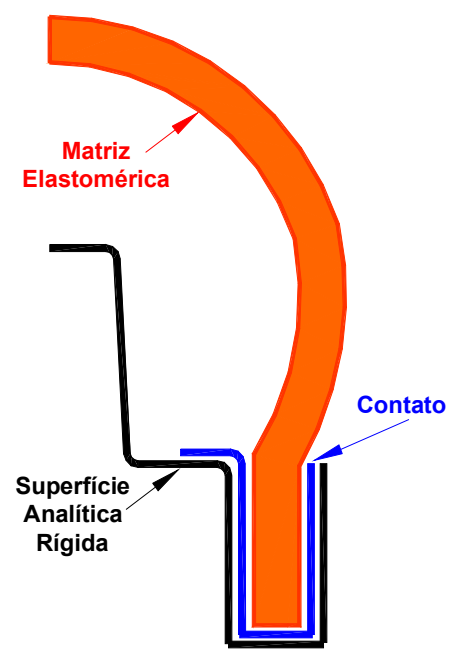

(c)

Figura 4.8 - Interação de contato entre material cerâmico e macho

$\mathrm{Na}$ Figura $4.8 \mathrm{~b}$ é esquematizada a interação de contato entre matriz elastomérica e o pó cerâmico. A superfície de contato da matriz elastomérica foi considerada como slave e a superfície do pó cerâmico como master. Nesse caso foi utilizada a interação de contato small sliding. Esta opção foi utilizada devido aos pequenos deslizamentos relativos entre as duas superfícies. Nessa interação o coeficiente de atrito adotado foi de 0,2 . 
$\mathrm{Na}$ Figura 4.8c é esquematizada a interação de contato entre matriz elastomérica, macho metálico e gaiola. A superfície de contato da matriz elastomérica foi considerada como slave e a superfície analítica rígida que representa o macho e a gaiola como master. Nesse caso foi utilizada a interação de contato small sliding. Esta opção foi utilizada devido aos pequenos deslizamentos relativos entre as duas superfícies. O coeficiente de atrito adotado foi de 0,2. Somente a parte inferior da gaiola foi modelada nessa interação de contato a fim de simplificar a análise, haja vista que nas outras regiões não ocorre o contato.

\subsubsection{DETERMINAÇÃO DAS PROPRIEDADES E MODELAGEM DO MATERIAL CERÂMICO}

Para a determinação das propriedades de um material em pó, é necessário confiná-lo em uma matriz flexível ou rígida, onde se possa obter medidas do comportamento do material quando carregado. Dois tipos de ensaios são comumente utilizados, os ensaios triaxiais e uniaxiais. Os ensaios triaxiais permitem a obtenção dos parâmetros da superfície de Drucker-Prager, $\gamma$ e $c$ apresentados na eq. (2.3) enquanto os ensaios uniaxiais permitem a obtenção dos parâmetros de evolução da superfície cap (encruamento).

Os ensaios triaxiais são geralmente mais complexos e limitados quanto à magnitude de pressões aplicadas quando comparados aos ensaios uniaxiais. Entretanto, Aydin et al. (1996) baseados em Nelson (1977) e Dimaggio et al. (1971), obtém os principais parâmetros para a modelagem da prensagem de alumina utilizando somente um ensaio de compressão uniaxial em um dispositivo cilindropistão (DCP), e utilizam esses parâmetros para calibrar o modelo de DruckerPrager/cap.

Para a obtenção das propriedades do pó cerâmico utilizado neste trabalho, utilizou-se essa mesma metodologia. O DCP utilizado consiste basicamente de uma tampa, um pistão e um cilindro onde o material é depositado e levado até uma máquina universal de ensaios, onde de um ensaio de compactação uniaxial (ensaio de adensamento), se obtém a curva de compactação do pó. O projeto do dispositivo é mostrado na Figura 4.9. 


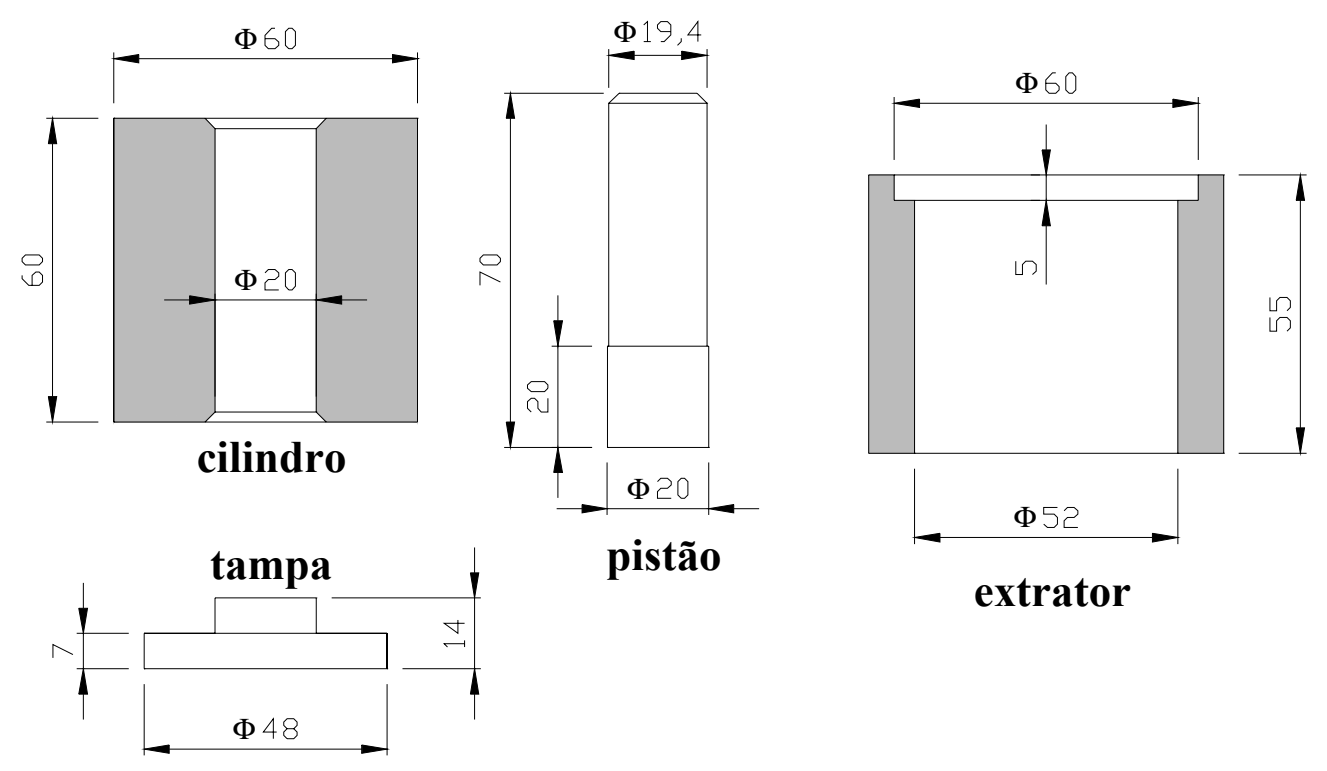

Figura 4.9 - Projeto do dispositivo cilindro-pistão (DCP).

O dispositivo foi confeccionado em aço ferramenta tipo VC131 que posteriormente recebeu um tratamento térmico de têmpera com duplo revenido. Após o tratamento a superfície interna do cilindro e a externa do pistão foram retificadas e montadas com ajuste folgado de aproximadamente $0,2 \mathrm{~mm}$.

O esquema de funcionamento do dispositivo e as fases do ensaio compressão uniaxial (montagem, compactação e extração) são esquematizados na Figura 4.10. Após a lubrificação da matriz com estearato de zinco em pó, o material é depositado no cilindro com o pistão, selado com a tampa e levado até a Máquina Universal de Ensaios, Instron 5500R (Figura 4.10a). Para a realização do ensaio aplicou-se um deslocamento gradativo a uma taxa de $5 \mathrm{~mm} / \mathrm{min}$ até atingir uma força responsável pela aplicação de uma tensão axial de $210 \mathrm{MPa}$ no "corpo-de-prova" (Figura 4.10b). Posteriormente o pistão foi descarregado gradativamente até atingir um valor nulo de carga. Após a compactação é necessária a retirada do material compactado (Figura 4.10c) e para isso utiliza-se a própria máquina de ensaios com auxílio de um anel de apoio (extrator). Na Figura 4.11 é mostrado o DCP utilizado neste trabalho com os corpos-de-prova obtidos no ensaio. 


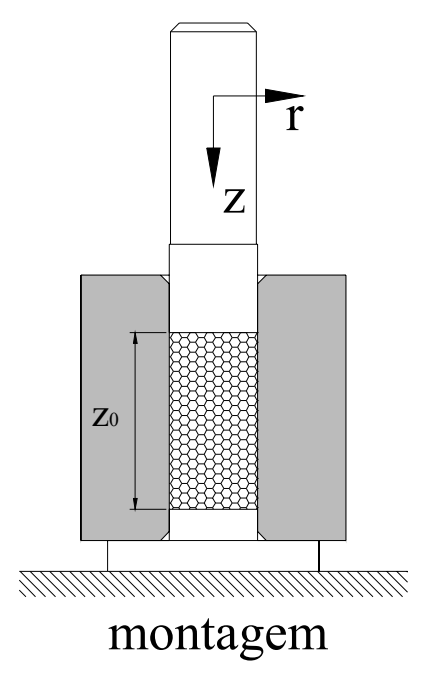

(a)

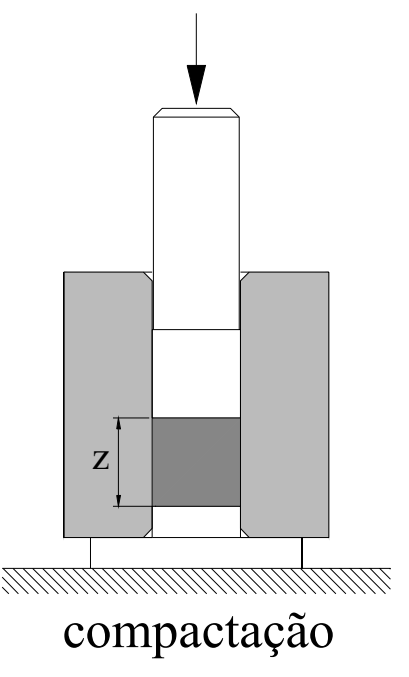

(b)

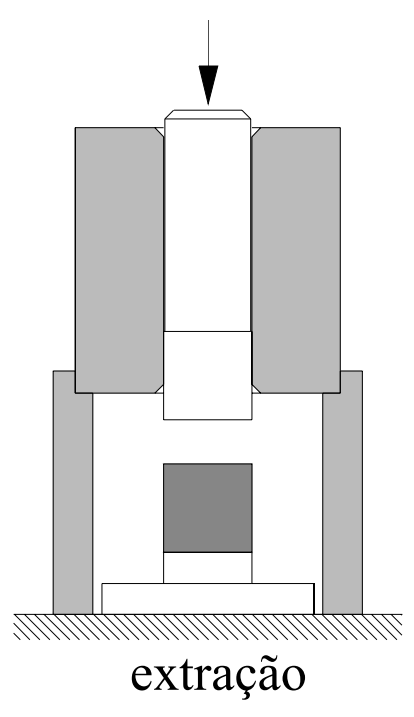

(c)

Figura 4.10 - Esquema de funcionamento do dispositivo cilindro-pistão (DCP) e as fases do ensaio de compressão uniaxial.

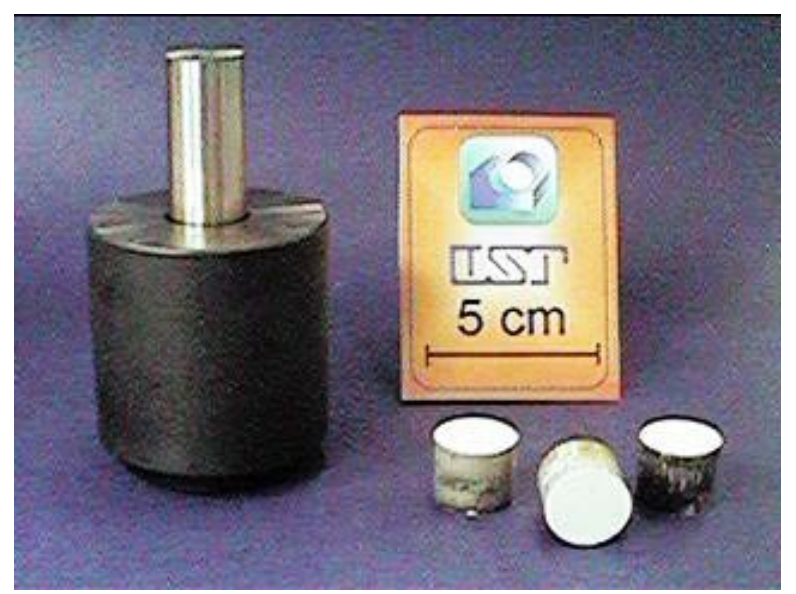

Figura 4.11 - Dispositivo cilindro-pistão (DCP) utilizado e "corpos-de-prova" obtidos nos ensaios.

Para o estudo do processo de compactação no interior do DCP e determinação das propriedades do material, considera-se um estado de tensões principais onde são assumidas as relações da eq.(4.1) e eq.(4.2) durante o carregamento (tensão de compressão considerada positiva).

$$
\begin{aligned}
& \sigma_{1}=\sigma_{z} \\
& \sigma_{2}=\sigma_{3}=k_{0} \sigma_{1}=\sigma_{r}
\end{aligned}
$$


onde $\sigma_{z}$ é a tensão axial tomada na direção da aplicação da carga no pistão, $\sigma_{r}$ é a tensão radial de reação nas paredes do cilindro e $k_{0}$ é o coeficiente de empuxo no repouso, dado pela relação entre a tensão axial aplicada no pistão e sua reação radial nas paredes do cilindro.

Sendo $p$ a tensão média definida em função do primeiro invariante das tensões, definido pela eq.(4.3), e o segundo invariante das tensões desviadoras definido pela eq.(4.4),

$$
\begin{aligned}
& p=\frac{I_{1}}{3}=\frac{\left(\sigma_{1}+\sigma_{2}+\sigma_{3}\right)}{3} \\
& J_{2}=\frac{1}{6}\left[\left(\sigma_{1}-\sigma_{2}\right)^{2}+\left(\sigma_{2}-\sigma_{3}\right)^{2}+\left(\sigma_{3}-\sigma_{1}\right)^{2}\right]
\end{aligned}
$$

os estados de tensões desenvolvidos durante o ensaio de compactação uniaxial serão dados por:

$$
\begin{aligned}
& p=\frac{\left(\sigma_{z}+2 \sigma_{r}\right)}{3} \\
& \sqrt{J_{2}}=\frac{\left|\sigma_{z}-\sigma_{r}\right|}{\sqrt{3}}
\end{aligned}
$$

A curva de compactação do material, obtida do ensaio é mostrada no esquema da Figura 4.12 e o correspondente caminho das tensões no plano meridional é mostrado na Figura 4.13. 


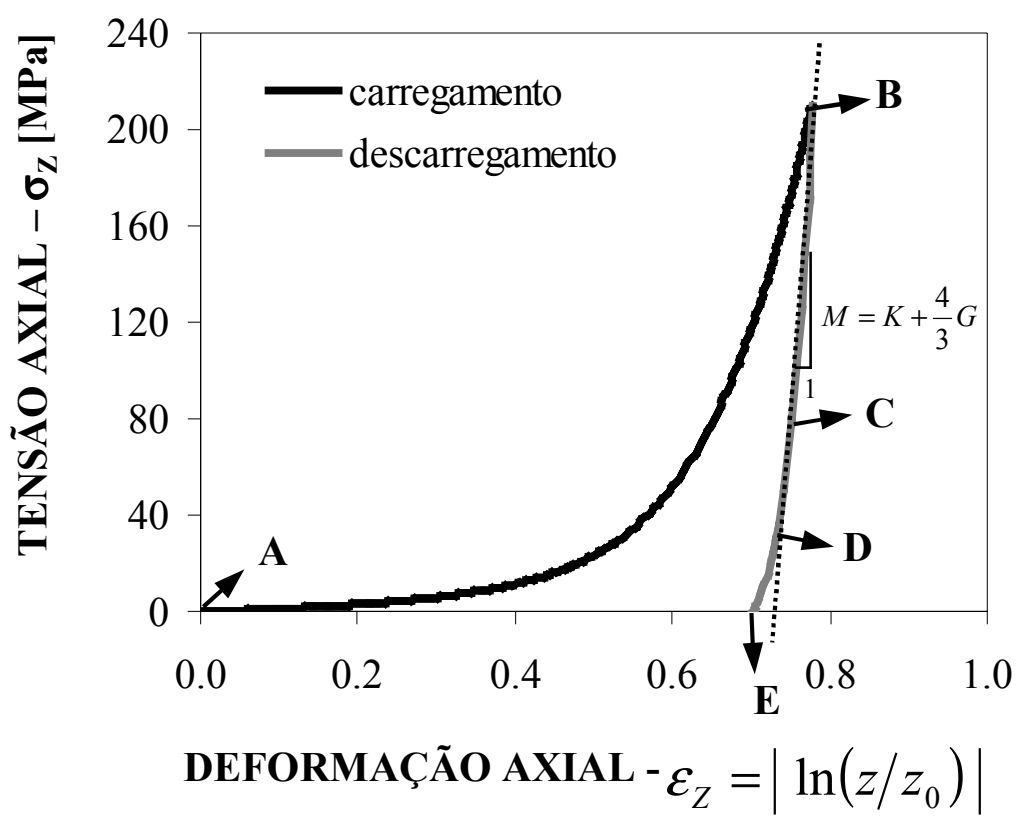

Figura 4.12 - Curva tensão-deformação no ensaio de compressão uniaxial do pó cerâmico.

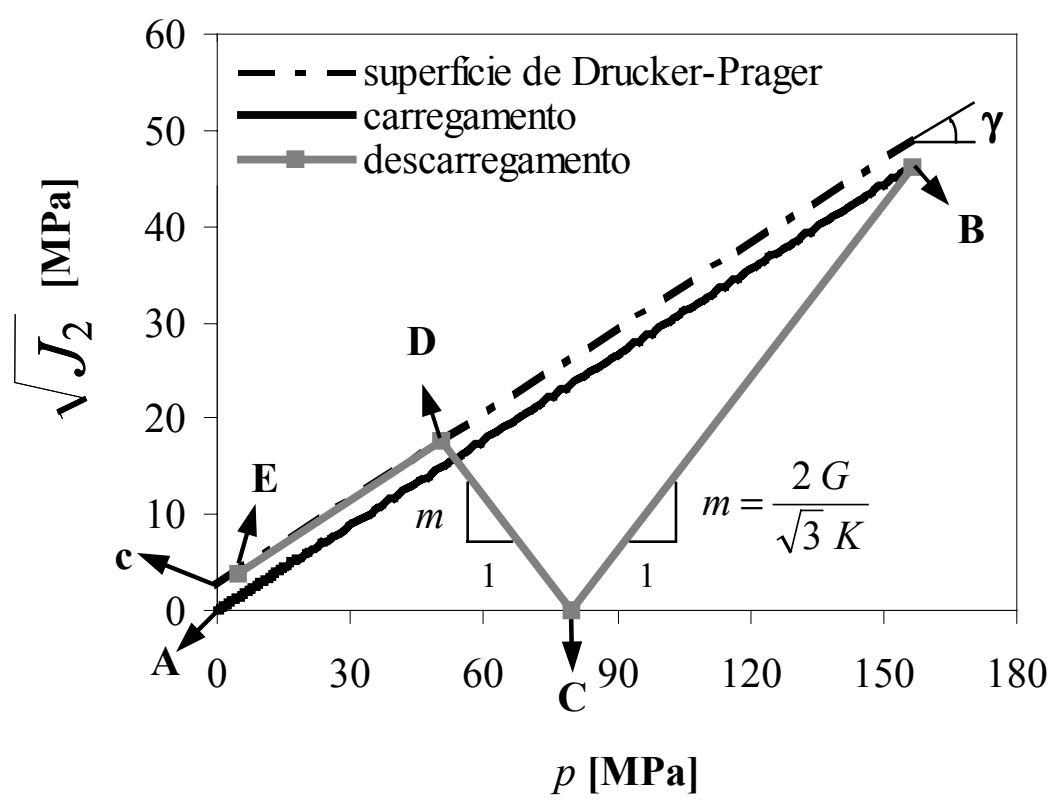

Figura 4.13 - Caminho das tensões no plano meridional $\sqrt{J_{2}} \times p$ relacionado à curva tensãodeformação no ensaio de compressão uniaxial do pó cerâmico.

A primeira etapa para a obtenção dos parâmetros é discriminar a curva de compactação do material em partes pelos pontos A, B, C, D e E. O trecho AB é a fase de carregamento do material, onde se dá a sua compactação. O trecho BCDE é a 
fase de descarregamento, que é considerada linear no trecho BD. O ponto C representa um estado hidrostático de tensões onde a tensão axial se iguala ao valor da sua reação radial.

Pela inclinação obtida pela aproximação da região BD por uma reta (Figura 4.12), obtém-se o valor de $M$ (“constrained modulus"), que é dado pela tangente do ângulo formado por essa reta (Figura 4.12) e o eixo das deformações. Da eq.(4.7) que relaciona $M, K$ (módulo volumétrico) e $G$ (módulo de cisalhamento) e da eq.(2.14), descrita anteriormente, que relaciona o Coeficiente de Poisson ( $v$ ) com $K$ e $G$, obtém-se os valores de $G$ e $K$, desde que o valor do Coeficiente de Poisson seja conhecido (extraído da literatura neste trabalho). O módulo de Young $(E)$ do material pode ser obtido pela eq.(2.13) descrita anteriormente que o relaciona com $K$ e $G$.

$$
\mathrm{M}=\mathrm{K}+\frac{4}{3} \mathrm{G}
$$

O valor do estado de tensão no ponto $C$ é obtido pela eq.(4.8) que relaciona o coeficiente $m$, que é igual à tangente do ângulo formado entre a curva $\mathrm{BC}$ e o eixo das tensões médias $p$ no plano meridional da Figura 4.13 .

$$
\mathrm{m}=\frac{2 \mathrm{G}}{\sqrt{3} \mathrm{~K}}=\frac{\left(\sqrt{\mathrm{J}_{2}}\right)_{\mathrm{B}}}{(\mathrm{p})_{\mathrm{B}}-(\mathrm{p})_{\mathrm{C}}}
$$

Para a determinação do ponto $\mathrm{D}$, considera-se uma relação linear entre as tensões radiais e axiais no descarregamento, que é estabelecida pelo estado de tensões no ponto $\mathrm{C}$ e mostrada na Figura 4.14. Assim, a determinação do ponto D se faz graficamente adotando a tensão axial do ponto D correspondente ao ponto em que se considera o final da "linearidade" da curva de descarregamento BE (Figura 4.12), que ocorre pelo início de uma segunda plastificação, definindo a superfície de plastificação de Drucker-Prager (Figura 4.13). Conhecida essa superfície, obtém-se o valor do parâmetro $c$, que é dada pelo ponto onde a superfície de plastificação cruza o eixo $\sqrt{\mathrm{J}_{2}}$. O ponto E é obtido pelo gráfico do plano meridional e por ser conhecido que a tensão axial é nula nesse ponto. 


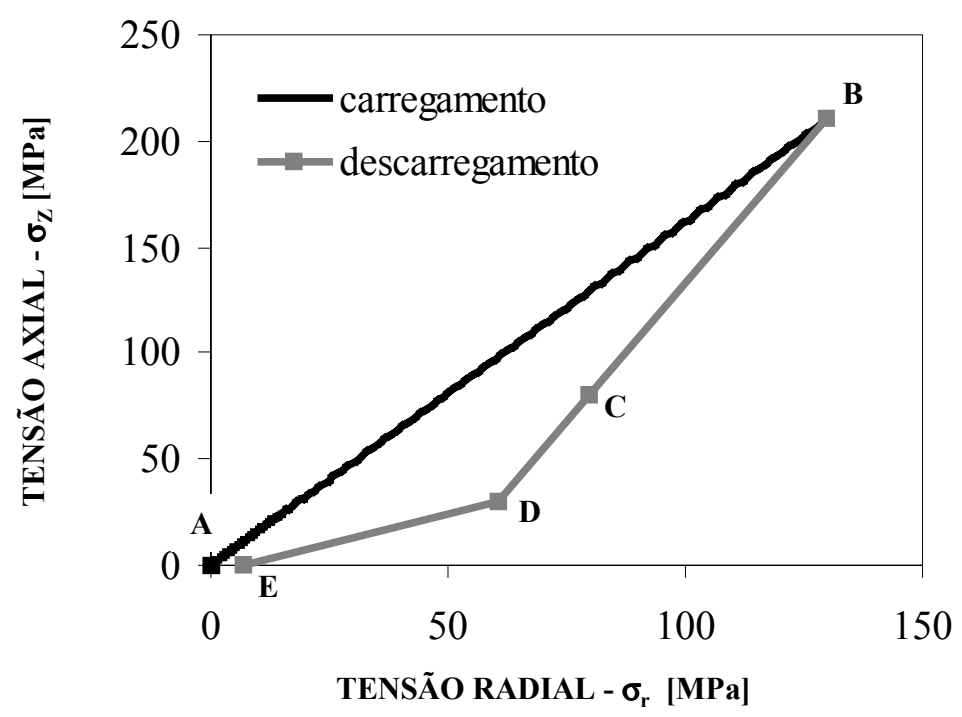

Figura 4.14 - Relação das tensões axiais e radiais no ensaio de compressão uniaxial do pó cerâmico.

Pelo ângulo $\gamma$ obtido da Figura 4.13 é possível obter o ângulo $\beta$ pela relação da eq. (4.9) e o parâmetro $d$ é obtido pela relação da eq. (4.10).

$$
\begin{aligned}
& \operatorname{tg}(\beta)=\sqrt{3} \operatorname{tg}(\gamma) \\
& d=\sqrt{3} c
\end{aligned}
$$

Os parâmetros $\alpha$ e $R$ (parâmetros de forma da curva cap) são aproximados graficamente, de forma a obter uma transição suave entre a superfície de DruckerPrager, a superfície de Transição e a superfície cap. Partindo de parâmetros extraídos da literatura (AYDIN et al., 1996), como o Coeficiente de Poisson $v=0,278$ e $\mathrm{K}_{0}=0,62$, obtém-se os parâmetros necessários para a análise em elementos finitos do pó cerâmico, utilizando o modelo de Drucker-Prager/cap implementado no programa ABAQUS $^{\circledR}$, dados na Tabela 4.1. 
Tabela 4.1 - Parâmetros do pó cerâmico utilizado neste trabalho

\begin{tabular}{|c|c|c|c|c|c|c|}
\hline$v$ & $\alpha$ & $\mathrm{K}_{0}$ & $\mathrm{R}$ & $\beta$ & $E[\mathrm{MPa}]$ & $d[\mathrm{MPa}]$ \\
\hline 0,278 & 0,05 & 0,62 & 0,5 & $27,2^{\circ}$ & 2850 & 4,85 \\
\hline
\end{tabular}

Conforme mostrado na Figura 4.15, adota-se que as curvas de descarregamento $\mathrm{BN}_{\mathrm{n}}$ a partir dos pontos $\mathrm{B}_{1}, \mathrm{~B}_{2}, \ldots$, Bn possuem mesma inclinação com a curva de descarregamento BN (obtida pelo ajuste da curva BD por uma reta). As deformações plásticas volumétricas para esses pontos, $\left(\varepsilon_{v o l}^{p l}\right)_{B_{n}}$, são respectivamente iguais às deformações plásticas na direção axial, $\left(\varepsilon_{z}^{p l}\right)_{B_{n}}$, para cada ponto, considerando-se que o diâmetro do cilindro não se altera durante a compactação. Assim é possível obter valores das deformações plásticas volumétricas para cada valor de tensão média $p$, associado aos pontos $\mathrm{B}_{\mathrm{n}}$ (eq.4.5). Estes pares de pontos $\left(p, \varepsilon_{v o l}^{p l}\right)_{B_{n}}$ constituem uma relação usada para se estabelecer os parâmetros de encruamento do material (evolução da curva cap) dada pela eq.(4.11).

$$
p=0,060 \times 10^{4,786 \varepsilon_{v o l}^{p l}}
$$

Assim a curva de encruamento do modelo de Drucker-Prager/cap é obtida pela eq.(4.12) que relaciona a eq.(4.11) com a eq.(2.9) adotando-se que a tensão média $p$ é igual ao parâmetro de evolução $p_{a}$.

$$
p_{b}=2,425+0,075 \times 10^{4,786 \varepsilon_{v o l}^{p l}}
$$

onde $p_{b}$ é a tensão hidrostática. 


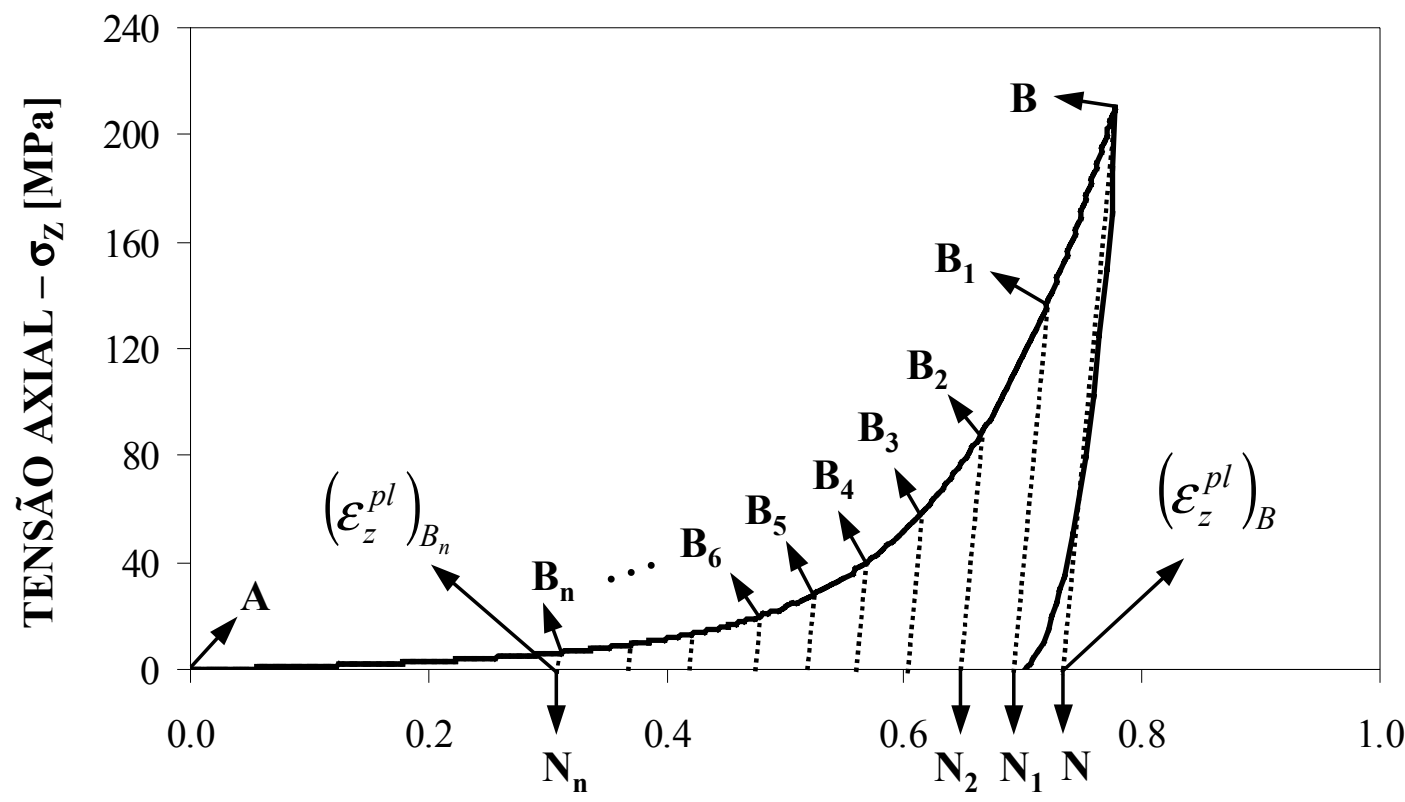

DEFORMAÇÃO AXIAL - $\varepsilon_{Z}=\left|\ln \left(z / z_{0}\right)\right|$

Figura 4.15 - Esquema de obtenção da evolução do encruamento pela curva de compactação uniaxial do pó cerâmico.

\subsubsection{DETERMINAÇÃO DAS PROPRIEDADES E MODELAGEM DO MATERIAL ELASTOMÉRICO}

O programa comercial ABAQUS ${ }^{\circledR}$, baseado no Método dos Elementos Finitos, possui modelos hiperelásticos adequados para representar o comportamento de materiais elastoméricos. Estes modelos possuem vários parâmetros que determinam a função de densidade de energia de deformação. Sendo assim, o programa possibilita duas maneiras para o cálculo da função de densidade de energia: a primeira consiste em fornecer diretamente ao programa os parâmetros quando esses são conhecidos, e a segunda consiste em fornecer os dados de ensaios mecânicos e o programa calcula os parâmetros desejados. Geralmente os valores desses parâmetros não são fornecidos pelo fabricante do material elastomérico, por não serem convencionalmente conhecidos. Dessa forma, faz-se necessária uma série de ensaios mecânicos de tração e/ou compressão, em estados uniaxial, planar, biaxial e/ou volumétrico (Figura 4.16). 
A maioria dos modelos não necessita de todos os ensaios para se calcular os parâmetros, porém a capacidade do modelo em representar o comportamento do material reduz-se à medida que o número de ensaios é reduzido.

tração

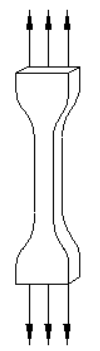

$\lambda_{1}=\lambda_{\mathrm{U}}=1+\epsilon_{\mathrm{U}}, \lambda_{2}=\lambda_{3}=1 / \sqrt{\lambda_{\mathrm{u}}}$

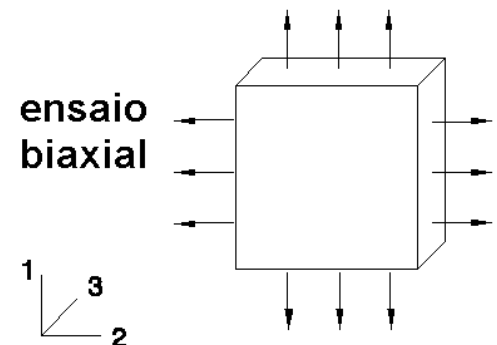

$\lambda_{1}=\lambda_{2}=\lambda_{B}=1+\epsilon_{B}, \lambda_{3}=1 / \lambda_{B}^{2}$
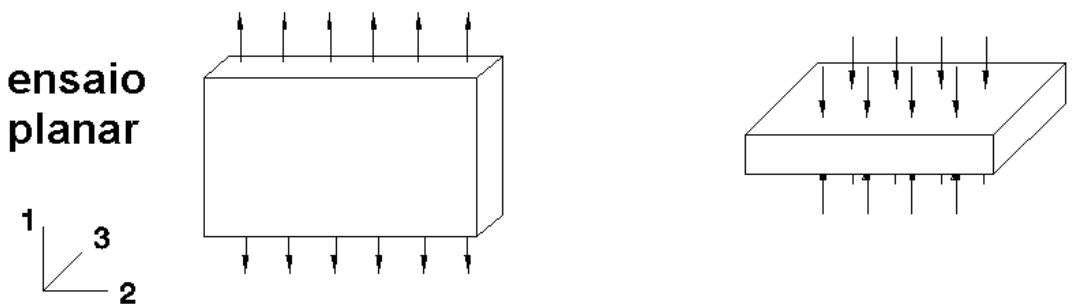

$$
\lambda_{1}=\lambda_{\mathrm{s}}=1+\epsilon_{\mathrm{s}}, \lambda_{2}=1, \lambda_{3}=1 / \lambda_{\mathrm{s}}
$$

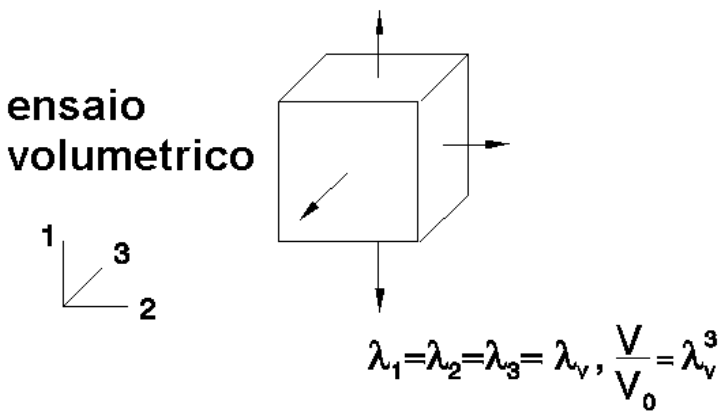

Figura 4.16 - Ensaios mecânicos para a calibração de modelos hiperelásticos (adaptado de HIBBIT et al., 2000) 
Apesar do programa possibilitar a entrada de dados de todos os ensaios representados na Figura 4.16, alguns destes ensaios não são viáveis na prática. Os ensaios mais comumente utilizados são os de tração e compressão uniaxiais, seguidos pelos ensaios de tração planar, compressão volumétrica e tração biaxial. Este ensaios são representados pelas fotos da Figura 4.17, Figura 4.18, Figura 4.19, Figura 4.20 e Figura 4.21.

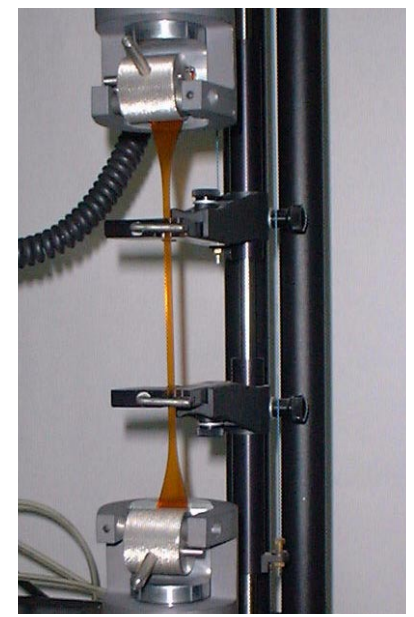

Figura 4.17 - Ensaio de tração uniaxial (desenvolvido nesse trabalho)

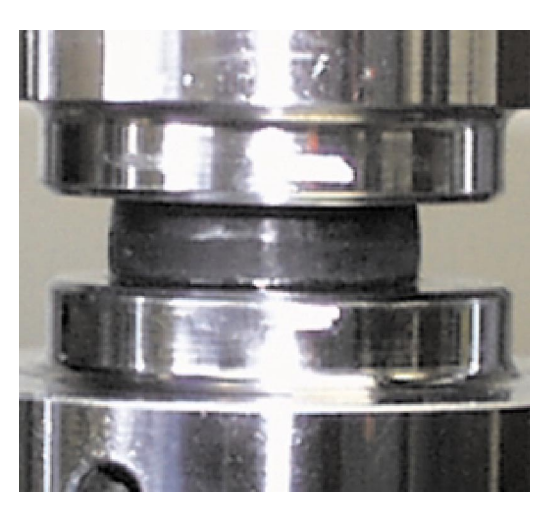

Figura 4.18 - Ensaio de compressão uniaxial (Axel Products, 2000)

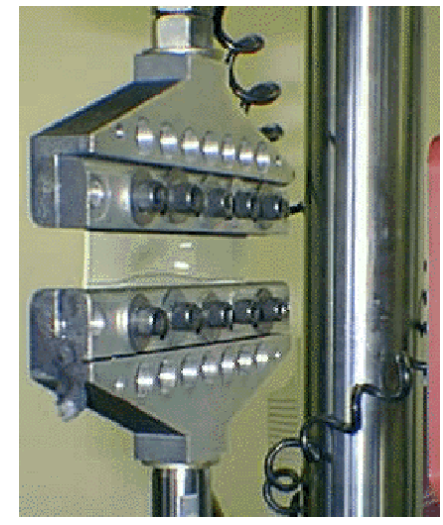

Figura 4.19 - Ensaio de tração planar (Axel Products, 2000)

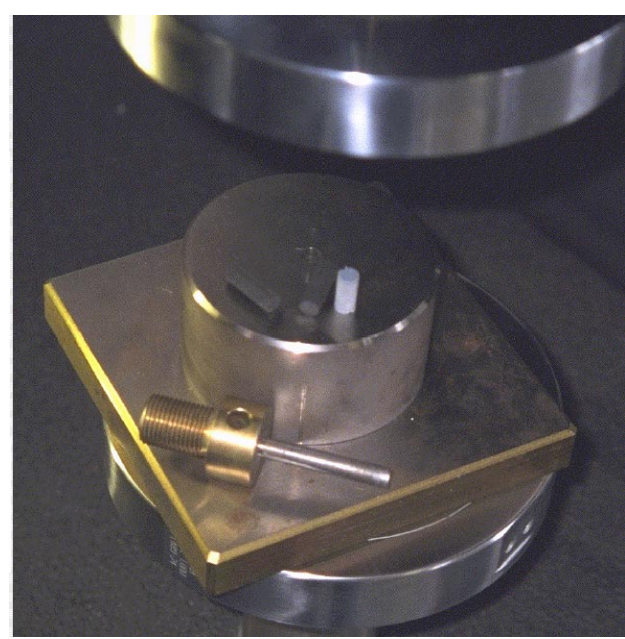

Figura 4.20 - Ensaio de compressão volumétrica adaptado (Axel Products, 2000)

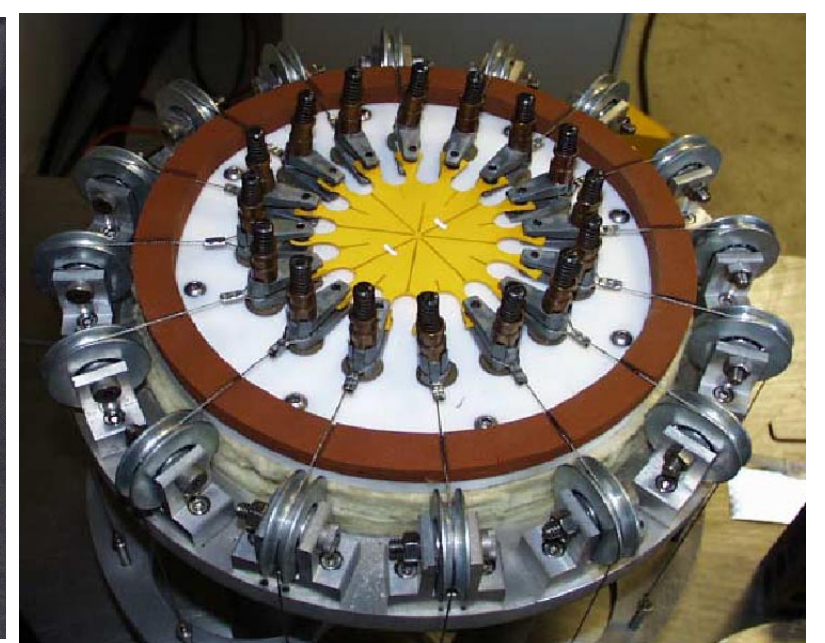

Figura 4.21 - Ensaio de tração Equibiaxial (Axel Products, 2000)

O modelo utilizado nesse trabalho, por sua relativa simplicidade, é o modelo Polinomial de ordem 2, mais comumente conhecido como modelo de Mooney-Rivlin 
descrito na eq.(2.22). Vale ressaltar que esse modelo se comporta melhor para deformações menores que 100\% (HIBBIT et al, 2000).

Para a realização dos ensaios mecânicos utilizou-se a Máquina Universal de Ensaios INSTRON - 5569 do grupo de Polímeros do Departamento de Engenharia de Materiais da Universidade Federal de São Carlos, mostrada na Figura 4.22.

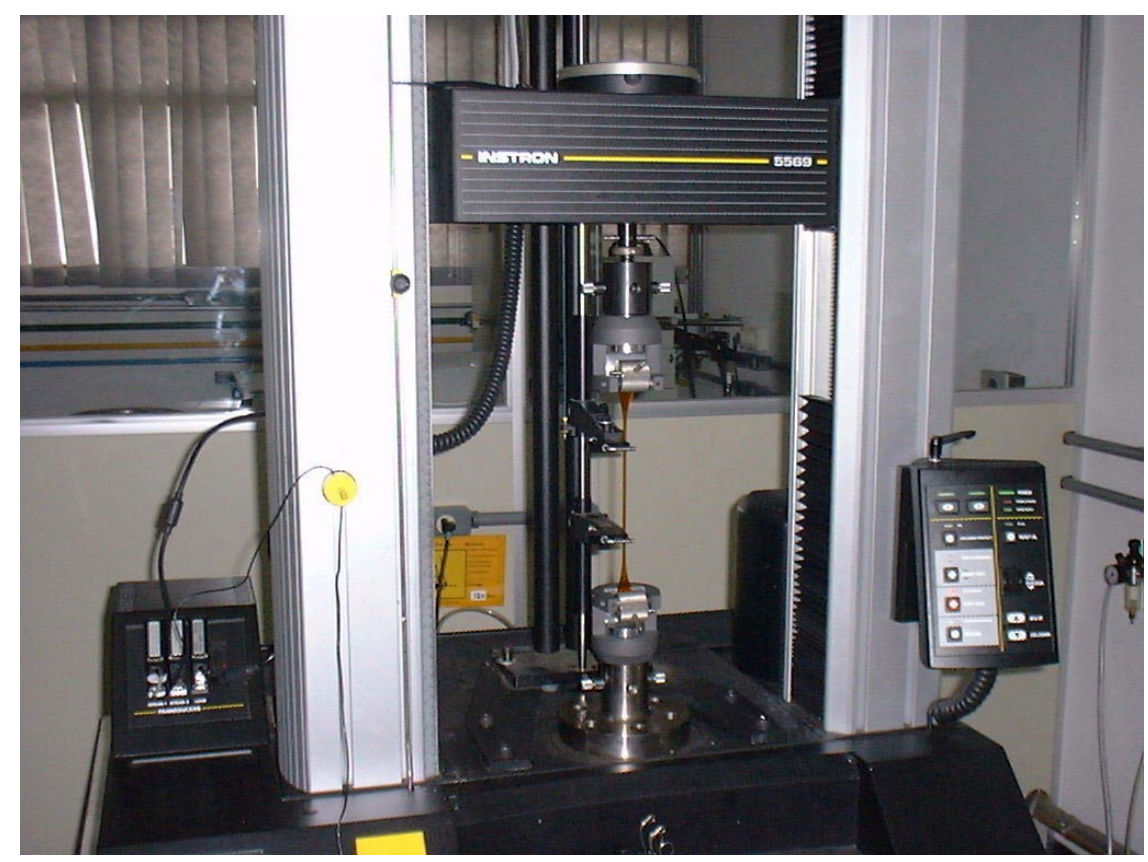

Figura 4.22 - Máquina Universal de Ensaios - INSTRON - 5569 (DEMA, UFSCAR).

Foram realizados os ensaios de compressão uniaxial, tração uniaxial e compressão volumétrica. Apesar do modelo de Mooney-Rivlin apresentar bom desempenho utilizando parâmetros desses três tipos de ensaios, uma maior precisão poderia ser obtida se outros ensaios fossem realizados. Outra importante consideração, pela natureza do processo de prensagem isostática, é que a matriz elastomérica se encontra confinada entre o pó cerâmico, o macho e a pressão exercida pelo fluido. Dessa forma, para se modelar com precisão a "quase incompressibilidade" do material elastomérico foi necessário o ensaio de compressão volumétrica.

O ensaio de compressão uniaxial foi realizado seguindo as orientações da norma ASTM - D575-91, "Standard Test Methods for Rubber Properties in Compression”. As principais especificações da norma são: 
- diâmetro do corpo-de-prova $=28,6 \pm 0,1 \mathrm{~mm}$;

- $\quad$ espessura do corpo-de-prova $=12,5 \pm 0,5 \mathrm{~mm}$;

- velocidade de ensaio $=12 \pm 3 \mathrm{~mm} / \mathrm{min}$.

Na Figura 4.23 é mostrado o corpo-de-prova e suas dimensões. Os corpos-deprova foram confeccionados por vazamento do polímero num molde de nylon, mostrado na Figura 4.24, e posteriormente cortados num torno universal, utilizando o dispositivo mostrado na Figura 4.25. Vale destacar que este procedimento garantiu uma tolerância dimensional adequada à norma ASTM - D575-91.

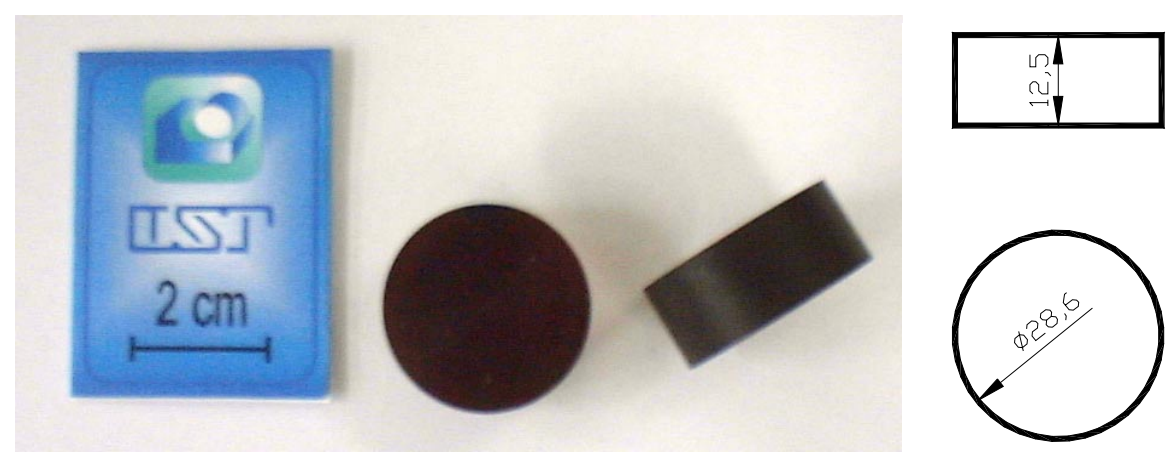

Figura 4.23 - Corpos-de-prova para compressão uniaxial

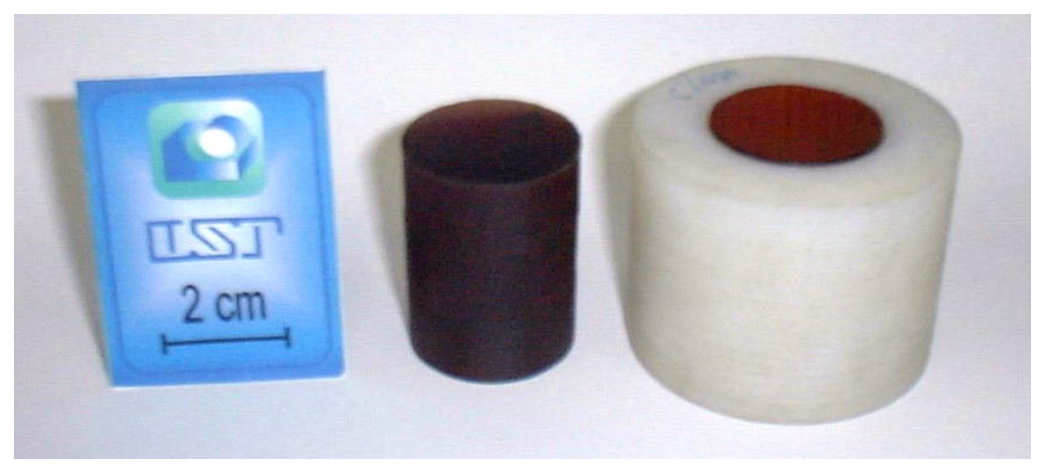

Figura 4.24 - Molde em nylon para vazamento do elastômero. 


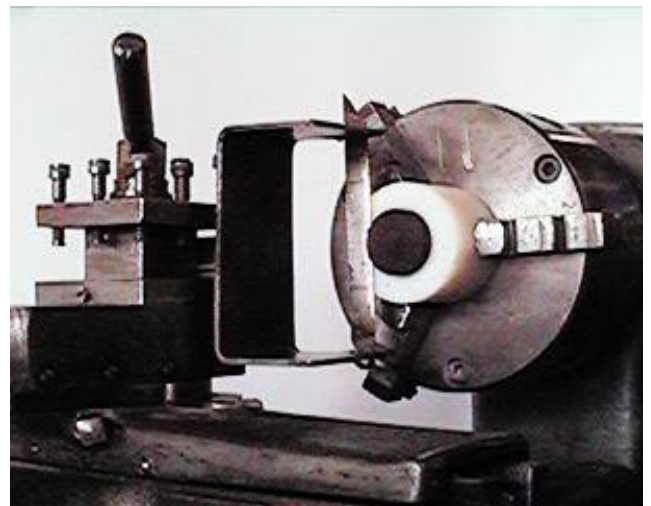

(I)

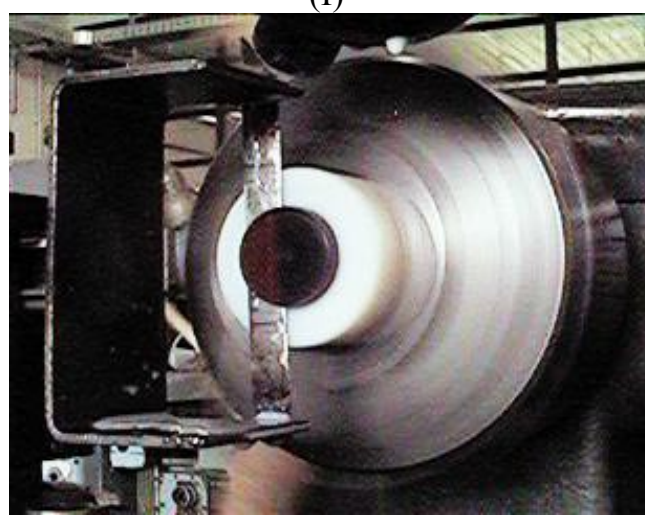

(III)

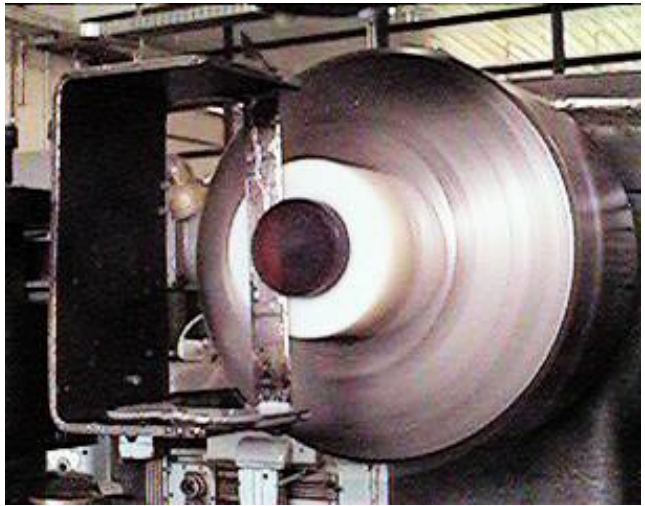

(II)

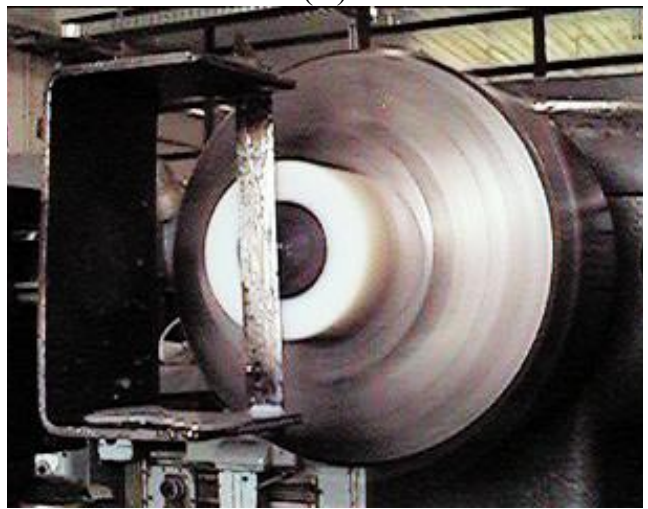

(IV)

Figura 4.25 - Dispositivo para corte dos corpos-de-prova para ensaio de compressão uniaxial e seqüência de corte

Os ensaios foram realizados em três corpos-de-prova, sendo que para cada um, foram feitos três ensaios a fim de permitir a relaxação do polímero conforme recomendação da norma. Os corpos-de-prova foram lubrificados com vaselina líquida que permitiu a deformação radial do corpo-de-prova conforme mostrado na Figura 4.26.

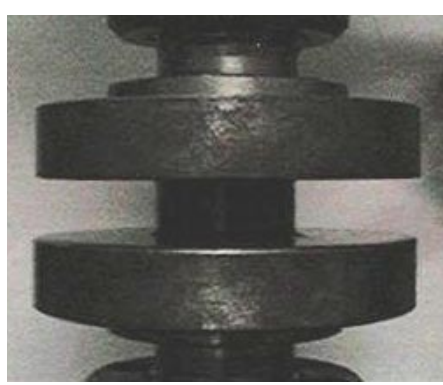

(I)

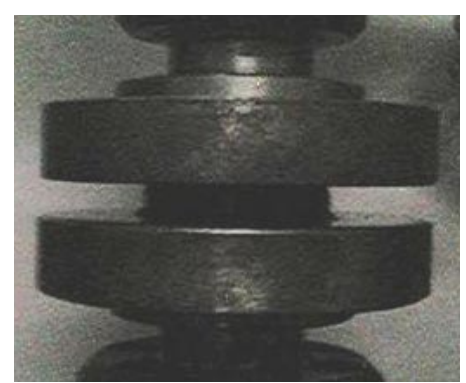

(II)

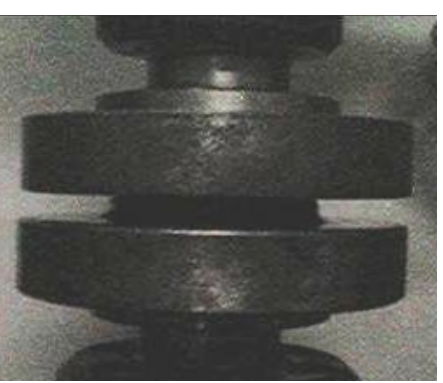

(III)

Figura 4.26 - Ensaio de compressão uniaxial 
$\mathrm{Na}$ terceira repetição do ensaio foi obtida a curva de carga-deslocamento dada pela Máquina Universal de Ensaios. A partir desta curva pôde-se obter a curva tensão-deformação, mostrada na Figura 4.27, que será utilizada no programa ABAQUS $^{\circledR}$ para a determinação dos parâmetros do modelo. As tensões e deformações são as tensões e deformações de engenharia, ou seja, calculadas a partir da área e espessura iniciais do corpo-de-prova.

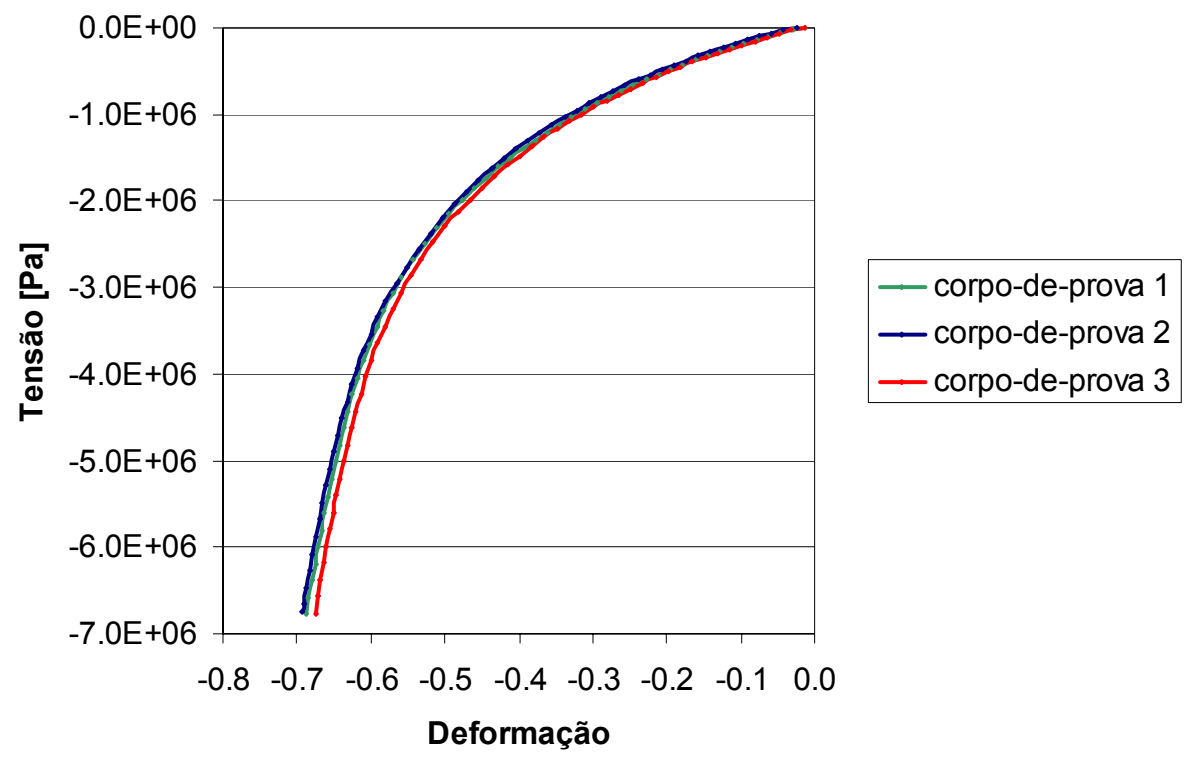

Figura 4.27 - Curvas tensão-deformação do ensaio de compressão uniaxial para três corpos-de-prova.

O ensaio de tração uniaxial foi realizado seguindo as orientações da norma ASTM - D412-97, "Standard Test Methods for Vulcanized Rubber and Thermoplastic Rubbers and Thermoplastic Elastomers - Tension”. As principais especificações da norma são:

- $\quad$ espessura do corpo-de-prova $=1,3 \sim 3,3 \mathrm{~mm}$;

- geometria tipo C (dimensões na Figura 4.28);

- velocidade de ensaio $=500 \mathrm{~mm} / \mathrm{min}$.

Na Figura 4.28 são mostrados os corpos-de-prova e suas dimensões. Esses foram confeccionados por vazamento do elastômero numa caixa de vidro com superfície lisa, mostrada na Figura 4.29, e posteriormente cortados numa prensa, 
utilizando uma matriz conforme mostrado na Figura 4.30. Este procedimento garantiu uma tolerância dimensional adequada à norma ASTM - D412-97.
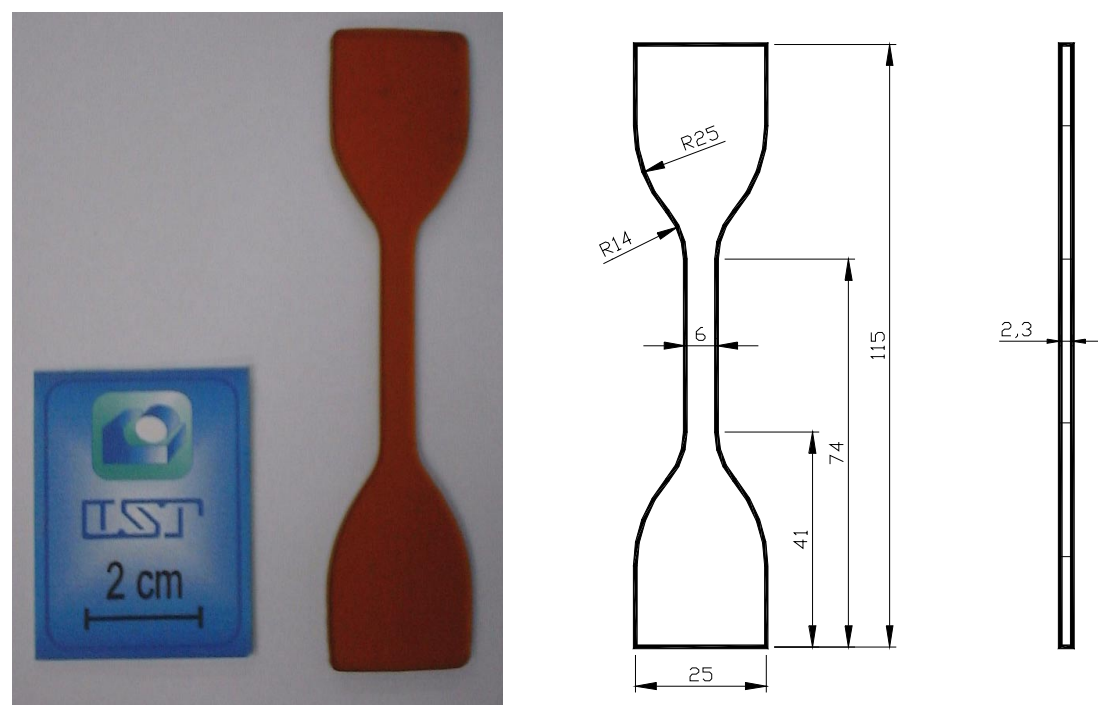

Figura 4.28 - Corpo-de-prova para tração uniaxial (unidades em mm)

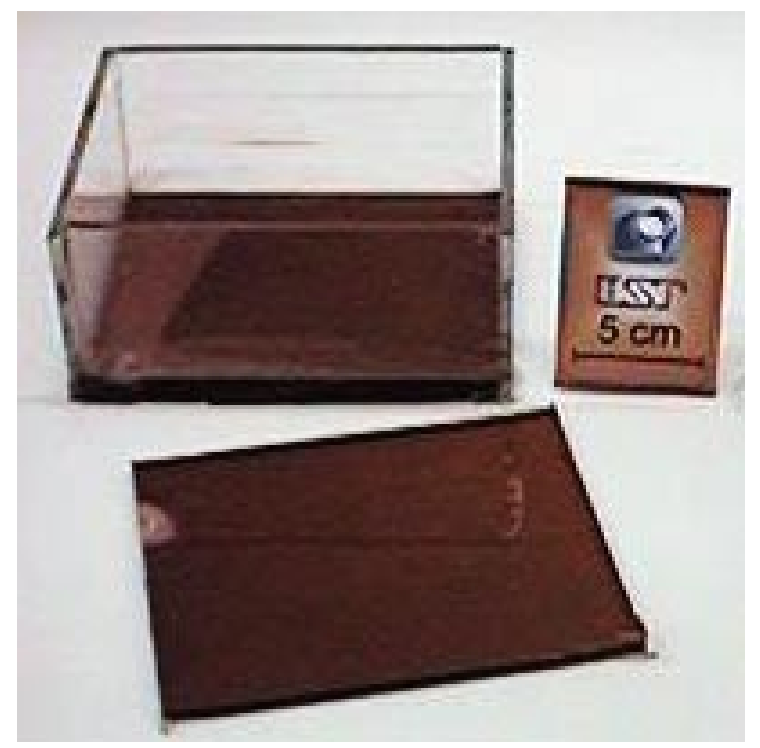

Figura 4.29 - Caixa de vidro para vazamento do polímero 

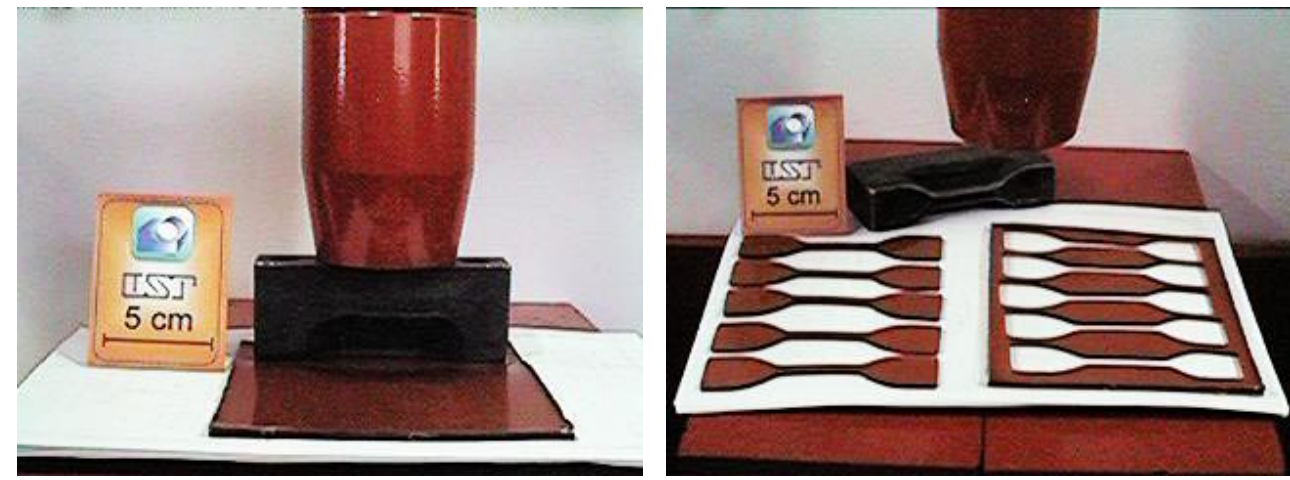

Figura 4.30 - Matriz para corte dos corpos-de-prova para ensaio de tração uniaxial e seqüência de corte.

Os ensaios foram realizados com três corpos-de-prova sendo que para cada um foram feitos três ensaios a fim de permitir a relaxação do polímero. Durante os testes de tração, medidores de deslocamento foram utilizados para captar a deformação (deslocamento) apenas da parte útil do corpo-de-prova conforme mostrado na Figura 4.31.

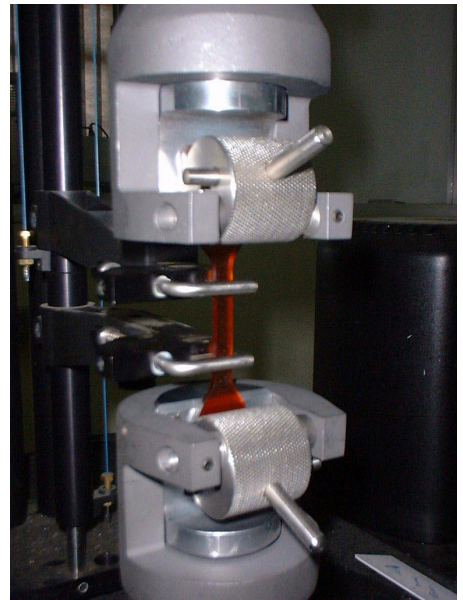

(I)

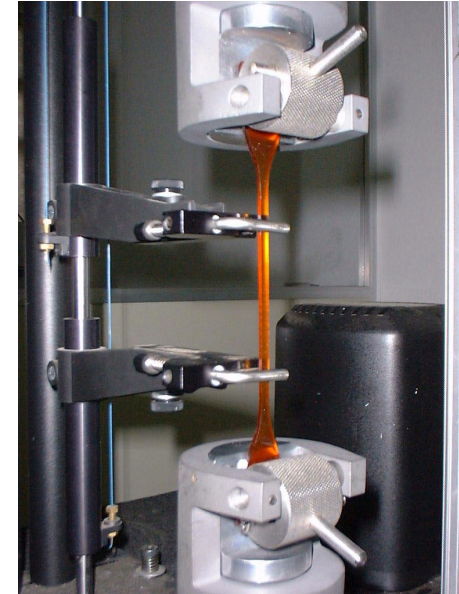

(II)

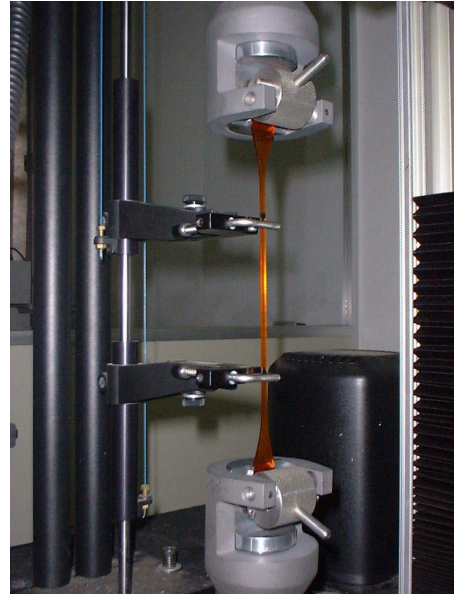

(III)

Figura 4.31 - Ensaio de tração uniaxial

Na terceira repetição do ensaio foi obtida a curva de carga-deslocamento dada pela Máquina Universal de Ensaios. Dessa curva pôde-se obter a curva tensãodeformação, mostrada na Figura 4.32, que foi utilizada no programa ABAQUS ${ }^{\circledR}$ para determinação dos parâmetros do modelo. As tensões e deformações, novamente, são as tensões e deformações de engenharia. 


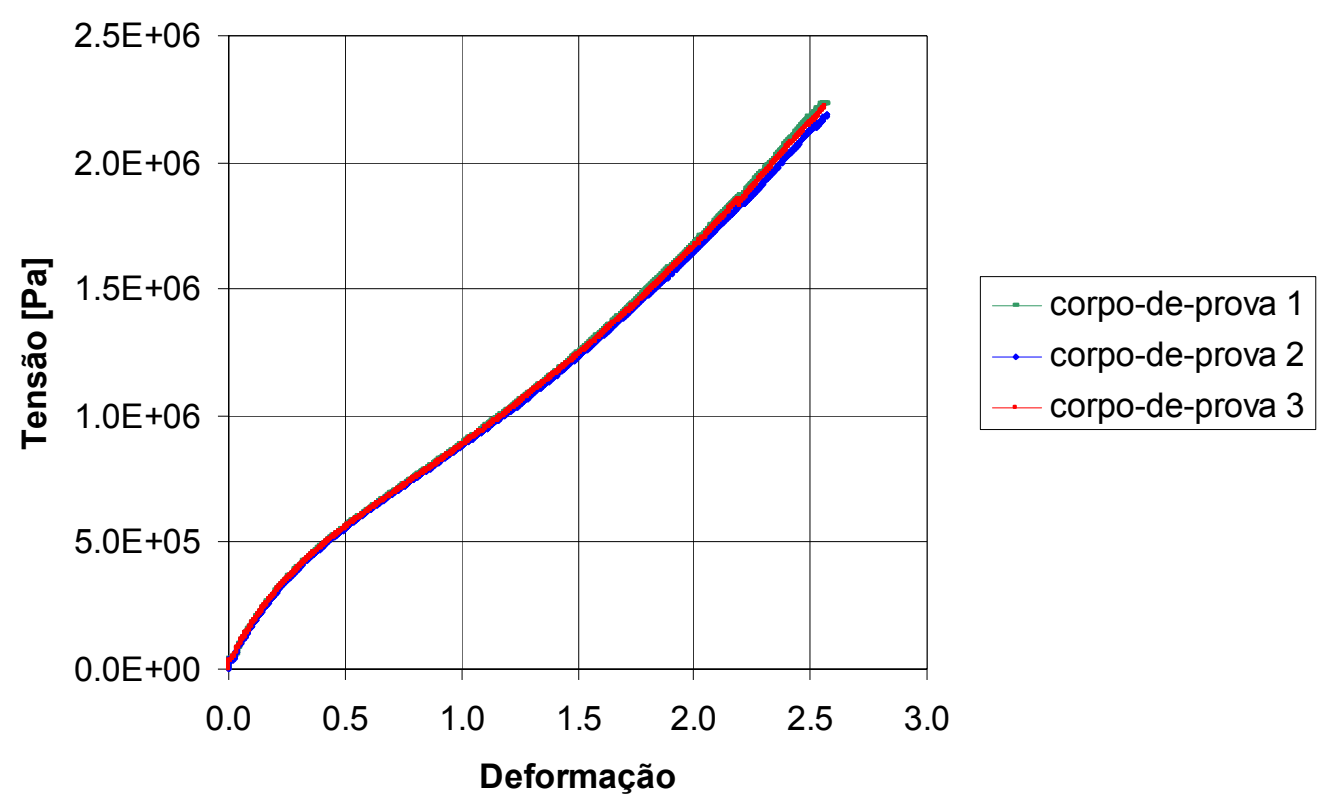

Figura 4.32 - Curvas tensão-deformação do ensaio de tração uniaxial para três corpos-de-prova.

$\mathrm{Na}$ realização do ensaio de compressão volumétrica não foi utilizada nenhuma norma específica, mas sim as recomendações do manual do programa ABAQUS $^{\circledR}$. Utilizou-se o Dispositivo Cilindro-Pistão da Figura 4.9 para a obtenção do corpo-de-prova, por vazamento do polímero no cilindro, e realização do ensaio conforme esquematizado na Figura 4.33.

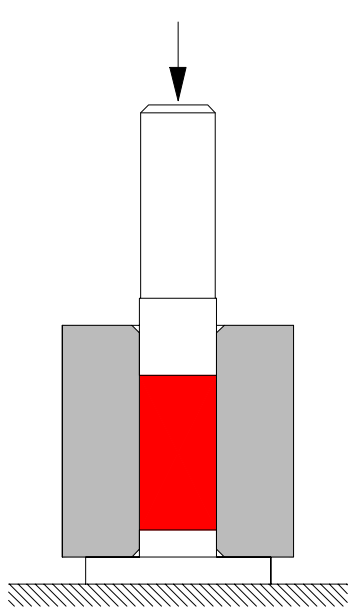

Figura 4.33 - Ensaio de compressão volumétrica confinado no DCP.

Como resultado desse ensaio foi obtida a curva de carga-deslocamento dada pela Máquina Universal de Ensaios. Dessa curva pôde-se obter a curva tensão- 
contração volumétrica, mostrada na Figura 4.34, que foi utilizada no programa ABAQUS $^{\circledR}$ para determinação dos parâmetros de compressibilidade para o modelo. As tensões são obtidas pela relação entre a carga no pistão e a área da seção circular do corpo-de-prova e a contração volumétrica é obtida pela relação da altura atual pela altura inicial do corpo-de-prova.

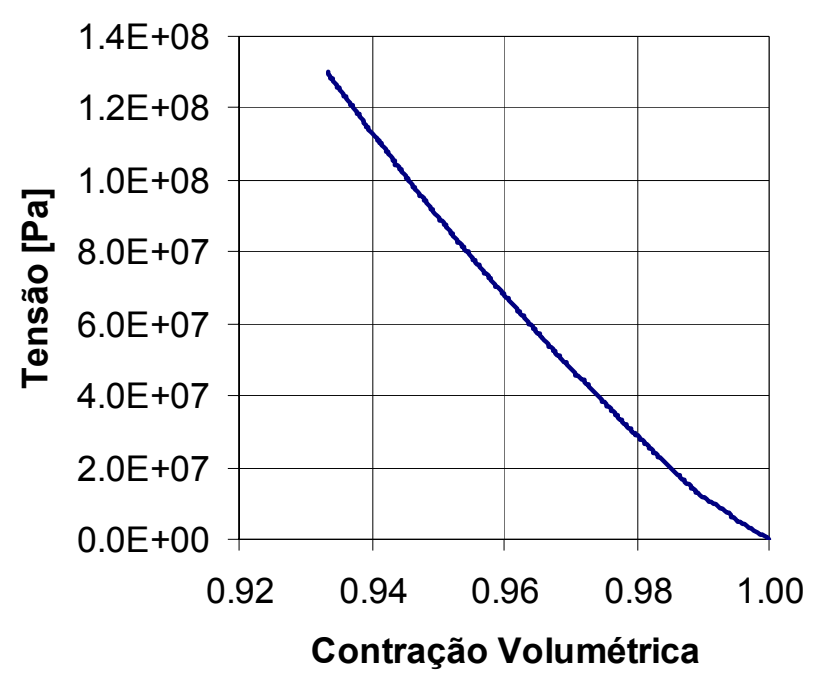

Figura 4.34 - Curva tensão-contração volumétrica do ensaio de compressão volumétrica confinado.

\subsubsection{FABRICAÇÃO DO MOLDE}

\subsubsection{PROTOTIPAGEM RÁPIDA}

Partindo-se da geometria adequada do molde obtida nas simulações do processo, desenvolveu-se um protótipo virtual pela modelagem sólida num sistema $C A D$ (Solid Edge ${ }^{\circledR}$ ), mostrado na Figura 4.35a. O protótipo físico é gerado após transferência do modelo $C A D$ para o sistema de Prototipagem Rápida, e é mostrado na Figura 4.35b. Esta transferência se dá com a conversão dos dados geométricos do modelo sólido para um formato de arquivo de comunicação padronizado, STL (STereoLithography) (SILVESTRE FILHO et al., 2000).

A técnica de Prototipagem Rápida utilizada (FDM) produz protótipos com geometria complexa em intervalos de tempo relativamente curtos se comparados com os processos convencionais. A FDM cria protótipos físicos a partir de um material termoplástico aquecido, extrudado através de um bico posicionado sobre 
uma mesa controlada por computador. O bico (cabeçote) é movimentado depositando na mesa o material até que uma fina camada (slice) seja formada. A próxima camada é construída em cima desta, e assim sucessivamente, até que o objeto esteja completamente formado. O sistema utiliza uma variedade de materiais, sendo o mais comum o plástico ABS (HUBINGER et al., 1999). O equipamento de Prototipagem Rápida utilizado foi o modelo FDM 8000 da Stratasys ${ }^{\circledR}$ com capacidade volumétrica de 457 x 457 x $609 \mathrm{~mm}$.

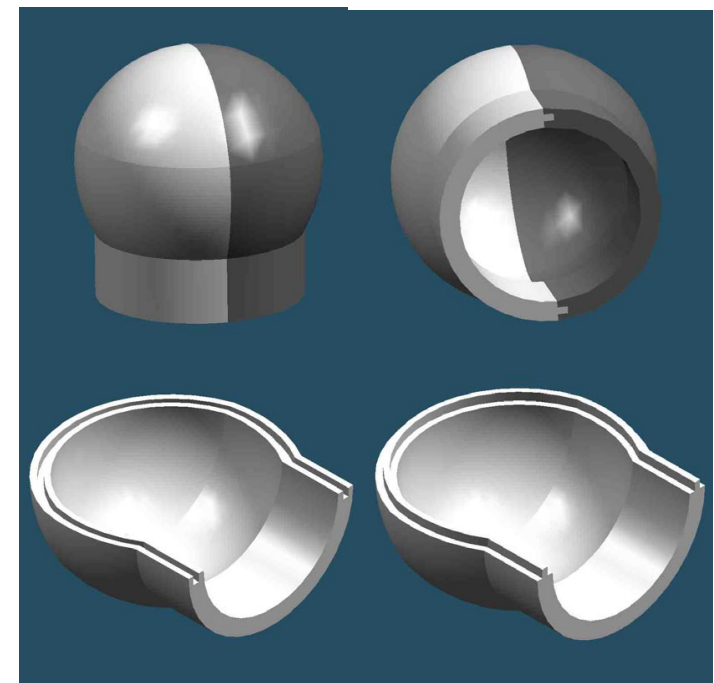

(a)

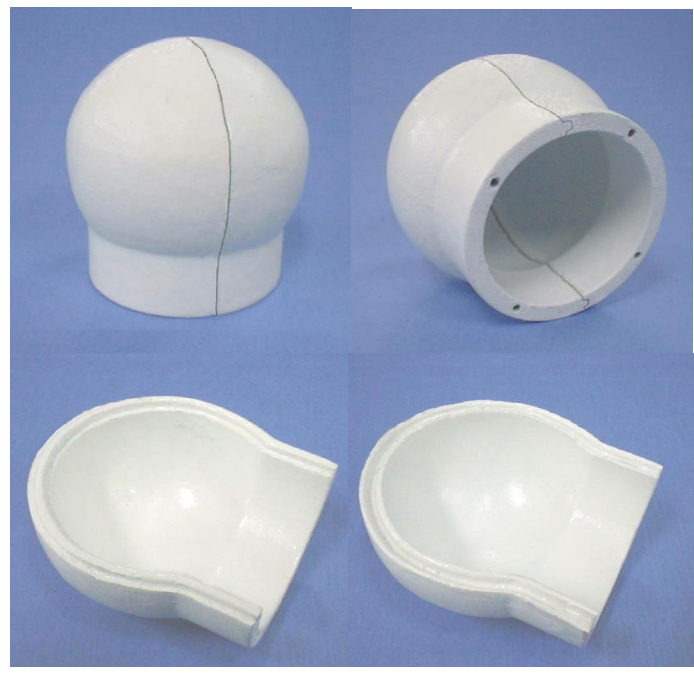

(b)

Figura 4.35 - (a) Protótipo virtual da matriz elastomérica obtido pela modelagem sólida no sistema $C A D$; (b) Protótipo físico da matriz elastomérica obtido pela tecnologia de Prototipagem Rápida.

A fabricação do molde completo estudado nesse trabalho envolve etapas de usinagem das partes metálicas (macho interno) e moldagens das partes poliméricas (matriz elastomérica, gaiola suporte) e de estruturas auxiliares (matrizes flexíveis em silicone e uma matriz rígida em poliuretana a base de óleo de mamona). O macho metálico é obtido por processos de usinagem, furação e polimento da superfície que entrará em contato com o material em pó. Assim, maior ênfase é dada à fabricação das partes poliméricas.

O protótipo físico, obtido pela tecnologia de Prototipagem Rápida, depois de corrigida as imperfeições de sua superfície com massa plástica, é fixado numa base em nylon montada numa estrutura tubular, mostrada na Figura 4.36. 

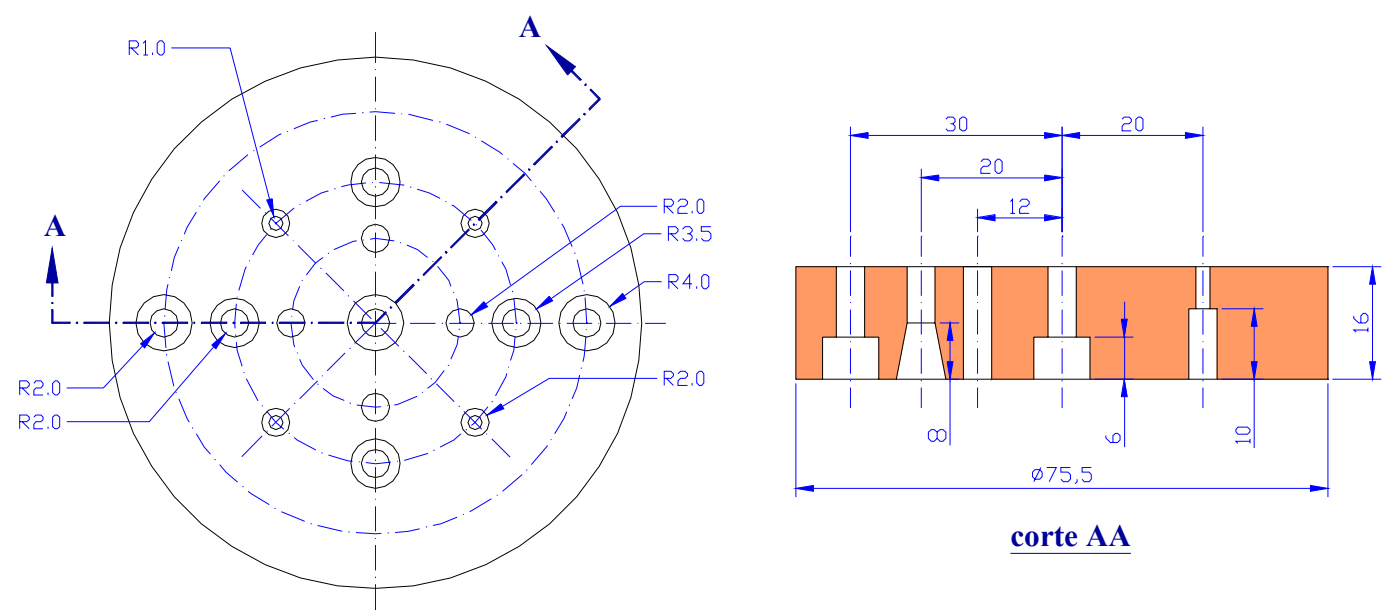

Figura 4.36 - Base em nylon para a fixação do protótipo físico para realização das moldagens

Na Figura 4.37 é mostrada a seqüência de moldagem para a obtenção da matriz elastomérica.

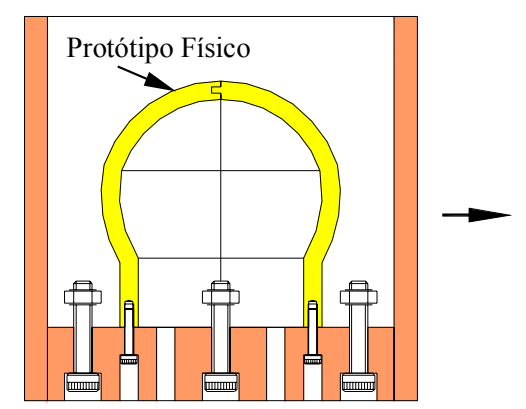

(a)

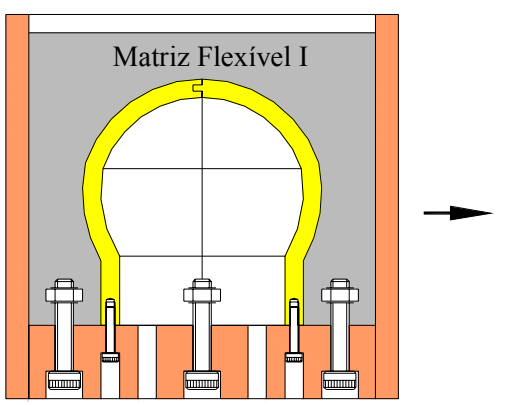

(b)

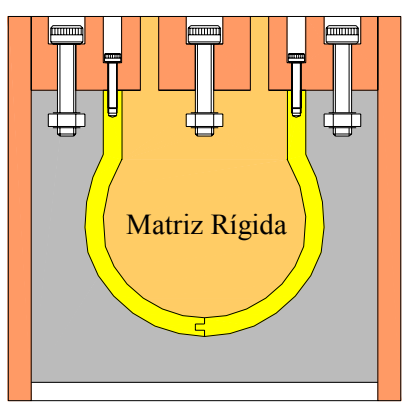

(c)

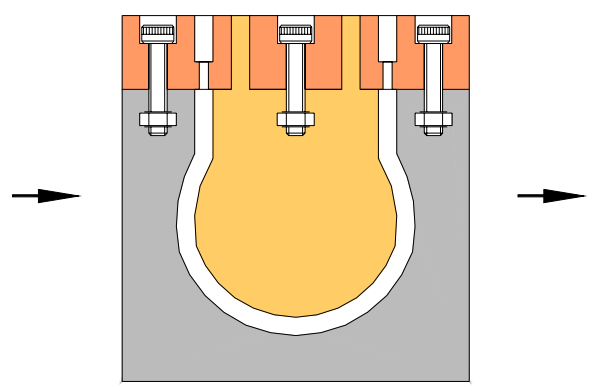

(d)

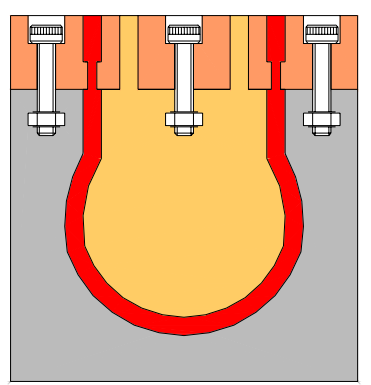

(e)

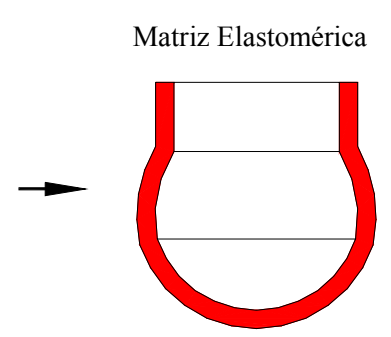

(f)

Figura 4.37 - Seqüência de moldagem para a obtenção da matriz elastomérica

Primeiramente fixa-se o protótipo físico e a base é montada na estrutura tubular (Figura 4.37a). No passo seguinte é moldada a matriz flexível I por vazamento de silicone (Figura 4.37b). Em seguida, após a cura do silicone, é 
moldada a matriz rígida por vazamento da poliuretana à base de óleo de mamona (Figura 4.37c). Após a cura da poliuretana, é feita a desmontagem de todo o conjunto para a extração do protótipo físico (Figura 4.37d), de onde é obtida a cavidade para o vazamento da poliuretana UREOL $^{\circledR}$ (Figura 4.37e) para a obtenção da matriz elastomérica (Figura 4.37f).

A fabricação da gaiola suporte é mostrada na seqüência de moldagem da Figura 4.38. À partir da cavidade do esquema da Figura 4.38a (que é a mesma da Figura 4.37d) é moldada uma réplica da matriz elastomérica (Figura 4.38b) em silicone, chamada de matriz flexível II, e esta servirá de base para a moldagem da gaiola suporte. Assim, fixa-se a matriz flexível II na base com o auxílio do macho metálico e monta-se o conjunto na estrutura tubular (Figura 4.38c). No passo seguinte é moldada a gaiola suporte por vazamento da poliuretana à base de óleo de mamona (Figura 4.38d). Após a cura da poliuretana, é feita a desmontagem de todo o conjunto e é feita a furação dos canais para entrada de fluido na gaiola suporte, que depois de montada com a base, o macho metálico e a matriz elastomérica, formam o conjunto do molde para a prensagem isostática wet bag (Figura 4.38e).

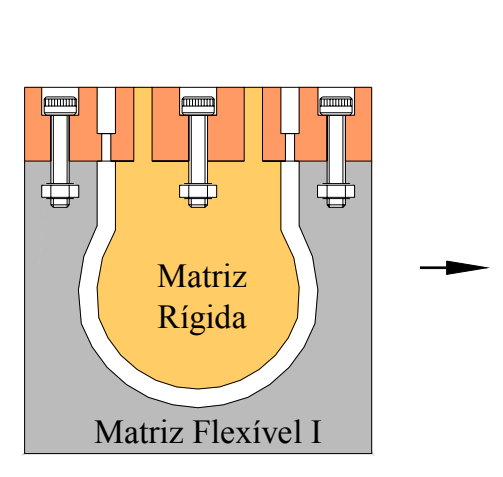

(a)

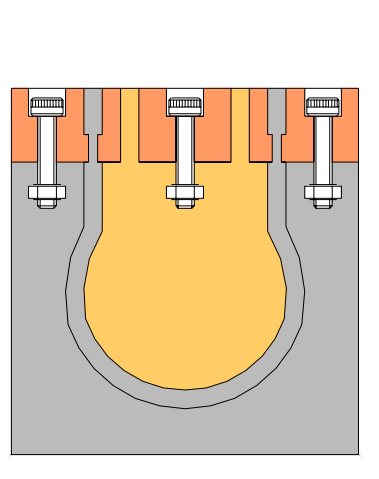

(b)

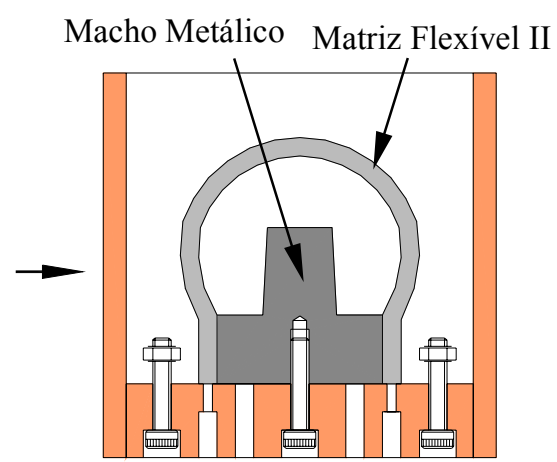

(c)

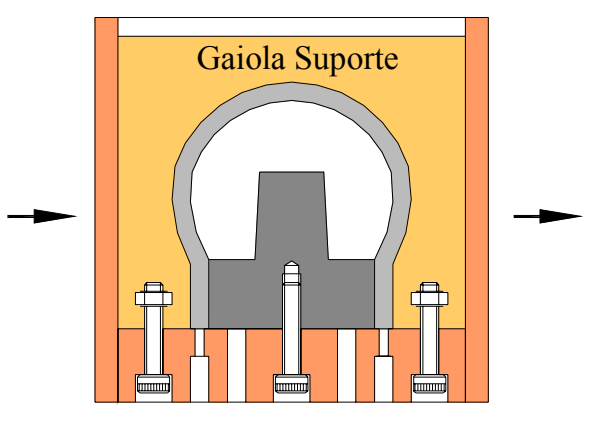

(d)

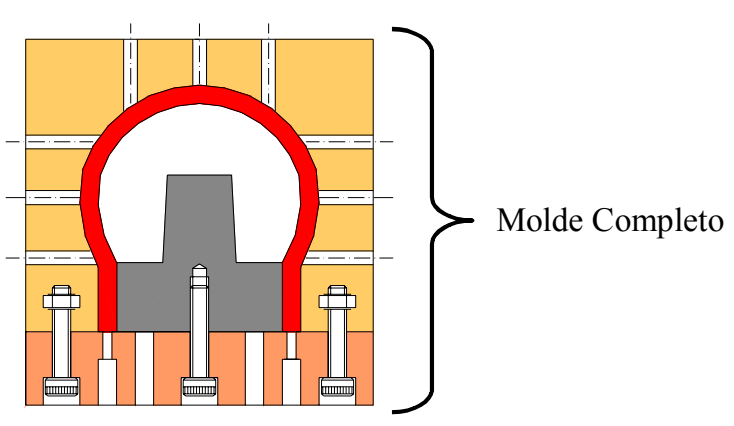

(e)

Figura 4.38 - Seqüência de moldagem para a obtenção da gaiola suporte. 


\section{Capítulo 5}

\section{RESULTADOS E DISCUSSÕES}

\subsection{SIMULAÇÃO DO PROCESSO - MOLDE PRELIMINAR}

Na Figura 5.1a é mostrada a geometria inicial do molde preliminar e na Figura 5.1 b a geometria após a simulação do processo de prensagem isostática.

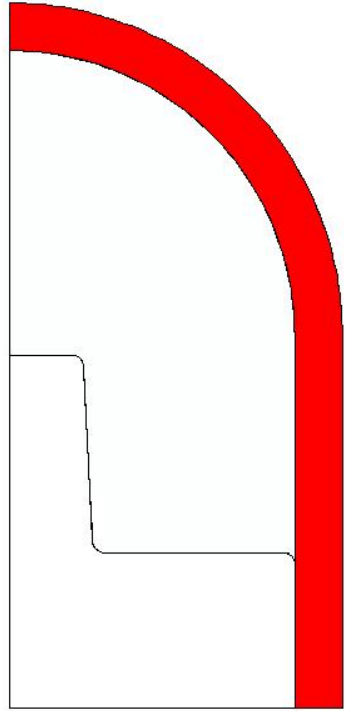

(a)

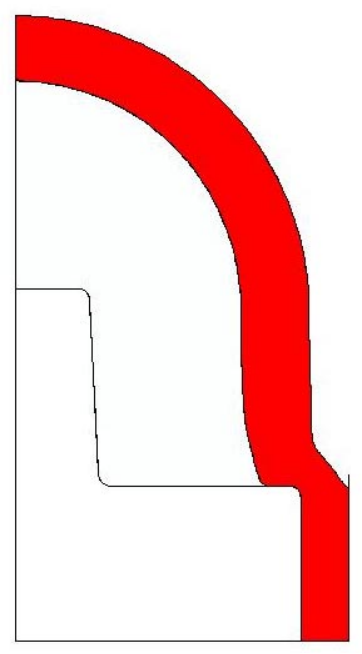

(b)

Figura 5.1 - Simulação do processo de prensagem isostática para o molde preliminar: (a) geometria inicial; (b) geometria após a simulação do processo de prensagem isostática.

Com exceção das dimensões, a malha utilizada na simulação do molde preliminar (tipo dos elementos, condições de contorno e interações de contato) é análoga ao do molde adequado apresentado no item 4.2.2

Os resultados teóricos são comparados aos do componente fabricado e ao componente pretendido na Figura 5.2. Os resultados obtidos numericamente retratam com boa aproximação a forma e dimensões finais do componente prensado isostaticamente. A região próxima à base do compacto não foi prevista com grande 
precisão pela análise numérica. Tal fato se deve à dificuldade em se modelar uma região de um corpo deformável (matriz elastomérica) em contato com um "canto vivo" $\left(90^{\circ}\right)$. Uma alternativa encontrada para tentar solucionar tal problema foi introduzir um raio de arredondamento, relativamente pequeno para que não interferisse nos resultados da análise, que amenizou o problema. Outros fatores importantes que podem ter interferido na precisão da simulação nessa região, são a imprecisão do modelo hiperelástico do elastômero e o coeficiente de atrito adotado que pode não condizer com valores reais.

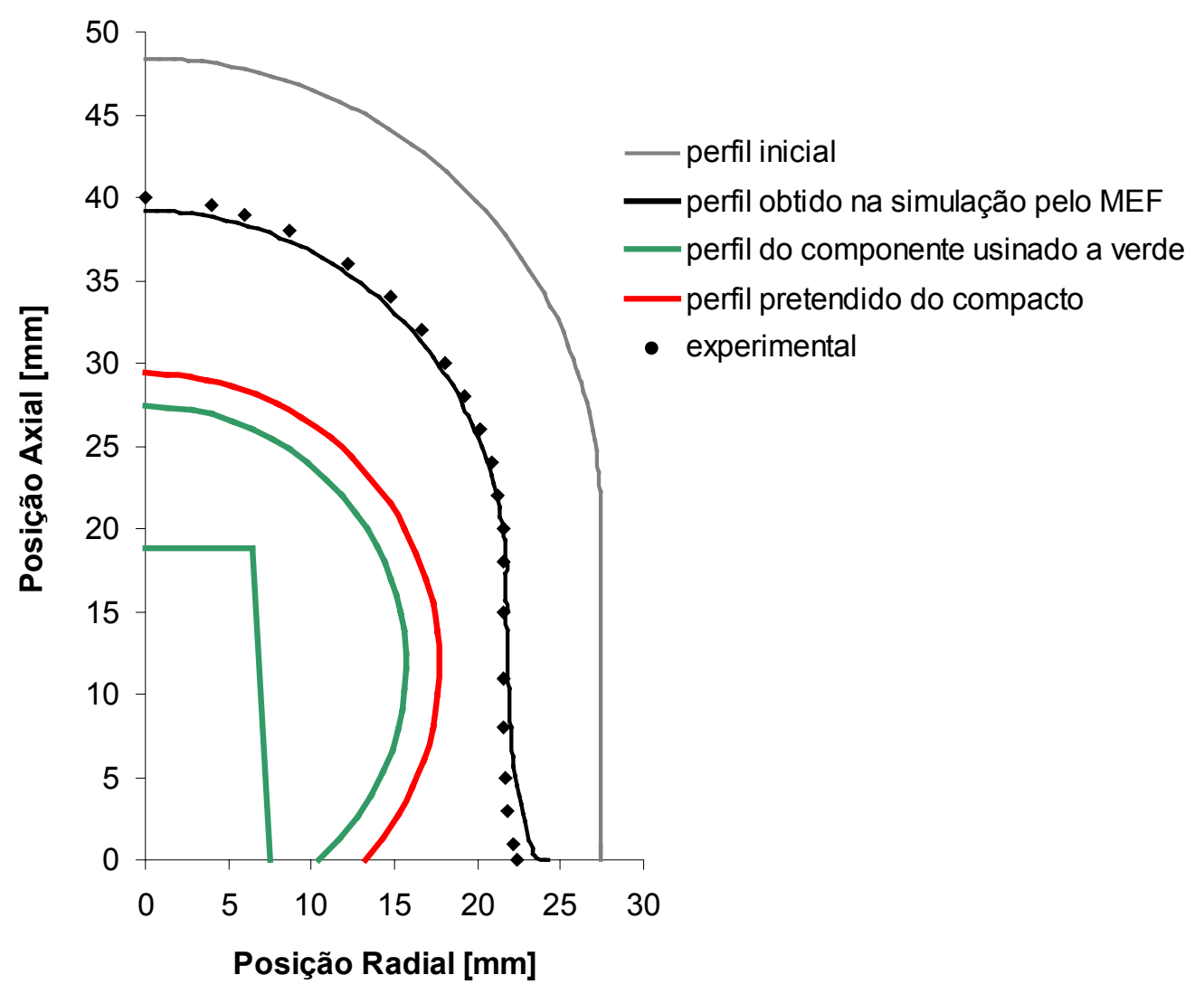

Figura 5.2 - Simulação do processo de prensagem isostática para o molde preliminar: Resultados teóricos obtidos pelo método dos elementos finitos (MEF), perfil pretendido e resultados experimentais.

A simulação do processo para o molde preliminar foi importante para testar a precisão e a calibração dos modelos de material utilizados para os materiais cerâmico e elastomérico. Dessa forma foi possível comparar as dimensões do compacto obtidas nessa simulação às dimensões do compacto obtido pela prensagem em um molde já existente, descartando a etapa de confecção desse molde. 


\subsection{SIMULAÇÃO DO PROCESSO - MOLDE ADEQUADO}

$\mathrm{Na}$ Figura 5.3a é mostrada a geometria inicial do molde adequado e na Figura $5.3 \mathrm{~b}$ a geometria após a simulação do processo de prensagem isostática.

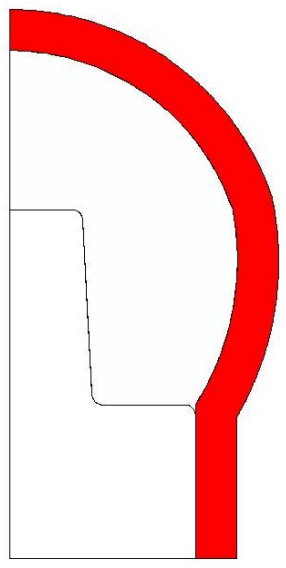

(a)

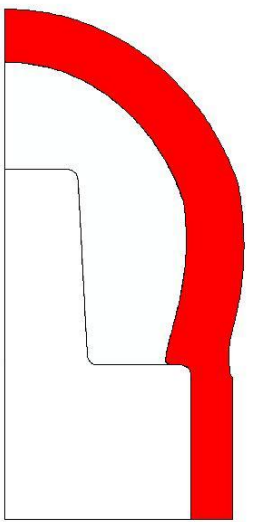

(b)

Figura 5.3 - Simulação do processo de prensagem isostática para o molde preliminar: (a) geometria inicial; (b) geometria após a simulação do processo de prensagem isostática.

A malha utilizada na simulação do molde adequado foi apresentada no item 4.2.2. Na Figura 5.4, os resultados teóricos são comparados aos do componente pretendido e, após fabricação do molde e realização da prensagem, são comparados aos resultados experimentais.

Os resultados obtidos numericamente retratam com boa aproximação a forma e dimensões finais do componente prensado isostaticamente. Novamente, a região próxima à base do compacto não foi prevista com grande precisão pela análise numérica por razões comentadas no item anterior. 


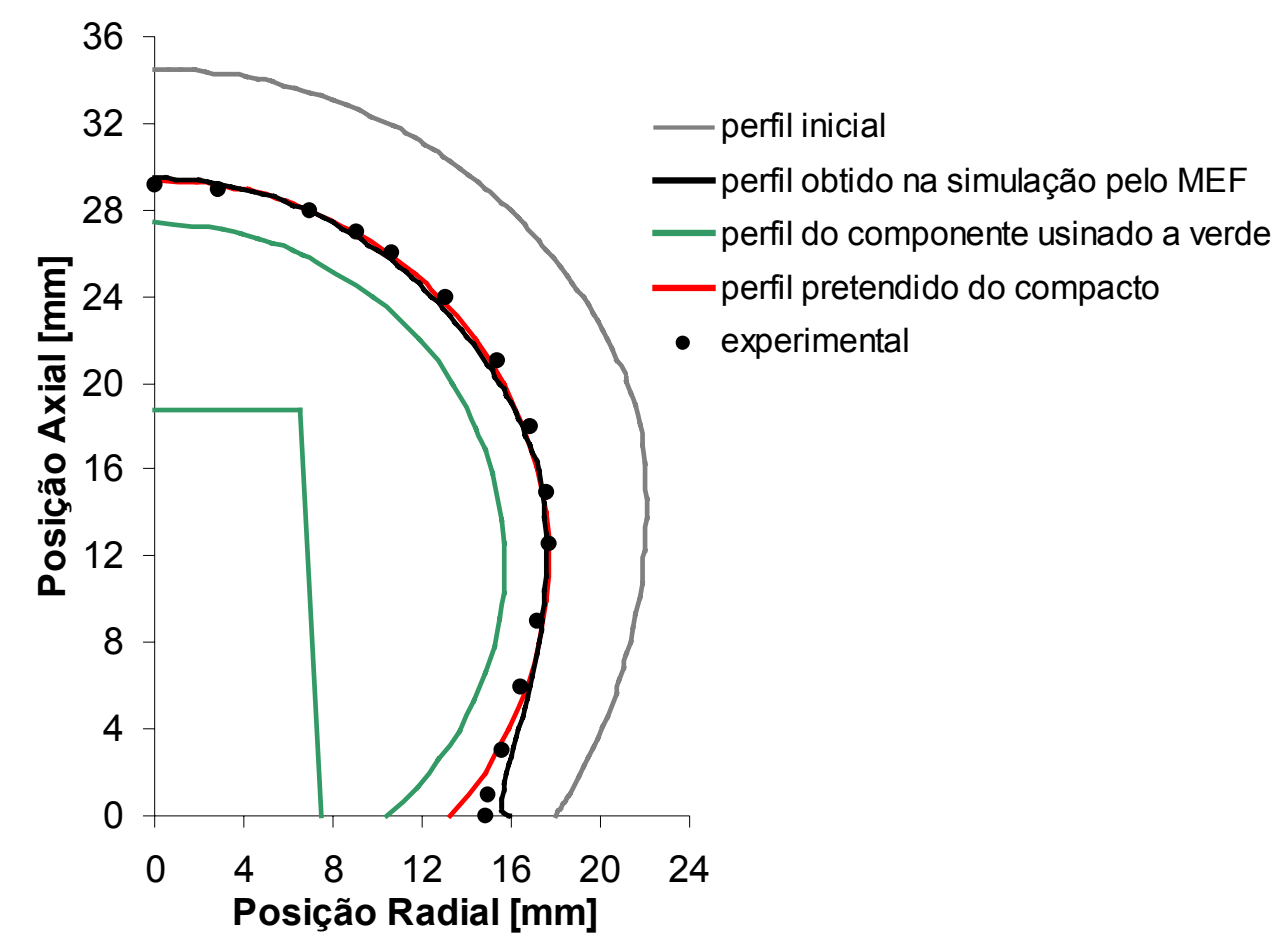

Figura 5.4 - Simulação do processo de prensagem isostática para o molde adequado: Resultados teóricos obtidos pelo método dos elementos finitos (MEF), perfil pretendido e resultados experimentais.

\subsection{CONSIDERAÇÕES GERAIS SOBRE AS SIMULAÇÕES}

Nas Figura 5.5a e b são mostradas as magnitudes dos deslocamentos nas direções axial e radial para o molde preliminar e molde adequado, respectivamente. Para o molde preliminar da Figura 5.5a verifica-se que os deslocamentos da região superior no sentido axial são maiores que os deslocamentos da região lateral no sentido radial do molde. Tal fato mostra um desequilíbrio nas dimensões do molde, ou seja, esse se desloca mais no sentido axial em relação ao sentido radial e isso poderá influenciar na homogeneidade de densidades da peça compactada. Entretanto, analisando a magnitude de deslocamentos na Figura 5.5b para o molde adequado, nota-se um maior equilíbrio nos deslocamentos radiais e axiais. Dessa forma, uma análise qualitativa dos deslocamentos pode ser utilizada como uma maneira simplificada de se estabelecer dimensões ao molde para buscar uma melhoria na qualidade do compacto. 


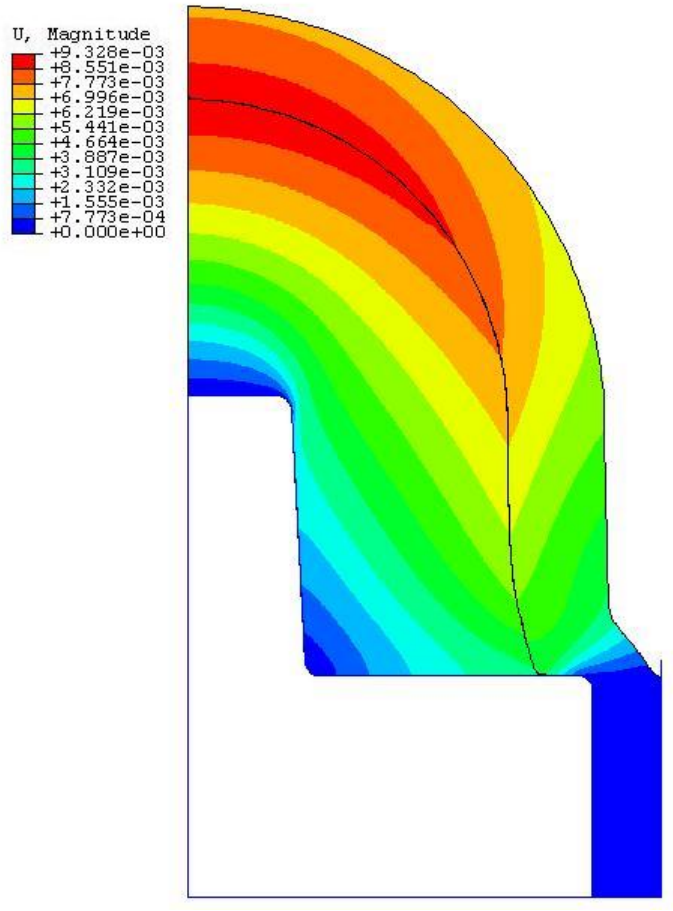

(a)

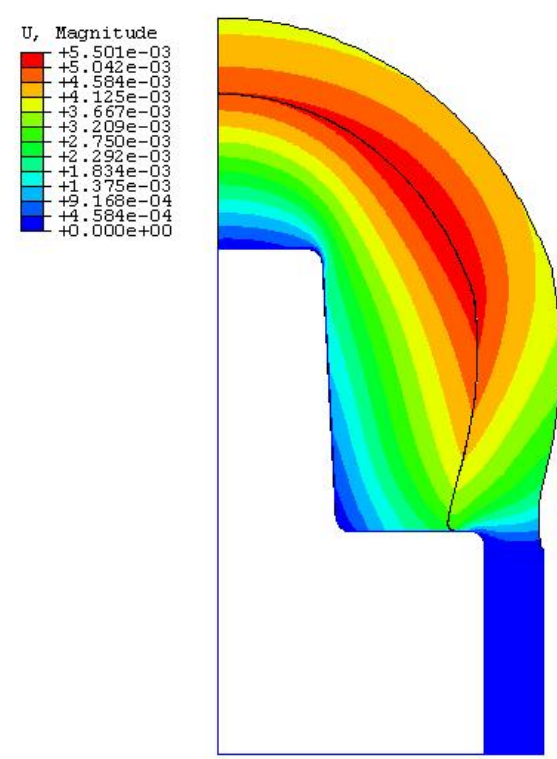

(b)

Figura 5.5 - Magnitude de deslocamentos nas direções axial e radial. [unidades em m].

Sendo o pó cerâmico representado através de um meio contínuo, as deformações plásticas sofridas por esse representam a compactação do material. Dessa forma é interessante analisar o estado de deformações plásticas, pois é possível associá-lo a um estado de densidades do material compactado, que é um fator de grande influência na qualidade e propriedades mecânica da peça prensada.

Nas Figura 5.6a e b são mostrados os estados de deformações plásticas no sentido circunferencial (perpendicular ao plano do papel) para o molde preliminar e o molde adequado, respectivamente. Para os dois casos, constata-se uma variação no grau de compactação (deformação plástica) ao longo do compacto, pois apesar da aplicação de uma pressão hidrostática, o estado atingido na peça devido a sua geometria, não é perfeitamente hidrostático.

Comparando-se os dois casos, nota-se que o grau de compactação nos compactos são próximos e correlacionados para regiões análogas. Tal fato pode mostrar que a alteração na geometria do molde altera pouco os níveis de compactação da peça de uma maneira geral, pois estes dependerão muito mais da pressão aplicada. 


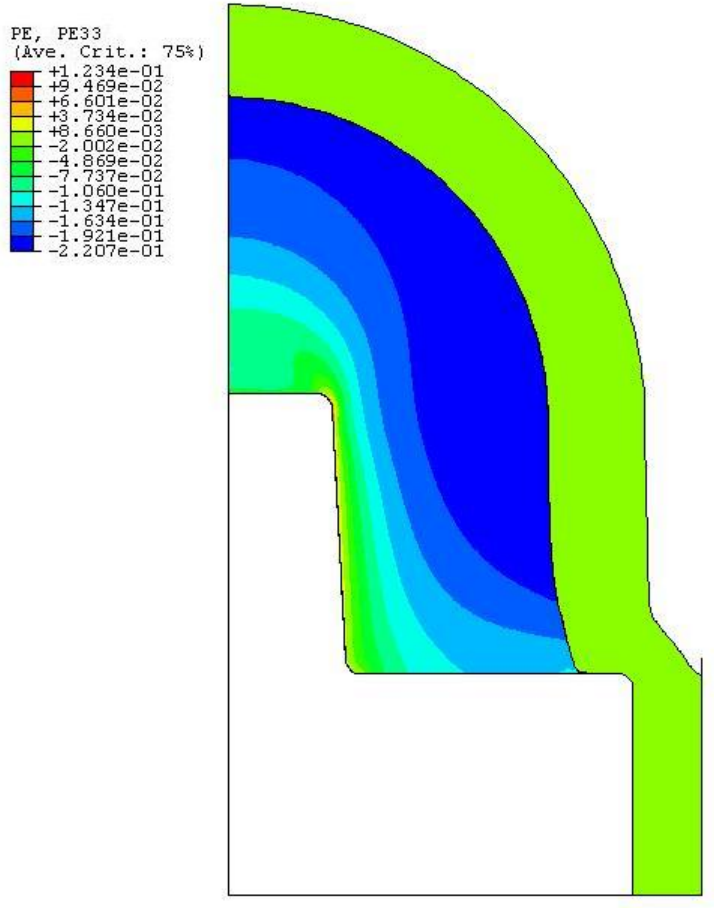

(a)

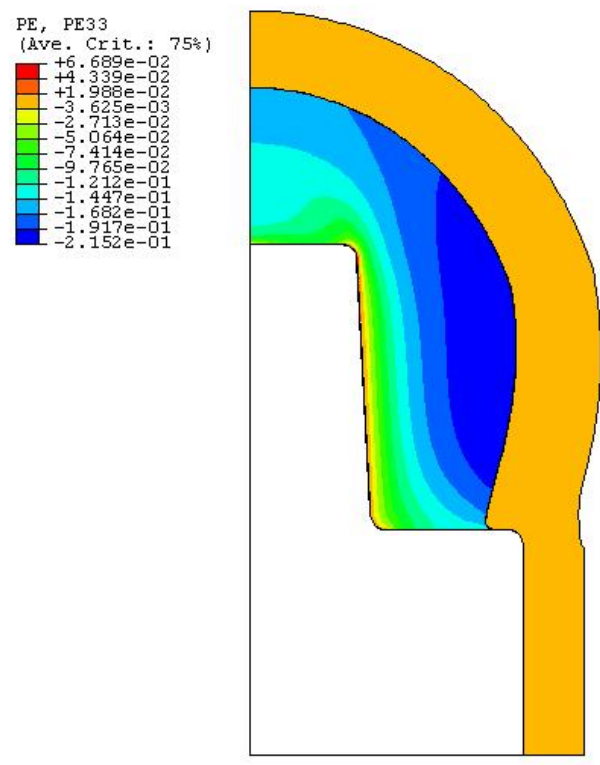

(b)

Figura 5.6 - Estado de deformações plásticas no sentido circunferencial

Com o objetivo de investigar o tipo de plastificação ocorrido na simulação do processo de prensagem isostática, alguns pontos no interior da peça foram escolhidos na disposição mostrada na Figura 5.7. O caminho das tensões no plano meridional foi traçado para cada um dos seis pontos, conforme mostrado nos gráficos da Figura 5.8. Tal investigação é interessante para analisar a influência das superfícies que definem o critério de plastificação utilizado: a superfície de plastificação de Drucker-Prager e a superfície cap.

Pela natureza do processo de prensagem isostática, a maioria dos pontos tomados $(1,2,4,5$ e 6$)$ plastificam na superfície cap, expandindo-a segundo sua lei de encruamento. Apesar do processo aplicar sobre a superfície da peça tensões com predominância hidrostática, a geometria da peça possibilita o surgimento de regiões com tensões cisalhantes consideráveis a ponto de ocorrer plastificação (ponto 3). Como resultado dessa análise, nota-se que a dependência dos parâmetros da superfície de Drucker-Prager varia com a geometria da peça a ser compactada e no estudo de caso desse trabalho essa dependência é pequena. 


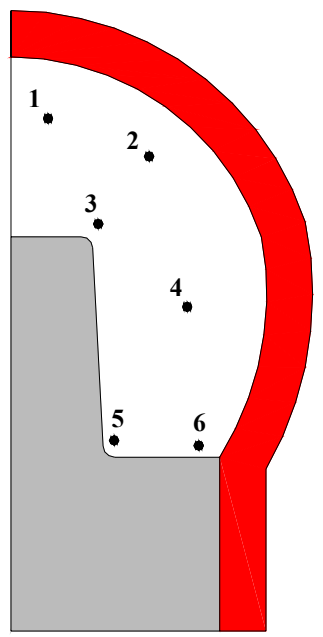

Figura 5.7 - Localização dos pontos escolhidos para analisar o caminho das tensões desenvolvidos na simulação do processo de prensagem isostática.

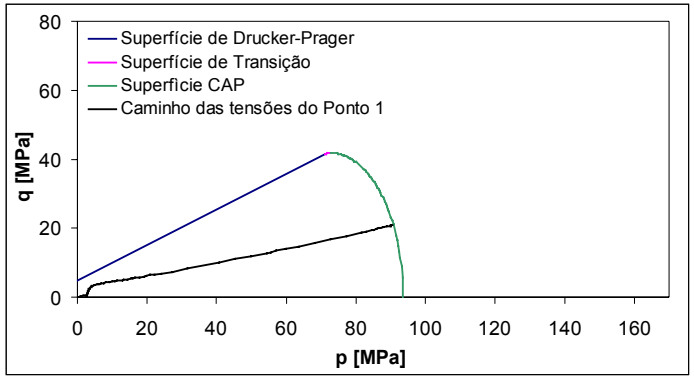

(a)

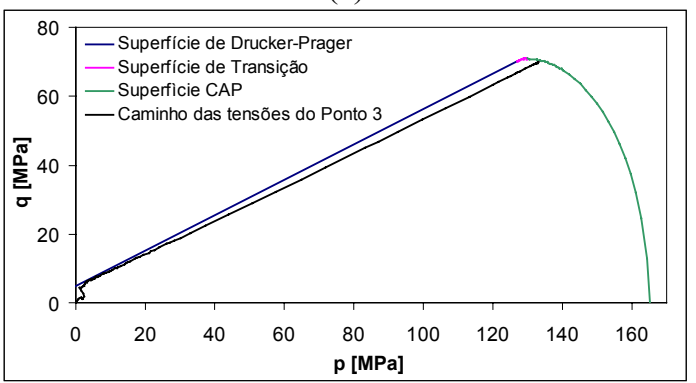

(c)

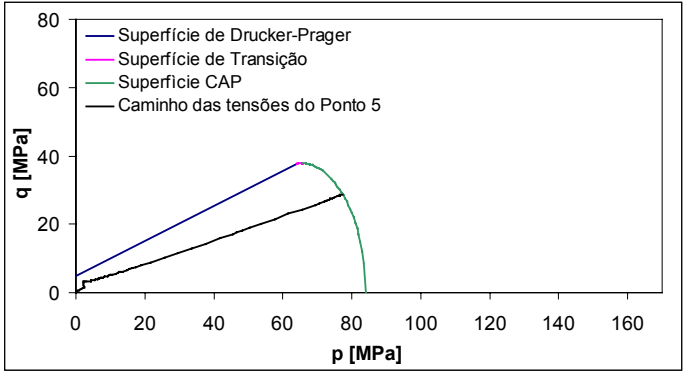

(e)

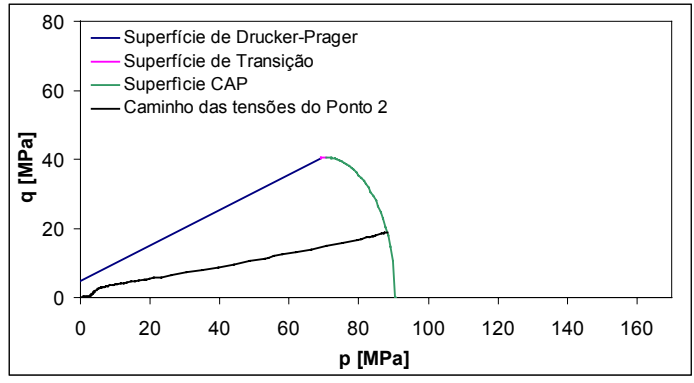

(b)

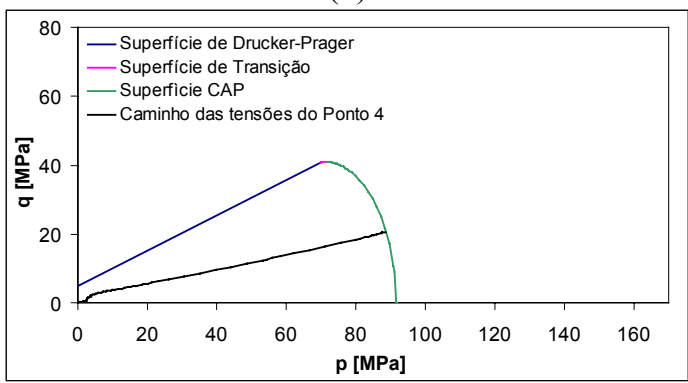

(d)

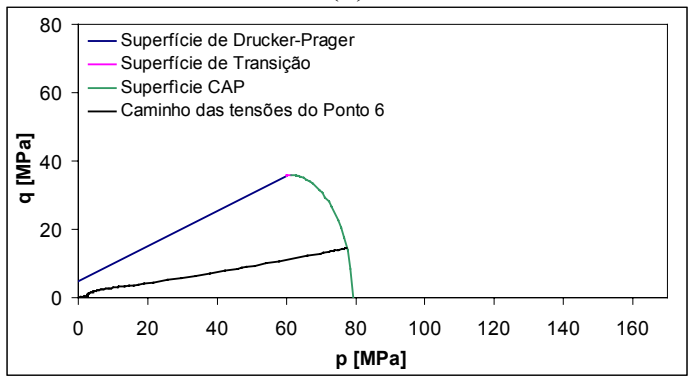

(f)

Figura 5.8 - Caminho das tensões para os pontos de 1 a 6 traçados no plano meridional $q \times p$. 
Uma consideração importante refere-se à necessidade da modelagem da matriz elastomérica nas simulações. Considerando a simplificação de que esta apenas transmite ao compacto as cargas introduzidas pelo fluido pressurizado, a simulação pode ser simplificada aplicando-se os carregamentos diretamente no material cerâmico. Porém a presença da matriz elastomérica e do modelo de contato aumentam consideravelmente o custo computacional e dificultam bastante a convergência da análise numérica, uma vez que a análise envolve um modelo de material altamente compressível (compactação do pó cerâmico) com outro quase incompressível (elastômero), interagidos com superfícies de contato.

Embora Henderson et al (2000) tenham constatado que a presença da matriz elastomérica na análise tenha evitado distorções na malha correspondente ao seu material (pó de material refratário), o mesmo não foi verificado na análise realizada com o molde preliminar do estudo de caso apresentado neste trabalho. O que se constatou é que a introdução da matriz elastomérica na análise da prensagem isostática da esfera cerâmica exerceu influência na forma final da peça prensada, bem como nos perfis de deformações plásticas na direção circunferencial, como é mostrado na Figura 5.9, Figura 5.10, Figura 5.11 e Figura 5.12.

Na Figura 5.9 e Figura 5.10 são mostradas análises do processo de prensagem isostática realizadas com a introdução da matriz elastomérica para diferentes coeficientes de atrito entre o núcleo metálico e o material cerâmico, $\mu=0,20$ e $\mu=0,05$ respectivamente. Análises análogas são mostradas na Figura 5.11 e Figura 5.12, porém sem a introdução da matriz elastomérica (a pressão foi aplicada diretamente no material cerâmico). Numa análise qualitativa comparativa entre as simulações verifica-se que a presença da matriz elastomérica permite uma menor dependência do atrito em relação às simulações realizadas sem a matriz elastomérica. Isto pode ser observado pela grande diferença na forma (Figuras "b") e perfil de deformações (Figuras "a") à medida que se alterou os coeficientes de atrito para as simulações sem a matriz elastomérica (Figura 5.11 e Figura 5.12), o que se observa em menor grau para as simulações com a matriz elastomérica (Figura 5.9 e Figura 5.10). 


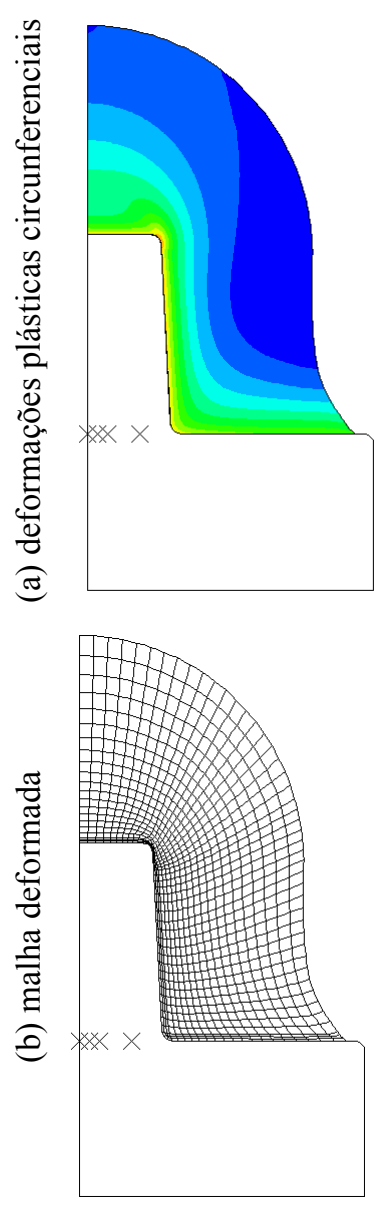

Figura 5.9 - Simulação com a matriz elastomérica $(\mu=0,20)$.
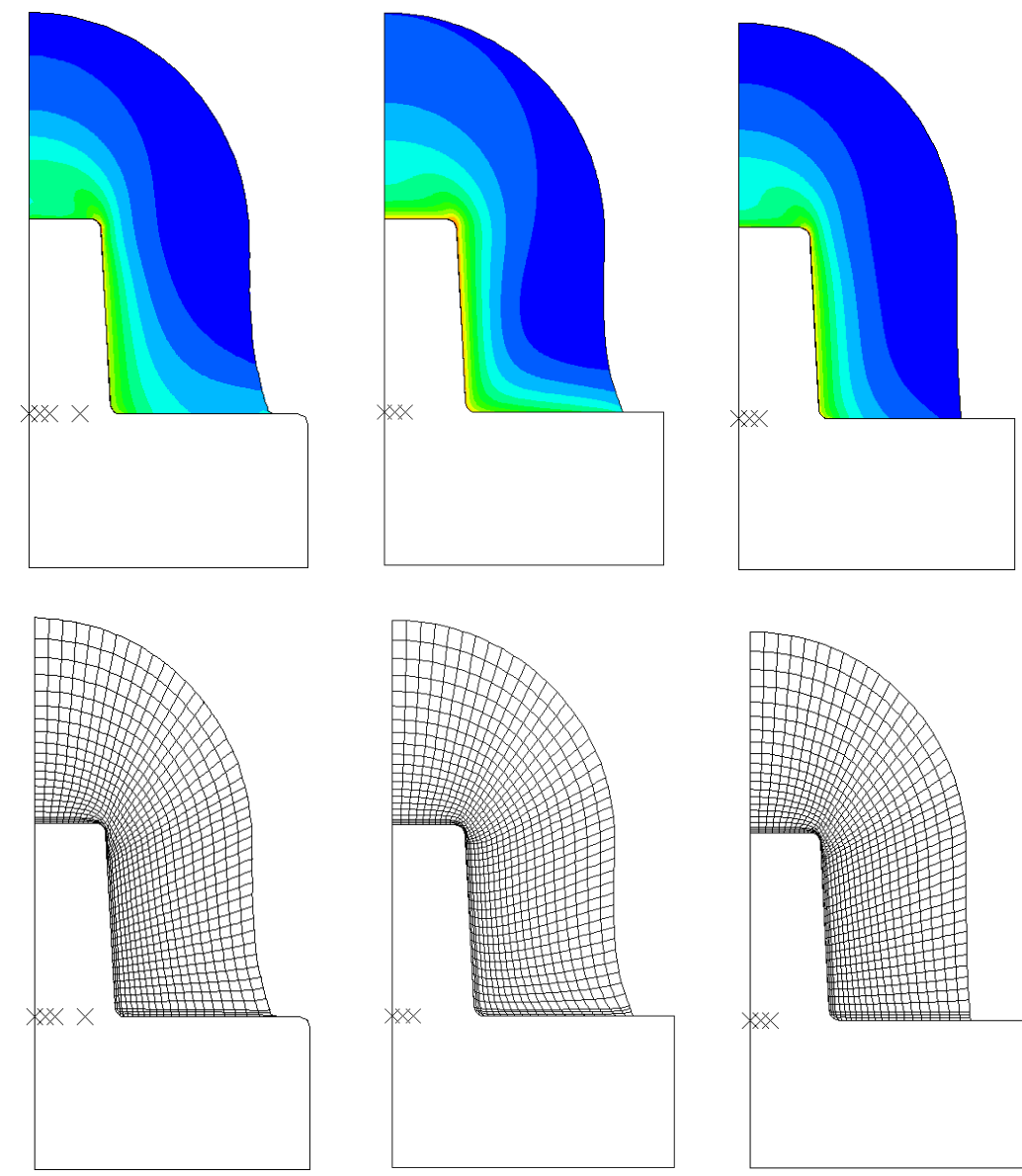

Figura 5.10 - Simulação com a matriz elastomérica $(\mu=0,05)$.

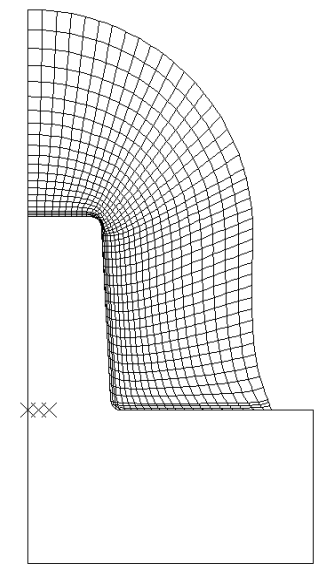

Figura 5.11 - Simulação sem a matriz elastomérica $(\mu=0,20)$.

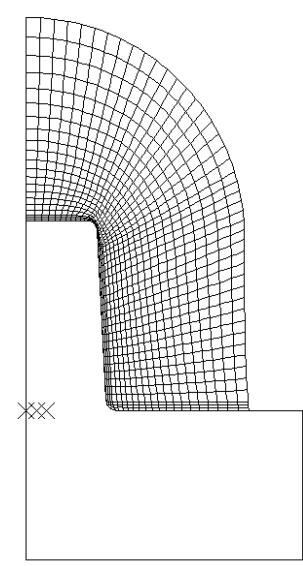

Figura 5.12 -

Simulação sem a matriz elastomérica $(\mu=0,05)$.

Dessa forma constata-se a importância da matriz elastomérica na simulação do processo prensagem isostática, que influencia diretamente no resultado, diferentemente das distorções observadas por Henderson et al. (2000), que pela simplicidade da geometria estudada e principalmente por não envolver um certo grau de complexidade em sua análise (contato entre as partes) não pôde verificar tal comportamento.

\subsection{FABRICAÇÃO DO MOLDE}

Na Figura 5.13 são mostradas as matrizes auxiliares para a fabricação do molde. As matrizes flexíveis em borracha de silicone, bem como a matriz elastomérica em PU - $\mathrm{UREOL}^{\circledR}$, reproduzem as formas e imperfeições das superfícies onde são moldadas e não permitem tratamento superficial posterior. Em 
vista dessa característica as superfícies rígidas devem ser perfeitamente acabadas, necessitando corrigir as suas imperfeições quando necessário. Para isso, pode-se utilizar a aplicação de massas plásticas e posterior acabamento. Um resultado desse tipo de tratamento pode ser visto na Matriz Rígida da Figura 5.13. Cabe ainda ressaltar, que tal matriz foi confeccionada em polímero rígido, para possibilitar tal um acabamento superficial adequado, haja vista que sua superfície reproduz as imperfeições da superfície interna do protótipo físico gerado na máquina de Prototipagem Rápida.

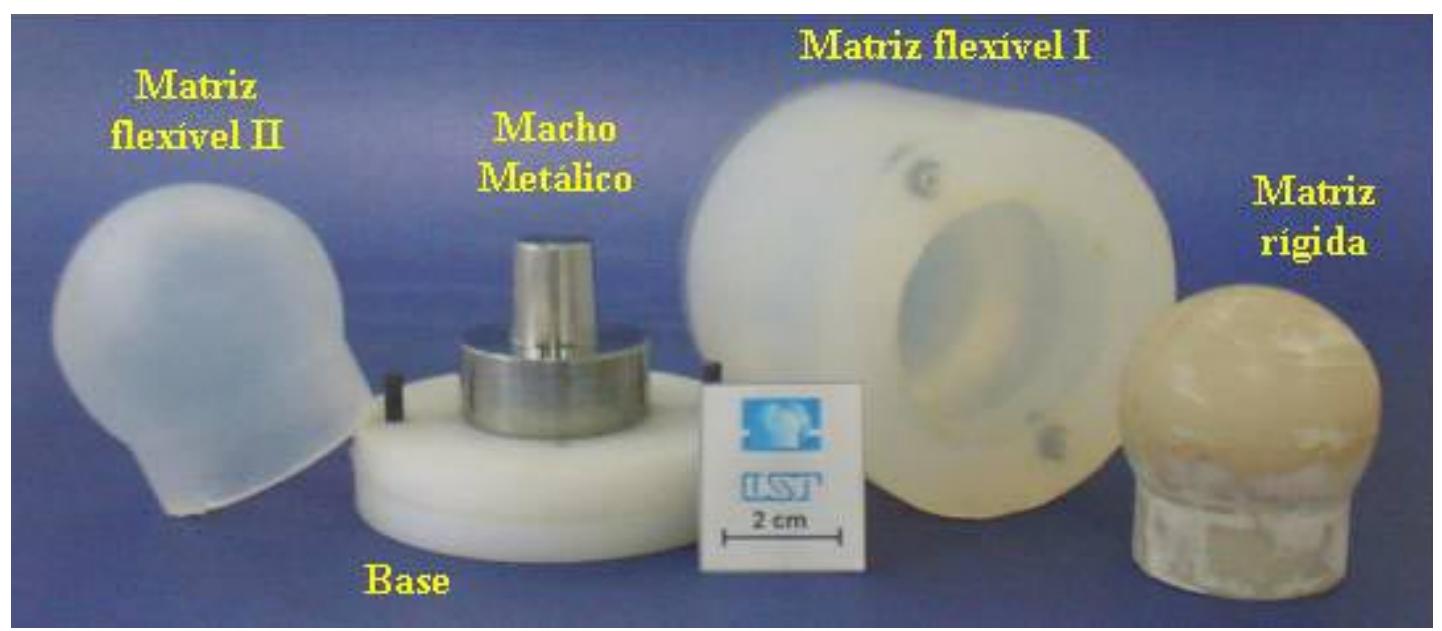

Figura 5.13 - Matrizes auxiliares para a fabricação do molde para prensagem isostática

Outro fator relevante foi a utilização da Matriz Flexível II para o vazamento da Gaiola Suporte. Devido ao calor liberado na reação durante a cura da PU à base de óleo de mamona, fato que impede a utilização da PU - UREOL ${ }^{\circledR}$ que não suporta o nível de temperatura desenvolvido $\left(\sim 60^{\circ} \mathrm{C}\right)$.

O molde completo desenvolvido na metodologia apresentada e o compacto obtido no molde após o processo de prensagem isostática wet bag do pó cerâmico são mostrados na Figura 5.14. Nota-se que o projeto do molde permitiu a obtenção de um compacto com a forma e dimensões muito próximas à prevista na simulação numérica, como pôde ser observada na Figura 5.3. 


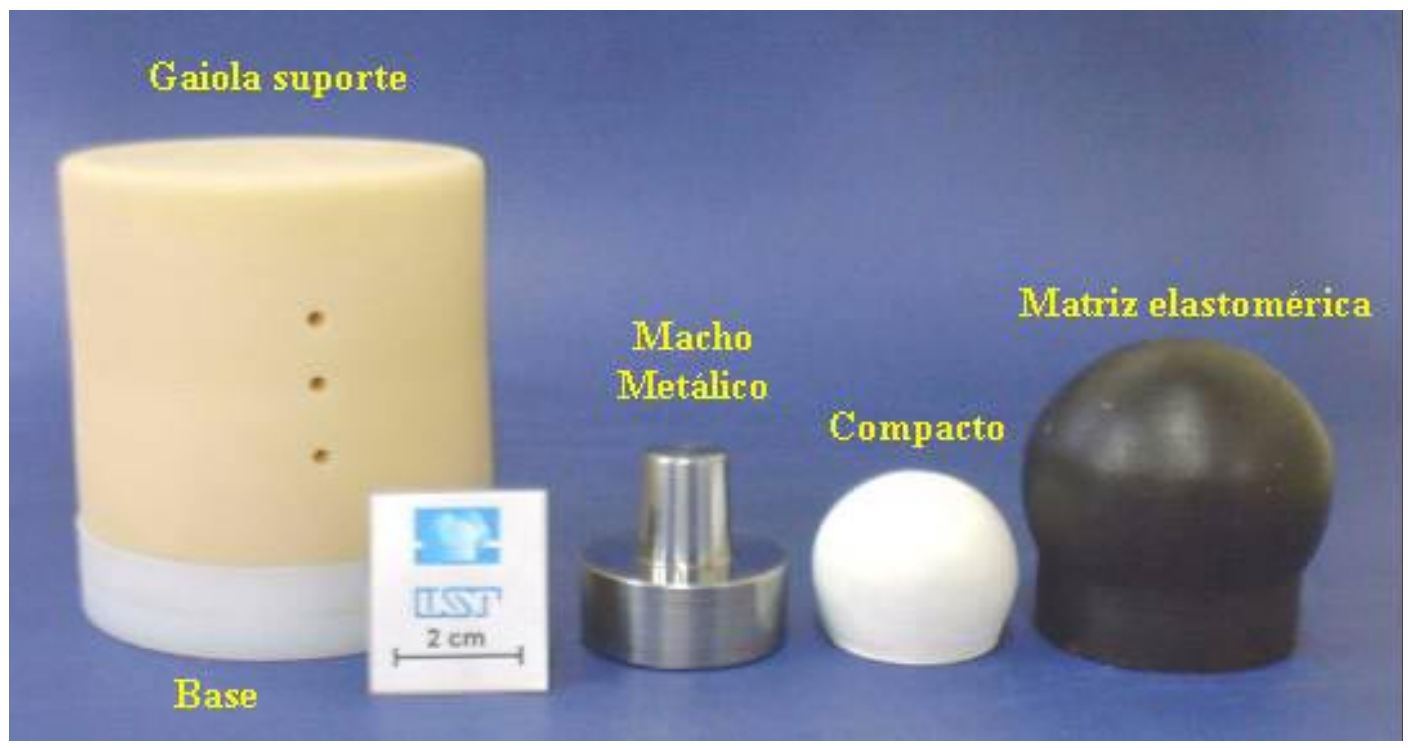

Figura 5.14 - Molde completo desenvolvido na metodologia apresentada e compacto obtido no molde após o processo de prensagem isostática wet bag do pó cerâmico.

Uma análise comparativa entre os processos de prensagem desenvolvidos no molde preliminar e no molde adequado pela metodologia proposta é esquematizada na Figura 5.15.

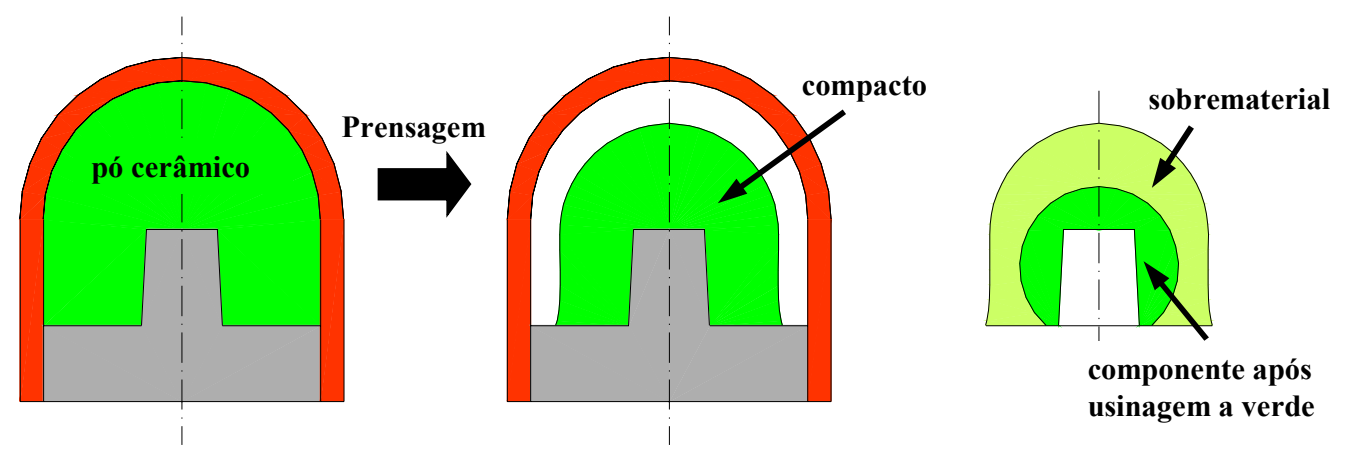

\section{Molde Preliminar}
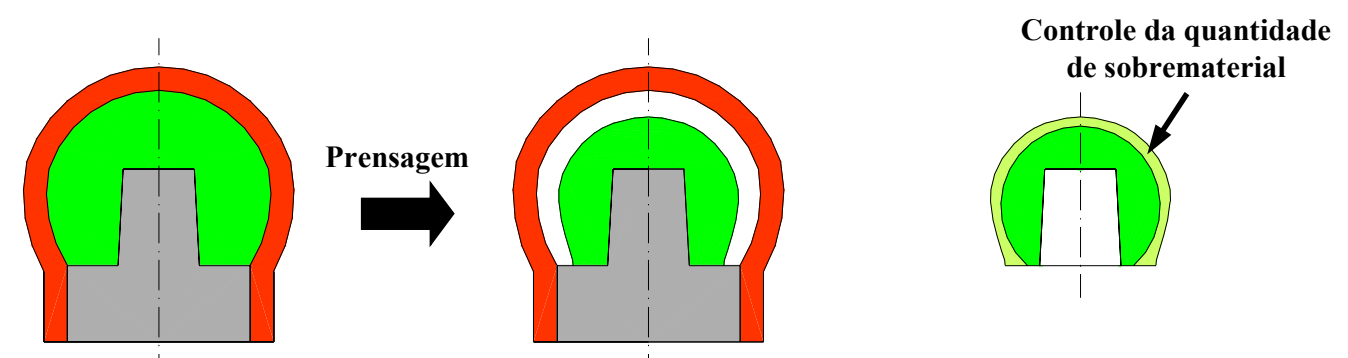

\section{Molde Adequado pela Metodologia proposta}

Figura 5.15 - Comparação entre os processos de prensagem isostática desenvolvidos no molde preliminar e no molde adequado pela metodologia proposta. 
Com a aplicação da metodologia proposta, conseguiu-se uma redução na massa de pó cerâmico inicialmente de $106 \mathrm{~g}$ para o molde preliminar contra $43 \mathrm{~g}$ para o molde adequado, representando uma redução de aproximadamente $60 \%$, conforme é mostrado na Figura 5.16. Pode-se somar a essa economia de material, o tempo de usinagem a verde, a redução de componentes perdidos nessa usinagem e a economia no ferramental de usinagem.

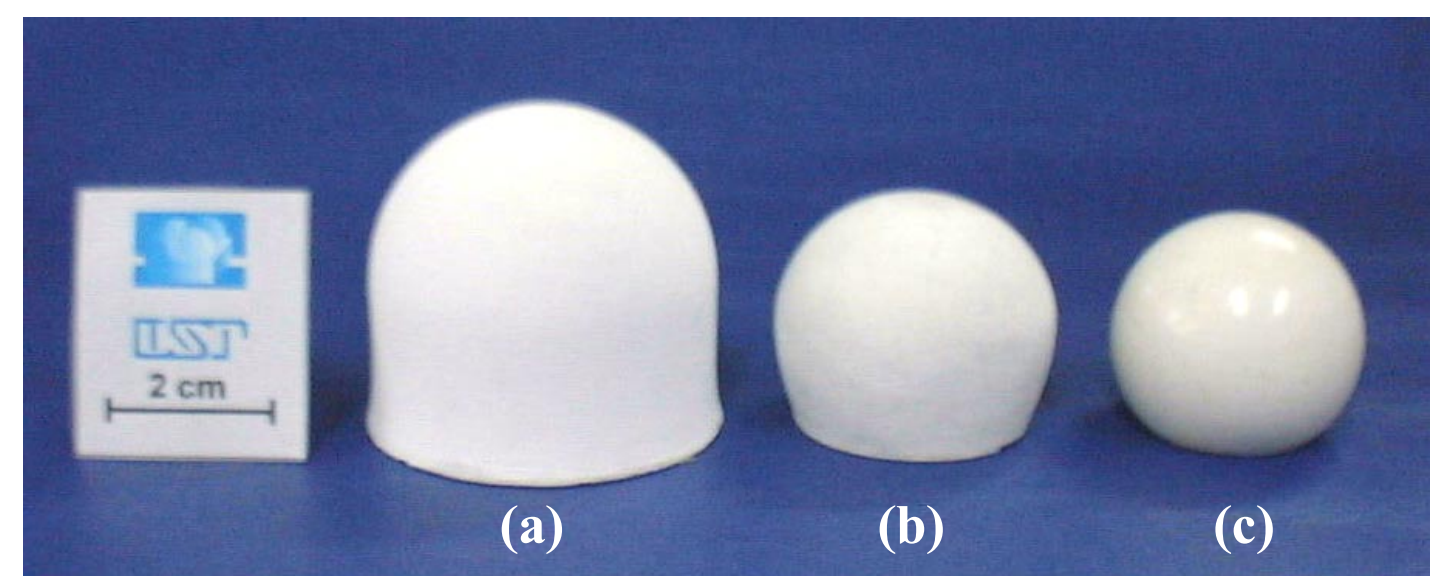

Figura 5.16 - Compactos obtidos pelo processo de prensagem isostática: (a) compacto obtido do molde preliminar e (b) compacto obtido do molde adequado. (c) componente após a usinagem a verde. 


\section{Capítulo 6}

\section{CONCLUSÕES E SUGESTÕES}

\subsection{CONCLUSÕES}

Constatou-se a viabilidade da utilização da metodologia de projeto e fabricação do molde para prensagem isostática de pós cerâmicos baseado em simulações computacionais do processo de prensagem isostática, com o auxílio de ferramentas $\mathrm{CAD}$ associadas à tecnologia de prototipagem Rápida e técnicas de moldagem em matrizes poliméricas rígidas e flexíveis.

As simulações mostraram-se bastante coerentes com os resultados experimentais, constatando-se a viabilidade da utilização e calibração dos modelos de material para a representação da compactação do pó cerâmico e do comportamento do material elastomérico. Com isso, verificou-se a potencialidade do uso da simulação do processo de prensagem isostática como ferramenta de análise no projeto do molde, bem como na adequação da quantidade de sobrematerial do componente cerâmico para posterior usinagem a verde.

A metodologia proposta se torna útil para a fabricação de moldes para peças com geometrias complexas, pois substitui processos avançados de usinagem (comando numérico) para a construção dos protótipos e matrizes. Por fim, conclui-se que a metodologia empregada na fabricação do molde é de fácil execução quando se dispõe das ferramentas envolvidas, fato que torna o processo de prensagem isostática mais eficiente quanto ao custo de implementação de um novo produto, e quanto à economia nos processos posteriores pela quantidade de sobrematerial apropriada, uma vez que reduz a um mínimo a quantidade de material cerâmico utilizada e o tempo de usinagem a verde, bem como o número de componentes perdidos durante essa usinagem. 


\subsection{SUGESTÕES}

Como sugestões para trabalhos futuros, são propostas:

- Um estudo visando uma correlação quantitativa entre níveis de deformações residuais no compacto, obtidos em simulações do processo de prensagem isostática, com a distribuição de densidades no compacto;

- Aplicar uma metodologia onde a variável de adequação não mais é a forma final da peça compactada, mas sim as propriedades mecânicas do material. Isto pode ser feito a partir da proposta anterior, realizando um estudo para melhorar a qualidade de compactos quanto à homogeneidade de densidades;

- Realizar os processos de usinagem para a esfera cerâmica a fim de avaliar as vantagens obtidas como, por exemplo, o tempo de usinagem a verde e o número de componentes perdidos durante essa usinagem;

- Estender a metodologia para outros componentes;

- Verificar o modelo de material para a compactação de outros tipos de materiais. 


\section{Capítulo 7}

\section{REFERÊNCIAS BIBLIOGRÁFICAS}

AKYSANYA, A.R.; COCKS, A.C.F.; FLECK, N.A. (1997). The yield behaviour of metal powders. International Journal of Mechanical Sciences, v.39, n.12, p.13151324.

AL-QURESHI, H. A., Elastomer: Metalforming Die, São José dos Campos, 1984.

AMERICAN SOCIETY FOR TESTING AND MATERIALS (1995). ASTM D412/97 - Standard Test Methods for Vulcanized Rubber and Thermoplastic Rubbers and Thermoplastic Elastomers - Tension. (CD ROM). West Conshohocken.

AMERICAN SOCIETY FOR TESTING AND MATERIALS (1991). ASTM D575/91 - Standard Test Methods for Rubber Properties in Compression (CD ROM). Philadelphia.

AXEL PRODUCTS, INC. (2000). Testing Elastomers for Hyperelastic Material Models in Finite Element Analysis. Testing and Analysis.

AYDIN, I.,; BRISCOE, B.J.; SANLITÜRK, K.Y. (1996). The internal form of compacted ceramic components: a comparison of a finite element modeling with experiment. Powder Technology, v.89, p.239-254.

BACCINO, R.; MORET, F. (2000). Numerical modeling of powder metallurgy processes. Materials \& Design, v.21, p.359-364.

BORTZMEYER, D. (1992). Modelling ceramic powder compaction. Powder Technology, v.70, p.131-139.

BRISCOE, B.J.; ÖZKAN, N. (1997). Compaction behaviour of agglomerated alumina powders. Powder Technology, v.90, n.3, p.195-203. 
BRISCOE, B.J.; ROUGH,S.L. (1998). The effects of wall friction in powder compaction. Colloids and Surfaces A: Physicochemical and Engineering Aspects, v.137, p.103-116.

CHEN, W.F.; BALADI, G.Y. (1985). Soil plasticity: Theory and implementation. Amsterdan. Ed. Elsevier.

CHIAVERINI, V. (2001). Metalurgia do pó. 4.ed. São Paulo, Associação Brasileira de Metalurgia e Materiais.

CHTOUROU, H.; GUILLOT, M.; GAKWAYA, A. (2002). Modeling of the metal powder compaction process using the cap model. Part I. Experimental material characterization and validation. International Journal of Solids and Structures, v. 39, n.4, p.1059-1075.

DIETER, G. E. (1981). Metalurgia Mecânica. Trad. por Antonio Sergio de Souza, Luiz Henrique de Almeida e Paulo Emílio Valadão de Miranda. 2.ed. Rio de Janeiro. Guanabara Koogan S.A.

DIMAGGIO, F.L.; SANDLER, I.S. (1971). Material model for granular soils. Journal of the Engineering Mechanics Division, ASCE, v.97, n.EM3, p.935-950.

DIMILIA, R.A.; REED, J.S. (1983). Stress transmission during the compaction of a spray-dried alumina powder in a steel die. Journal of the American Ceramic Society, v.66, n.9, p.667-672.

DRUCKER, D.C.; PRAGER, W. (1952). Soil mechanics and plastic analysis or limit design. Quarterly of Applied Mathematics, v.10, n.2, p.157-165.

FORTULAN, C.A. (1997). Influência dos métodos de injeção e de prensagem isostática no desempenho das cerâmicas estrutrais. São Carlos. 187p. Tese (Doutorado). Escola de Engenharia de São Carlos. Universidade de São Paulo.

GENT, A. N. (1992). Engineering with Rubber: How to Design Rubber Components. New York. Oxford University Press.

GONÇALVES, D.P. (2000). Análise e investigação de impactos em blindagem composta cerâmica/metal. São José dos Campos. 95p. Tese (Mestrado). Instituto Tecnológico de Aeronáutica.

GU, C.; KIM, M.; ANAND, L. (2001). Constitutive equations for metal powders: Application to powder forming processes. International Journal of Plasticity, v.17, n.2, p.147-209. 
HENDERSON, R.J.; CHANDLER, H.W.; AKISANYA, A.R.; BARBER, H.; MORIARTY, B. (2000). Finite element modeling of cold isostatic pressing. Journal of European Ceramic Society, v.20, p.1121-1128.

HENKE, M.; KLEMM, U.; SOBEK, D. (1986). Determination of specific parameters in dry pressing of ceramic powders. Journal of Powder \& Bulk Solids Technology, v.10, n.1, p.9-14.

HIBBIT, KARLSSON \& SORENSEN. (2000). ABAQUS user's Manual-Version 6.1, v.2.

KIM, H.G.; LEE, J.W (1998). Effect of friction between powder and a mandrel on densification of iron powder during cold isostatic pressing. International Journal of Mechanical Sciences, v.40, n.6, p.507-519.

KIM, H.G.; LEE, J.W.; KIM, K.T. (2001). The effect of a rubber mold on densification and deformation of a metal powder compact during cold isostatic pressing. Materials Science and Engineering A, v.318, p.174-182.

KINGERY, W.D.; BOWEN, H.K.; UHLMANN, D.R. (1976). Introduction to Ceramics. 2.ed. New York, John Wiley \& Sons.

MCENTIRE, B.J. (1984) Tooling design for wet-bag isostatic pressing. In: MANGELS, J. A. Advances in Ceramics: 9 Forming of ceramics, USA, p.16-31.

NELSON, I. (1977). Constitutive models for use in numerical computations. In: DYNAMICAL METHODS IN SOIL AND ROCK MECHANICS, Balkena, Rotterdam, 1978. v.2.

NIXON, S.A.; CHANDLER, H. W. (1999). On the elasticity and plasticity of dilatant granular materials. Journal of the Mechanics and Physics of Solids. v.47, p.1397-1408.

PARK, H.; KIM, K.T. (2001). Consolidation behavior of SiC powder under cold compaction. Materials Science and Engineering A, v.299, p.116-124.

PENG, S.H.; CHANG, W.V. (1997). A compressible approach in finite element analysis of rubber-elastic materials. Computers \& Structures, v.62, n.3, p.573593.

RANSING, R.S. et al. (2000). Powder compaction modelling via the discrete and finite element method. Materials \& Design, v.21, p.263-269. 
REED, J.S. (1995). Principles of Ceramics Processing. 2.ed. New York, John Wiley \& Sons.

SALA, G. (1996). Advances in elastomeric tooling technology. Materials \& Design, v.17, n.1, p.33-42.

SHIMA, S.; MIMURA, K. (1986). Densification behaviour of ceramic powder. International Journal of Mechanical Sciences, v.28, n.1, p.53-59.

SHIMA, S.; OYANE, M. (1976). Plasticity theory for porous metals. International Journal of Mechanical Sciences, v.18, n.6, p.285-291.

SILVESTRE FILHO, G.D.; CARVALHO, J.; PURQUERIO, B.M.; SANTOS, N.C.; CHIERICE, G.O. (2000). Desenvolvimento de uma Metodologia de Fabricação para Hastes de Implante Ortopédico em Compósito Polimérico. Anais do $1^{o}$ Congresso Brasileiro de Engenharia de Fabricação - COBEF 2000, Curitiba PR.

SONG, J.H.; CHANDLER, H. W. (1990). The determination of some compaction properties of ceramic powders using a simple cylindrical apparatus. British Ceramic Transactions and Journal, v.89, n.2, p.49-52.

TSZENG, T.C.; WU, W.T. (1996). A study of the coefficients in yield functions modeling metal powder deformation. Acta Materialia, v.44, n.9, p.3543-3552.

WREGE, P.A.S. (2000). Metodologia para a obtenção de esferas de cerâmica para próteses de quadril. São Carlos. 186p. Tese (Doutorado). Escola de Engenharia de São Carlos. Universidade de São Paulo.

ZEUCH, D.H.; GRAZIER, M.J.; ARGÜELlO, J.G.; EWSUK, K.G. (2001). Mechanical properties and shear failure surfaces for two alumina powders in triaxial compression. Journal of Materials Science, v.36, p. 2911-2924. 